Cochrane Database of Systematic Reviews

\title{
Cognitive rehabilitation for memory deficits after stroke (Review)
}

das Nair R, Cogger H, Worthington E, Lincoln NB

das Nair R, Cogger H, Worthington E, Lincoln NB.

Cognitive rehabilitation for memory deficits after stroke.

Cochrane Database of Systematic Reviews 2016, Issue 9. Art. No.: CD002293.

DOI: 10.1002/14651858.CD002293.pub3.

www.cochranelibrary.com 
TABLE OF CONTENTS

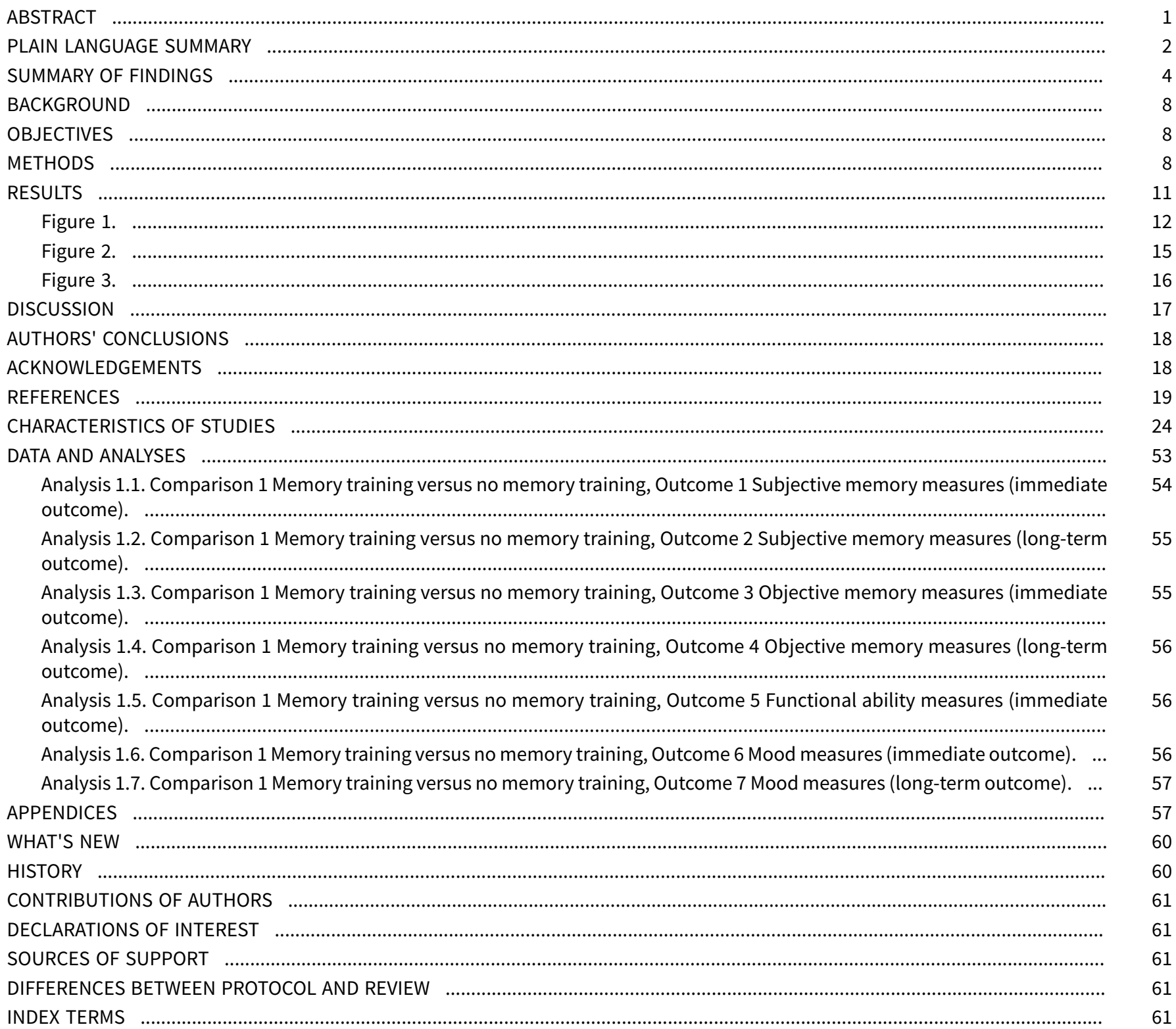


[Intervention Review]

\section{Cognitive rehabilitation for memory deficits after stroke}

Roshan das Nair ${ }^{1}$, Heather Cogger ${ }^{1}$, Esme Worthington ${ }^{2}$, Nadina B Lincoln 1

1Division of Rehabilitation and Ageing, University of Nottingham, Nottingham, UK. ${ }^{2}$ School of Health Sciences, University of Nottingham, Nottingham, UK

Contact: Roshan das Nair, Division of Rehabilitation and Ageing, University of Nottingham, B98, B Floor Medical School, Queen's Medical Centre, Nottingham, NG7 2UH, UK. roshan.nair@nottingham.ac.uk.

Editorial group: Cochrane Stroke Group.

Publication status and date: New search for studies and content updated (conclusions changed), published in Issue 9, 2016.

Citation: das Nair R, Cogger H, Worthington E, Lincoln NB. Cognitive rehabilitation for memory deficits after stroke. Cochrane Database of Systematic Reviews 2016, Issue 9. Art. No.: CD002293. DOI: 10.1002/14651858.CD002293.pub3.

Copyright (c) 2016 The Cochrane Collaboration. Published by John Wiley \& Sons, Ltd.

\section{A B S T R A C T}

\section{Background}

Memory problems are a common cognitive complaint following stroke and can potentially affect ability to complete functional activities. Cognitive rehabilitation programmes either attempt to retrain lost or poor memory functions, or teach patients strategies to cope with them.

Some studies have reported positive results of cognitive rehabilitation for memory problems, but the results obtained from previous systematic reviews have been less positive and they have reported inconclusive evidence. This is an update of a Cochrane review first published in 2000 and most recently updated in 2007.

\section{Objectives}

To determine whether participants who have received cognitive rehabilitation for memory problems following a stroke have better outcomes than those given no treatment or a placebo control.

The outcomes of interest were subjective and objective assessments of memory function, functional ability, mood, and quality of life. We considered the immediate and long-term outcomes of memory rehabilitation.

\section{Search methods}

We used a comprehensive electronic search strategy to identify controlled studies indexed in the Cochrane Stroke Group Trials Register (last searched 19 May 2016) and in the Cochrane Central Register of Controlled Trials (CENTRAL2016, Issue 5), MEDLINE (2005 to 7 March 2016), EMBASE 2005 to 7 March 2016), CINAHL (2005 to 5 February 2016), AMED (2005 to 7 March 2016), PsycINFO (2005 to 7 March 2016), and nine other databases and registries. Start dates for the electronic databases coincided with the last search for the previous review. We handsearched reference lists of primary studies meeting the inclusion criteria and review articles to identify further eligible studies.

\section{Selection criteria}

We selected randomised controlled trials in which cognitive rehabilitation for memory problems was compared to a control condition. We included studies where more than $75 \%$ of the participants had experienced a stroke, or if separate data were available from those with stroke in mixed aetiology studies. Two review authors independently selected trials for inclusion, which was then confirmed through group discussion.

\section{Data collection and analysis}

We assessed study risk of bias and extracted data. We contacted the investigators of primary studies for further information where required. We conducted data analysis and synthesis in accordance with the Cochrane Handbook for Systematic Reviews of Interventions. 
We performed a 'best evidence' synthesis based on the risk of bias of the primary studies included. Where there were sufficient numbers of similar outcomes, we calculated and reported standardised mean differences (SMD) using meta-analysis.

\section{Main results}

We included 13 trials involving 514 participants. There was a significant effect of treatment on subjective reports of memory in the short term (standard mean difference (SMD) $0.36,95 \%$ confidence interval $(\mathrm{Cl}) 0.08$ to $0.64, \mathrm{P}=0.01$, moderate quality of evidence), but not the long term (SMD $0.31,95 \% \mathrm{Cl}-0.02$ to $0.64, \mathrm{P}=0.06$, low quality of evidence). The SMD for the subjective reports of memory had small to moderate effect sizes.

The results do not show any significant effect of memory rehabilitation on performance in objective memory tests, mood, functional abilities, or quality of life.

No information was available on adverse events.

\section{Authors' conclusions}

Participants who received cognitive rehabilitation for memory problems following a stroke reported benefits from the intervention on subjective measures of memory in the short term (i.e. the first assessment point after the intervention, which was a minimum of four weeks). This effect was not, however, observed in the longer term (i.e. the second assessment point after the intervention, which was a minimum of three months). There was, therefore, limited evidence to support or refute the effectiveness of memory rehabilitation. The evidence was limited due to the poor quality of reporting in many studies, lack of consistency in the choice of outcome measures, and small sample sizes. There is a need for more robust, well-designed, adequately powered, and better-reported trials of memory rehabilitation using common standardised outcome measures.

\section{PLAIN LANGUAGE SUMMARY}

\section{Cognitive rehabilitation for memory deficits after stroke}

\section{Review question}

We reviewed the evidence for the effectiveness of cognitive rehabilitation for memory problems in people with stroke.

\section{Background}

People often struggle with memory problems following stroke and this can lead to difficulties in everyday life. The degree and kind of memory problems, mood changes, and performance of everyday activities can vary widely depending on many factors, including the location of the stroke in the brain, severity, age, and the previous health of the person experiencing a stroke.

Memory rehabilitation, a part of cognitive rehabilitation, is a therapeutic activity that may play a role in the recovery of memory functions, or in enabling the individual to adapt to the problems. Memory rehabilitation is a standard part of rehabilitation in many settings. However, it is uncertain whether memory rehabilitation can improve people's memory problems, or whether it has an effect on mood, performance in everyday activities, or quality of life.

\section{Study characteristics}

The evidence is current to May 2016. In this review, we included 13 studies with 514 participants. Seven trials were conducted with community participants, four with in-patients, and two with mixed community and in-patient samples. Participants received various types of memory retraining techniques, including training using computer programs and training in the use of memory aids, such as diaries or calendars. In three studies treatment was provided in groups and in 10 studies treatment was provided individually. Treatment lasted between two weeks and 10 weeks. In these studies, those who received the treatment were compared with a control group. The control group included those who did not receive cognitive rehabilitation or received another form of treatment. The control groups varied. Some studies had a control group wherein people received their usual care, whereas in others individuals in the control groups were placed on a waiting list to receive cognitive rehabilitation.

\section{Key results}

We found that people who received cognitive rehabilitation reported fewer memory problems in daily life immediately after treatment compared with the control groups. This represents a small to moderate effect of the intervention in comparison to the control group. However, there was no evidence that the benefits persisted in the long term. We found no evidence that cognitive rehabilitation improved people's independence in activities of daily living, mood, or quality of life. There was no information about any harm caused to participants from taking part in cognitive rehabilitation.

\section{Quality of the evidence}


The quality of the evidence ranged from very low (effect on outcomes that relate to everyday activities) to moderate (effect on self-reported memory problems, memory tests, and mood measures). There were a number of flaws in these studies, such as having very few people in them, and these could have affected our findings. 
SUMMARY OF FINDINGS

\section{Summary of findings for the main comparison.}

\section{Cognitive rehabilitation for memory deficits following stroke}

Patient or population: patients with memory deficits following stroke

Setting: multiple - hospital, outpatient, community; worldwide

Intervention: memory training

Comparison: no memory training or alternative training

\begin{tabular}{|c|c|c|c|c|c|c|}
\hline \multirow[t]{2}{*}{ Outcomes } & \multicolumn{2}{|c|}{ Anticipated absolute effects* $(95 \% \mathrm{Cl})$} & \multirow{2}{*}{$\begin{array}{l}\text { Relative effect } \\
(95 \% \mathrm{CI})\end{array}$} & \multirow{2}{*}{$\begin{array}{l}\text { № of partici- } \\
\text { pants } \\
\text { (studies) }\end{array}$} & \multirow{2}{*}{$\begin{array}{l}\text { Quality of the } \\
\text { evidence } \\
\text { (GRADE) }\end{array}$} & \multirow[t]{2}{*}{ Comments } \\
\hline & $\begin{array}{l}\text { Risk with no } \\
\text { memory train- } \\
\text { ing }\end{array}$ & Risk with memory training & & & & \\
\hline $\begin{array}{l}\text { Subjective memory measures } \\
\text { (immediate outcome) } \\
\text { Assessed with: Metamemory } \\
\text { in Adulthood Questionnaire, } \\
\text { EMQ, Memory Questionnaire, } \\
\text { Memory Assessments Clinics } \\
\text { rating scale, Memory Func- } \\
\text { tioning Questionnaire (fre- } \\
\text { quency of forgetting - carer), } \\
\text { CAPM-M self, CFQ } \\
\text { Follow-up: range } 4 \text { weeks to } 5 \\
\text { months }\end{array}$ & - & $\begin{array}{l}\text { The mean for subjective memory } \\
\text { measures (immediate outcome) } \\
\text { in the intervention group was } 0.36 \\
\text { standard deviations higher ( } 0.08 \text { to } \\
0.64 \text { higher) }\end{array}$ & - & $\begin{array}{l}215 \\
\text { (7 RCTs) }\end{array}$ & $\begin{array}{l}\oplus \oplus \oplus \odot \\
\text { MODERATE } 1\end{array}$ & $\begin{array}{l}\text { SMD of } 0.36 \text {, based on } \\
\text { Cohen's interpretation } \\
\text { of effect size, would } \\
\text { represent a small to } \\
\text { moderate effect. }\end{array}$ \\
\hline $\begin{array}{l}\text { Objective memory measures } \\
\text { (immediate outcome) - com- } \\
\text { prehensive batteries }\end{array}$ & - & $\begin{array}{l}\text { The mean for objective memory } \\
\text { measures (immediate outcome) } \\
\text { - comprehensive batteries in the } \\
\text { intervention group was } 0.25 \text { stan- }\end{array}$ & - & $\begin{array}{l}91 \\
\text { (5 RCTs) }\end{array}$ & $\begin{array}{l}\oplus \odot \odot \ominus \\
\text { VERY LOW } 3\end{array}$ & $\begin{array}{l}\text { SMD of } 0.25 \text {, based on } \\
\text { Cohen's interpretation } \\
\text { of effect size, would }\end{array}$ \\
\hline
\end{tabular}


The mean for objective memory measures (immediate outcome) - verbal memory sub-tests in the intervention group was $0.21 \mathrm{stan}$ dard deviations higher ( 0.03 lower to 0.46 higher)

\section{6}

(5 RCTs)

$\oplus \oplus \oplus \ominus$

MODERATE 4

SMD of 0.21 , based on Cohen's interpretation of effect size, would represent a small effect.

sessed with: RBMT story recall, 15 words test, RAVLT delayed, Claeson-Dahl delayed Follow-up: range 4 weeks to

12 weeks

Objective memory measures (long-term outcome) - comprehensive batteries

Assessed with: RBMT

Follow-up: range 18 weeks to

7 months

\section{Functional ability measures} (immediate outcome)

Assessed with: FIM, EADL, unspecified functional independence measure

Follow-up: range 4 weeks to 5 months

Mood measures (immediate outcome)

Assessed with: GHQ, HADS-D, CES-D

Follow-up: range 6 weeks to 5 months

$-$

The mean for objective memory measures (long-term outcome) comprehensive batteries in the intervention group was 0.17 standard deviations lower ( 0.74 lower to 0.41 higher)

The mean for functional ability

The mean for functional ability
measures (immediate outcome)
in the intervention group was 1.17
standard deviations higher $(0.35$

standard deviations high
lower to 2.68 higher)

\section{9}

(3 RCTs)

\section{$\oplus \oplus \ominus \ominus$}

LOW 5

SMD of 0.17 , based on

Cohen's interpretation

of effect size, would

represent a small effect.

The mean for functional ability
measures (immediate outcome)
in the intervention group was 1.17
standard deviations higher ( 0.35
lower to 2.68 higher)

\section{4}

(3 RCTs)

$\oplus \odot \odot \ominus$

SMD of 1.17, based on

Cohen's interpretation

of effect size, would

represent a large effect.

The mean for mood measures (immediate outcome) in the intervention group was 0.07 standard deviations undefined lower ( 0.35 lower to 0.21 higher)

$\begin{array}{ll}194 & \oplus \oplus \oplus \ominus \\ \text { (3 RCTS) } & \text { MODERATE } 7\end{array}$

SMD of 0.07 , based on Cohen's interpretation of effect size, would represent a small effect.

\section{Mood measures (long-term}

$$
\text { outcome) }
$$

Assessed with: GHQ, HADS-D,

CES-D

Follow-up: range 18 weeks to

7 months

The mean for mood measures

(long-term outcome) in the inter-

vention group was 0.17 standard

deviations lower ( 0.54 lower to 0.19

higher)

\section{5}

(3 RCTs)

$\oplus \oplus \oplus \ominus$

MODERATE 8

SMD of 0.17 , based on

Cohen's interpretation of effect size, would represent a small effect.

\begin{tabular}{lllll}
\hline $\begin{array}{l}\text { Quality of life measures (im- } \\
\text { mediate outcome) }\end{array}-$ & $\begin{array}{l}\text { There were no statistically signifi- } \\
\text { cant differences in the mean quali- }\end{array}$ & - & $\begin{array}{l}141 \\
(1 \text { RCT) }\end{array}$ & $\begin{array}{l}\oplus \oplus \oplus \odot \\
\text { Effect size of 0, based } \\
\text { on Cohen's interpre- }\end{array}$
\end{tabular}


Assessed with: EQ-5D Utility and VAS scores

Follow-up: 6 weeks ty of life measures (immediate outcome) between the intervention and control groups on the Utility score (Intervention: $\mathrm{m}=0.76$; SD

0.26; Control: $\mathrm{m}=0.76$; SD 0.25; $\mathrm{P}=$

$1.00 ; d=0$ ), or the VAS score (Intervention: $m=67.89$; SD 16.61; Control: $\mathrm{m}=70.23$; $\mathrm{SD} 15.67 ; \mathrm{P}=0.39 ; \mathrm{d}$ $=0.15$ ) tation of effect size, would represent no effect, and 0.15 would represent a small effect.

\section{There were no statistically signifi- cant differences in the mean qual- ity of life measures (long-term out- come) between the intervention and control groups on the Utility score (Intervention: $\mathrm{m}=0.76$; $\mathrm{SD}$ 0.26 ; Control: $\mathrm{m}=0.78$; SD 0.22; $\mathrm{P}$ $=0.63 ; \mathrm{d}=0.08$ ), or the VAS score (Intervention: $\mathrm{m}=68.38$; SD 17.94; Control: $\mathrm{m}=71.51 \cdot \mathrm{SD} 13.61 \cdot \mathrm{P}=$ $0.25 ; d=0.19$ )}

${ }^{\star}$ The risk in the intervention group (and its $95 \%$ confidence interval) is based on the assumed risk in the comparison group and the relative effect of the intervention (and its $95 \% \mathrm{Cl})$.

CAPM: Comprehensive Assessment of Prospective Memory; CES-D: Center for Epidemiological Studies Depression Scale; CFQ: Cognitive Failures Questionnaire; CI: confidence interval; EADL: Nottingham Extended Activities of Daily Living; EMQ: Everyday Memory Questionnaire; FIM: Functional Independence Measure; GHQ: General Health Questionnaire; HADS-D: Hospital Anxiety and Depression Scale - Depression; OR: odds ratio; RAVLT: Rey Auditory Verbal Learning Test; RBMT: Rivermead Behavioural Memory Test; RCT: randomised controlled trial; RR: risk ratio; SD: standard deviation; VAS: visual analogue scale; WMS: Wechsler Memory Scale

\section{GRADE Working Group grades of evidence}

High quality: we are very confident that the true effect lies close to that of the estimate of the effect

Moderate quality: we are moderately confident in the effect estimate: the true effect is likely to be close to the estimate of the effect, but there is a possibility that it is substantially different

Low quality: our confidence in the effect estimate is limited: the true effect may be substantially different from the estimate of the effect

Very low quality: we have very little confidence in the effect estimate: the true effect is likely to be substantially different from the estimate of effect

1Downgraded one level due to serious study limitations (four of the seven included studies had two areas with high risk of bias, alongside several unclear judgements).

2Downgraded two levels in total. Downgraded one level due to serious study limitations (one of the three included studies had two areas with high risk of bias), and one level due to indirectness (two of the three included studies used mixed diagnoses samples). Despite some asymmetry in the forest plot, there was no further downgrading for any suspected publication bias as this was likely to be accounted for by the small number of participants with stroke in otherwise large mixed diagnoses studies.

${ }^{3}$ Downgraded three levels in total. Downgraded one level due to inconsistency ( 12 statistic of $42 \%$ ), one level due to indirectness (four of the five included studies used mixed diagnoses samples), and one due to imprecision (wide confidence intervals for this outcome).

${ }^{4}$ Downgraded one level due to serious study limitations (four of the five included studies had two areas with high risk of bias, alongside several unclear judgements). 
Downgraded four levels in total. Downgraded one level due to serious study limitations (there were a number of unclear judgements, specifically in Chen 2006), one level due to inconsistency (12 statistic of 93\%), one level due to indirectness (the interventions in Chen 2006 and Zucchella 2014 included only a minor aspect of memory rehabilitation), and one level due to imprecision (confidence intervals for this outcome include both a null effect and an appreciable benefit).

7Downgraded one level due to serious study limitations (two of the three included studies had two areas with high risk of bias).

8Downgraded one level due to serious study limitations (two of the three included studies had two areas with high risk of bias).

${ }^{9}$ Downgraded one level due to serious study limitations (the included study had two areas with high risk of bias).

10Downgraded one level due to serious study limitations (the included study had two areas with high risk of bias). 


\section{B A C K G R O U N D}

\section{Description of the condition}

Memory impairment occurs after stroke (Lincoln 2012), and can persist over many years (Schaapsmeerders 2013). A systematic review of the prevalence of memory impairment after stroke estimated that between $23 \%$ and $55 \%$ have memory impairment three months after stroke and between $11 \%$ and $31 \%$ a year after stroke (Snaphaan 2007). A review of subjective cognitive complaints after stroke indicated that many stroke patients report problems with memory in daily life (van Rijsbergen 2014), and complaints about memory problems are more frequent than complaints about impairment in other cognitive domains (Lamb 2013). These cognitive impairments have been shown to have a negative effect on the patient's functional independence (Middleton 2014).

\section{Description of the intervention}

Cognitive rehabilitation is a "systematic, functionally oriented service of therapeutic activities that is based on assessment and understanding of the patient's brain-behavioural deficits" (Cicerone 2005). Memory rehabilitation is a component of this generic cognitive rehabilitation. Such rehabilitation facilitates the development of behavioural and cognitive strategies that have, as their goal, a positive impact on the structural and functional recovery of the damaged brain, and improve the quality of life of the individual in general (Robertson 2001).

Traditionally, memory rehabilitation has focused on teaching patients the use of internal aids (such as mnemonics, rehearsal, and mental imagery) and external memory aids (such as the use of diaries, notice boards, and lists) to help them remember and recall information. In addition, rehearsal is employed to attempt to restore memory function.

\section{How the intervention might work}

There is uncertainty about the precise mechanisms of how memory rehabilitation interventions work. However, it is widely believed that interventions work by providing people with information about their memory problems, by teaching them the use of internal and external memory aids, by training people to use different strategies to pay attention, and alternative ways of encoding, storing, and retrieving information. Targeted, repeated stimulation of certain brain areas using 'drill and practice' cognitive exercises is thought to trigger the activation of neural networks. For groupbased interventions, the therapeutic effects of being with others with similar problems may also help. Some of these behavioural strategies (referred to as 'restitution' or 'compensation') are believed to map onto the neural networks engaged in performing memory functions.

\section{Why it is important to do this review}

The effectiveness of memory rehabilitation after stroke has been examined by studies using different methodologies. Singlecase and small group studies have reported positive results of memory rehabilitation, but the results obtained from some systematic reviews have been less positive and they have reported inconclusive evidence. Cicerone 2011 suggested that teaching patients to use external memory aids (including assistive devices) with direct application to functional activities was recommended as a practice guideline in people with severe memory impairment after traumatic brain injury or stroke, but the evidence for other strategies for those with stroke is limited. Gillespie 2015 highlighted the fact that there is very little strong evidence for the effectiveness of rehabilitation for cognitive deficits found after stroke, and concluded that very few direct clinical recommendations could be made. A similar conclusion was reached by Cumming 2013.

This is an update of a Cochrane review first published in 2000 and most recently updated in 2007 (das Nair 2007).

\section{O B JECT IVES}

To determine whether participants who have received cognitive rehabilitation for memory problems following a stroke have better outcomes than those given no treatment or a placebo control.

The outcomes of interest were subjective and objective assessments of memory function, functional ability, mood, and quality of life. We considered the immediate and long-term outcomes of memory rehabilitation.

\section{METHODS}

\section{Criteria for considering studies for this review}

\section{Types of studies}

For inclusion in the review, we sought randomised controlled trials, as defined by the Cochrane Handbook for Systematic Reviews of Interventions (Higgins 2011), and the pre-cross-over component of randomised cross-over trials with participants who have had a stroke, in which a memory treatment is compared with a control. Where publications were based on the same sample, or sub-set of a larger sample, we only included the study with the full sample to avoid double counting.

\section{Types of participants}

We confined trials included in this review to those with people who had memory deficits following stroke (based on a clinical definition as defined by the trialists). Thus, we excluded trials that included participants whose memory deficits were the result of traumatic brain injury, brain tumour, multiple sclerosis, epilepsy, or any other neurological condition unless at least $75 \%$ of the sample had a stroke, or a stroke subgroup could be identified for which there were separate data, or such data could be obtained from the study authors. Memory deficits were not defined in advance, but we assumed that those patients given treatment for impaired memory had memory deficits. We placed no restrictions on the types of memory deficits participants reported.

\section{Types of interventions}

We included trials in which there was a comparison between a treatment group that received one of various memory rehabilitation strategies, and a control group that received either an alternative form of treatment or no memory intervention.

We considered memory rehabilitation to be any attempt to modify memory function by means of 'drill and practice', or by the use of internal or external memory aids, or by teaching patients strategies to cope with their memory problems. We did not include drug studies. 
We considered memory rehabilitation that took place over more than a single session. Therefore, we did not consider laboratorybased experiments (such as single session list-recall or mnemonic strategy training) to be cognitive rehabilitation.

\section{Types of outcome measures}

\section{Primary outcomes}

Primary outcomes were measures of the extent of memory problems in everyday life. If there was more than one outcome measure measuring this construct in a study, we used the following hierarchy of commonly used tests that assess subjective reports of memory function: Everyday Memory Questionnaire (EMQ) (Sunderland 1983), Subjective Memory Questionnaire (Davis 1995), Memory Assessment Clinics Questionnaire (Crook 1992), Internal and External Memory Aids Questionnaires, Cognitive Failures Questionnaire (Broadbent 1982).

\section{Secondary outcomes}

- Objective reports of memory. Rivermead Behavioural Memory Test (RBMT) (Wilson 1985 or newer versions of this test), Wechsler Memory Scale (WMS) (Wechsler 1997 or newer versions of this test), Cambridge Test of Prospective Memory (Wilson 2005), Doors and People Memory Test (Baddeley 1994).

- The hierarchies of measures of memory function above were based on the tests' degree of sensitivity to assess everyday memory problems. For objective assessments, where the outcomes were not in the above hierarchy, general memory test scores were used over verbal memory, which were used over visual memory. If there were other outcome measures used that were not in this hierarchy, we arrived at a consensus following discussion regarding which measures to consider as the primary outcome measure, before the statistical analyses were conducted, so as to minimise bias.

- We used both total scores and individual domain scores, as appropriate. Domain scores were included as some tests (such as the Doors and People Test, Baddeley 1994) do not provide a total score, but only domain-specific scores. In the event that several types of scores were reported for various outcomes, we used the following hierarchy: total profile scores over index scores (indices) or composite scores over subtest scores.

- Measures of functional abilities, such as the Nottingham Extended Activities of Daily Living (EADL) (Nouri 1987), Functional Independence Measure (FIM) (Hamilton 1987), Functional Assessment Measure (FAM) (Hall 1997), Barthel Index (Mahoney 1965).

- Mood, such as the General Health Questionnaire (GHQ) (Goldberg 1988), Hospital Anxiety and Depression Scale (HADS) (Zigmond 1983), Beck Depression Inventory-Fast Screen (Beck 2003), Beck Anxiety Inventory (Beck 1990), Wimbledon selfreport scale (Coughlan 1988).

- Quality of life, such as the Stroke Impact Scale (Duncan 1999), Stroke Specific Quality of life scale (Williams 1999), SF-36 (Ware 2001), WHO-QoL (WHOQoL 1993).

If more than one measure was used for each domain, then tests were included in the priority order listed above.

We classified all outcomes as immediate or longer-term and we conducted separate analyses for each of these. We defined immediate outcomes as shortly after the end of intervention, and longer-term outcomes as the second outcome following the immediate outcome.

\section{Search methods for identification of studies}

See the 'Specialized register' section in the Cochrane Stroke Group module. We searched for trials in all languages and, where necessary, arranged translation of relevant papers published in languages other than English.

\section{Electronic searches}

We searched the Cochrane Stroke Group Trials Register, which was last searched by the Managing Editor on 19 May 2016. In addition, we searched the following electronic databases.

- Cochrane Central Register of Controlled Trials (CENTRAL 2016, Issue 5) (from 2005) (Appendix 1).

- MEDLINE (Ovid) (2005 to 7 March 2016) (Appendix 2).

- EMBASE (Ovid) (2005 to 7 March 2016) (Appendix 3).

- Cumulative Index to Nursing and Allied Health Literature (CINAHL) (EBSCO host) (2005 to 5 February 2016).

- Allied and Complementary Medicine Database (AMED) (2005 to 7 March 2016).

- PsyciNFO (2005 to 7 March 2016).

- ClinicalTrials.gov (www.clinicaltrials.gov/) (5 February 2016).

- World Health Organization (WHO) International Clinical Trials Registry Portal (http://apps.who.int/trialsearch/) (8 February 2016).

- The NIHR Clinical Research Network database (http:// public.ukcrn.org.uk/) (8 February 2016).

- UK CRN Study Portfolio (8 February 2016).

- Latin American and Caribbean Health Science Information Database (LILACS) (Bireme) (1982 to 8 February 2016).

- CAB Abstracts (2005 to 7 March 2016).

- REHABDATA (www.naric.com/research/rehab/) (5 February 2016).

- Stroke Trials Registry (www.strokecenter.org/trials/) (5 February 2016).

- ISRCTN Registry (http://www.isrctn.com/) (5 February 2016).

Start dates for the electronic databases coincided with the last search for the previous review. Two review authors (HC, EW) identified potential studies.

\section{Searching other resources}

\section{Handsearching}

In an effort to identify trials not included in the electronic databases, we handsearched the following journals in 1999 for the first version of this review.

- American Journal of Occupational Therapy (1947 to 1998).

- Aphasiology (1987 to 1998).

- Australian Occupational Therapy Journal (1965 to 1998).

- British Journal of Occupational Therapy (1950 to 1998).

- British Journal of Therapy and Rehabilitation (1994 to 1998).

- Canadian Journal of Occupational Therapy (1970 to 1998).

- Clinical Rehabilitation (1987 to 1998). 
- Disability Rehabilitation (1992 to 1998), formerly International Disability Studies (1987 to 1991), formerly International Rehabilitation Medicine (1979 to 1986).

- International Journal of Language \& Communication Disorders (1998), formerly European Journal of Disorders of Communication (1985 to 1997), formerly British Journal of Disorders of Communication (1977 to 1984).

- International Journal of Rehabilitation Research (1977 to 1998).

- Journal of Clinical Psychology in Medical Settings (1994 to 1998), formerly Journal of Clinical Psychology (1944 to 1994).

- Journal of Developmental and Physical Disabilities (1992 to 1998), formerly Journal of the Multihandicapped Person (1989 to 1991).

- Journal of Rehabilitation (1963 to 1998).

- Journal of Rehabilitation Science (1989 to 1996).

- Neuropsychological Rehabilitation (1987 to 1998).

- Neurorehabilitation (1991 to 1998).

- Occupational Therapy International (1994 to 1998).

- Physiotherapy Theory and Practice (1990 to 1998), formerly Physiotherapy Practice (1985 to 1989).

- Physical Therapy (1988 to 1998).

- Rehabilitation Psychology (1982 to 1998).

- Journal of Cognitive Rehabilitation (1988 to 1998), formerly Cognitive Rehabilitation (1983 to 1987).

The 1999 handsearch included a broad range of journals, as it covered searches for trials in four areas of rehabilitation. For the 2006 update, we checked the Master List of journals searched by Cochrane (http://www.cochrane.us/masterlist.asp).

We did not handsearch any scientific journals for this update as relevant trials were found from the search of the Cochrane Central Register of Controlled Trials (CENTRAL), for which handsearching is carried out periodically, and we did not wish to duplicate this effort.

Citation tracking of all primary study articles, and scanning reference lists from book chapters and review articles, provided an additional search strategy.

\section{Data collection and analysis}

\section{Selection of studies}

One review author (RdN), in consultation with a senior librarian, developed the electronic search strategy. Two review authors ( $\mathrm{HC}$ $E W$ ) evaluated the abstracts of the studies obtained by this search strategy and identified trials for inclusion in the review using four inclusion criteria (types of trials, participants, interventions, and outcome measures).

Another review author (NBL) cross-checked the search strategy and confirmed the inclusion and exclusion of studies.

\section{Data extraction and management}

We conducted the review using RevMan 5 (RevMan 2014).

We used the data extraction tool employed in the previous version of this review (das Nair 2007), which is similar to that proposed by the CONSORT statement (Moher 2010). Two review authors (HC, EW) extracted and cross-checked study characteristics and outcomes.
We recorded the following information for each trial.

- Methods: number of sites, unit of allocation, timing of outcomes.

- Participants: country, setting, method of stroke diagnosis, age, time since onset, loss to follow-up.

- Interventions: content, duration, frequency.

- Outcomes: measures used.

If these data were not available or were unclear from the reports, we contacted the first author of the trial for further information. Where studies were not available in the English language, we had them translated into English by someone fluent in the language.

\section{Assessment of risk of bias in included studies}

Two authors (HC, EW) independently assessed the methodological quality of the included trials and completed 'Risk of bias' tables as described in the Cochrane Handbook for Systematic Reviews of Interventions (Higgins 2011).

The table includes the following items:

- Random sequence generation.

- Allocation concealment.

- Blinding (of participants, personnel and outcome assessors).

- Incomplete outcome data.

- Selective outcome reporting.

- Other biases (e.g. attrition bias, design flaws).

We judged these aspects on the basis of the information provided in the studies or, if this information was not available or was unclear from the reports(particularly relating to the randomisation procedure) we contacted the first author of the trial for further information. Two review authors completed ratings for each domain as being low or high risk of bias, or 'unclear' if sufficient information was not available, according to the Cochrane Handbook for Systematic Reviews of Interventions (Higgins 2011). A third review author (NBL) arbitrated any disagreements. None of the review authors were blinded to the names of the study authors, institutions, or the publishing journal of the included trials, as two of the review authors (RdN and NBL) work in this area and are familiar with the studies published in memory rehabilitation, and therefore could not be blinded.

\section{Measures of treatment effect}

We used the standardised mean difference (SMD) with 95\% confidence intervals $(\mathrm{CI})$ for the continuous outcomes.

\section{Unit of analysis issues}

We considered for inclusion parallel-group, cross-over, and clusterRCTs, and included the data from all of these types of studies (where available) in the meta-analyses. For cross-over studies, we only included the pre-cross-over phase of the trials. We did not combine the first and second phases of the cross-over studies because of uncertainty about the carryover effects in such trials, given that they are psychological interventions, where the wash-out period is difficult to determine. For cluster-RCTs, our analyses followed the Cochrane Handbook for Systematic Reviews of Interventions recommendation (16.3.4) (Higgins 2011). We included trials with more than two intervention or control groups and analysed them by pooling together the data from all of the experimental groups 
and comparing these with the control group. If there was more than one control group, we pooled the results from these.

\section{Dealing with missing data}

Where data were not available or were unclear from the reports, we contacted the corresponding author of the study in question for further information. We rated studies as high risk of bias if they had a post-randomisation attrition rate of $30 \%$ or more (even if an intention-to-treat analysis was used).

\section{Assessment of heterogeneity}

We assessed heterogeneity by comparing the distribution of important participant factors between trials (age, gender, type of stroke), and trial factors (sequence generation, allocation concealment, blinding, losses to follow-up). We used the $\mathrm{I}^{2}$ statistic to statistically assess heterogeneity (Higgins 2011). We further scrutinised the studies to explore reasons for the heterogeneity if the $I^{2}$ statistic was significant at $\geq 50 \%$.

\section{Assessment of reporting biases}

We assessed reporting bias by comparing the published paper with any published protocol, or with any raw data for the study provided by the study authors on request.

\section{Data synthesis}

We consulted the Cochrane Handbook for Systematic Reviews of Interventions to plan the data synthesis and we followed the procedures outlined therein (Higgins 2011). As most psychological and neuropsychological outcome measures in memory rehabilitation tend to be ordinal level measures, we treated these as continuous data (as recommended by Higgins 2011). We used the SMD as a summary statistic as we predicted that multiple trials would employ various outcome measures to assess memory. If low scores represented a better outcome, we changed the valence of the score from positive (+) to negative (-). In situations where studies combined scores from scales in which high scores were in some instances good and in some instances poor outcomes, we reversed the signs of the discrepant scores to keep them consistent. For the meta-analysis we only considered data that we deemed to be similar or comparable enough to meaningfully pool on the basis of the outcome measures employed. Depending on the heterogeneity of the data, we considered fixedeffect or random-effects models.

\section{GRADE and 'Summary of findings' table}

We summarised an evaluation of the overall risk of bias, based on the relative importance of the various domains listed. In addition to the 'Risk of bias' table, we used the GRADE approach to assess the quality of the studies (GRADEpro). We completed this process across outcomes (Summary of findings for the main comparison). This approach allowed for judgements to be made about the quality of the studies included in each outcome, so that any conclusions could be drawn from the outcome and the quality of studies included in that outcome. Where studies had two or more categories graded as high risk of bias we downgraded the quality by one grade.

\section{Subgroup analysis and investigation of heterogeneity}

We considered subgroup analysis according to type of intervention (group versus individual cognitive rehabilitation).

\section{Sensitivity analysis}

We considered sensitivity analyses to assess the impact of study quality (whether there was a difference between studies employing an intention-to-treat analysis and those using ontreatment analysis) where data to perform such analyses were available from the included papers. We also considered a sensitivity analysis to assess the influence of methodological quality on the intervention effect for each outcome by comparing the outcomes of those trials with low risk of bias with all the included studies.

\section{RES U L T S}

\section{Description of studies}

\section{Results of the search}

The previous version of this review identified two studies. For this update, we identified a total of 4934 articles. We carried out preliminary screening on the basis of information obtained from the titles of the articles; we excluded 3400 after we had removed duplicates. We examined abstracts for the 298 studies selected and obtained full papers if the abstracts suggested that they might satisfy the inclusion criteria.

From the 64 articles, 10 were non-unique and related to other studies otherwise discussed in this review, and we classified seven as ongoing. Ongoing studies were those still recruiting participants $(n=5)$, or the analyses were not yet available with no response from the authors $(n=2)$. These studies are presented in the Characteristics of ongoing studies table.

We classified studies where only conference proceedings or abstracts with no full paper were available as awaiting classification $(n=4)$, which are presented in the Characteristics of studies awaiting classification table.

We formally excluded a total of 32 papers according to our review criteria that were: not stroke participants, or groups of participants with different diagnoses without separate data available for those with stroke $(n=6)$; not an RCT $(n=8)$; not a memory study $(n=13)$; and not a cognitive rehabilitation study $(n=5)$.

We added the two studies from the previous review to the 11 new studies in the final analysis (Figure 1). 
Figure 1. Flow diagram showing article screening process for updated search

\section{2 studies included in the previous version of this review}

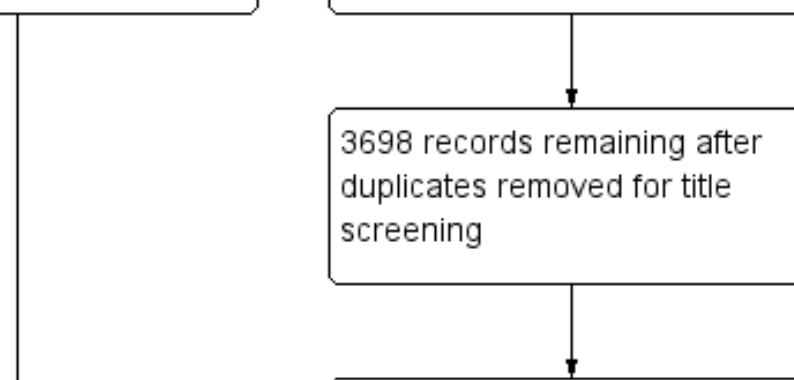

298 records abstract screened

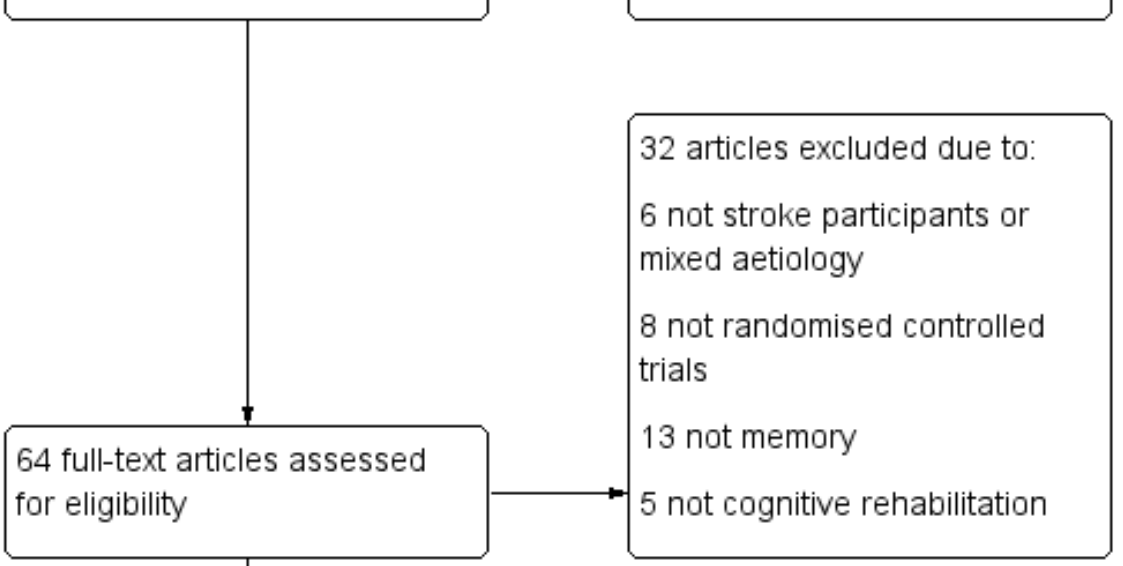

1 new studies included

4 records classified as awaiting classification

7 records classified as ongoing studies

10 non-unique records relating to included or excluded studies
3400 records excluded

234 records excluded

32 articles excluded due to:

6 not stroke participants or

not randomised controlled

13 not memory

5 not cognitive rehabilitation

See the Characteristics of included studies table for more details of the 13 included studies. 


\section{Included studies}

\section{Study location}

The 13 included studies were based in the following countries: Australia (Lannin 2014; Radford 2012), China (Chen 2006; Lin 2014), Italy (Zucchella 2014), the Netherlands (Aben 2014; Doornhein 1998), Russia (Prokopenko 2013), Sweden (Åkerlund 2013; Westerberg 2007), the UK (das Nair 2012), and the USA (Lemoncello 2011). One was a multi-centre study involving seven centres in Europe (Kaschel 2002).

Seven trials included community participants (Aben 2014; Åkerlund 2013; das Nair 2012; Lemoncello 2011; Lin 2014; Radford 2012; Westerberg 2007), four trials included in-patients (Chen 2006; Doornhein 1998; Prokopenko 2013; Zucchella 2014), and two included both community and in-patient participants (Kaschel 2002; Lannin 2014).

\section{Participant characteristics}

The number of participants with stroke in the studies varied from four (Lemoncello 2011) to 153 (Aben 2014). The number of participants with stroke in the treatment or control groups varied from one (Lemoncello 2011) to 77 (Aben 2014). Varied gender ratios were reported, with the percentage of men ranging from 50\% (Radford 2012) to 75\% (Lemoncello 2011). Mean ages of stroke participants ranged from 31 years (Lannin 2014) to 68 years (Zucchella 2014), and the mean time since participants' stroke onset ranged from less than one month (Prokopenko 2013; Zucchella 2014) to 91 months (Lannin 2014).

In four studies participants were diagnosed with stroke using neuroimaging (positron emission tomography (PET), computed tomography (CT) or magnetic resonance imaging (MRI)) (Chen 2006; Lannin 2014; Westerberg 2007; Zucchella 2014), in one this was described as a confirmed diagnosis (Lin 2014), and one used clinical neurological examination (Prokopenko 2013). The method of diagnosis of stroke was not stated in seven studies (Aben 2014; Åkerlund 2013; das Nair 2012; Doornhein 1998; Lannin 2014; Lemoncello 2011; Radford 2012), but participants were recruited from rehabilitation medicine outpatient clinics, specialist brain injury rehabilitation centres, and community rehabilitation groups, or were referred by neurologists, speech and language pathologists, or acquired brain injury specialists.

There were seven studies that included only participants with stroke (Aben 2014; Chen 2006; Doornhein 1998; Lin 2014; Prokopenko 2013; Westerberg 2007; Zucchella 2014), none that included more than $75 \%$ with stroke in a mixed aetiology sample, and six that were mixed aetiology samples for which separate data were available for those with stroke (Åkerlund 2013; das Nair 2012; Kaschel 2002; Lannin 2014; Lemoncello 2011; Radford 2012). In the studies with participants with various diagnoses, the proportion with stroke ranged from 68\% (Åkerlund 2013) to 12\% (Lannin 2014).

The groups were comparable on assessed baseline characteristics in eight studies (Aben 2014; Åkerlund 2013; das Nair 2012; Doornhein 1998; Lin 2014; Prokopenko 2013; Westerberg 2007; Zucchella 2014). This information was not available for four studies (Chen 2006; Kaschel 2002; Lemoncello 2011; Radford 2012), and in one study there was an imbalance in time since onset but this was considered unlikely to affect outcomes (Lannin 2014).

\section{Study design}

Seven studies used standard rehabilitation or usual care as a control group (Åkerlund 2013; Chen 2006; Lannin 2014; Lemoncello 2011; Lin 2014; Prokopenko 2013; Westerberg 2007), one used a waiting list control (Radford 2012), two used alternative forms of memory rehabilitation (Doornhein 1998; Kaschel 2002), and three used a non-memory related attention (placebo) control (Aben 2014; das Nair 2012; Zucchella 2014).

\section{Treatment characteristics}

The structure and contents of the treatment programmes were diverse. Three studies provided group treatment (Aben 2014; das Nair 2012; Radford 2012), and 10 provided individual interventions (Åkerlund 2013; Chen 2006; Doornhein 1998; Kaschel 2002; Lannin 2014; Lemoncello 2011; Lin 2014; Prokopenko 2013; Westerberg 2007; Zucchella 2014). The contents of the group treatment programmes included education and teaching of compensatory strategies. Individual treatments included computerised memory training in five studies (Åkerlund 2013; Lin 2014; Prokopenko 2013; Westerberg 2007; Zucchella 2014), strategy training in two studies (Chen 2006; Doornhein 1998), imagery mnemonics in one study (Kaschel 2002), and the use of external memory aids in two studies (Lannin 2014; Lemoncello 2011).

Four studies provided interventions lasting between eight and 10 weeks (das Nair 2012; Kaschel 2002; Lannin 2014; Lin 2014), in six studies treatment lasted between four and six weeks (Aben 2014; Åkerlund 2013; Doornhein 1998; Radford 2012; Westerberg 2007; Zucchella 2014), in two studies treatment was delivered in two weeks (Lemoncello 2011; Prokopenko 2013), and for one study this was not clear (Chen 2006). Each session lasted between 30 minutes for computerised training (Åkerlund 2013; Prokopenko 2013), and up to two hours for group treatments (Radford 2012).

\section{Outcomes assessed}

A range of outcome measures were used by the included studies. Subjective measures of memory were used in six studies (Doornhein 1998; das Nair 2012; Kaschel 2002; Lannin 2014; Radford 2012; Westerberg 2007). Each study used a different questionnaire measure. Objective memory abilities were assessed in 11 studies. Chen 2006 used the Loewenstein Occupational Therapy Cognitive Assessment (LOTCA) as a measure of cognitive abilities but this does not include an assessment of memory. Lemoncello 2011 did not use any objective measures. Of the 11 studies, six studies used a battery of memory tests, the Rivermead Behavioural Memory Test (RBMT; Åkerlund 2013; das Nair 2012; Kaschel 2002; Lannin 2014), the Wechsler Memory Scale (Lin 2014), and the Montreal Cognitive Assessment (MoCA) (Prokopenko 2013). Five studies used measures of verbal learning, such as the RBMT Story Recall (Aben 2014), Rey AVLT (RAVLT) (Radford 2012; Zucchella 2014), 15 word test (Doornhein 1998), and the Word list recall (Westerberg 2007).

Three studies examined whether their rehabilitation programme had an effect on functional abilities and all used different measures (das Nair 2012; Prokopenko 2013; Zucchella 2014). Four studies assessed mood (Aben 2014; Åkerlund 2013; das Nair 2012; Prokopenko 2013). All used different measures. Quality of life was assessed in only two studies (Aben 2014; Prokopenko 2013). Each used different measures. 


\section{Conclusions from individual studies}

Six studies included data from mixed diagnoses groups and therefore there were no specific conclusions for those with stroke (Åkerlund 2013; das Nair 2012; Kaschel 2002; Lannin 2014; Lemoncello 2011; Radford 2012). Of the seven studies that included only those with stroke (Aben 2014; Chen 2006; Doornhein 1998; Lin 2014, Prokopenko 2013; Westerberg 2007; Zucchella 2014), the conclusions suggested some beneficial effect of memory rehabilitation in five studies (Aben 2014; Chen 2006; Lin 2014; Westerberg 2007; Zucchella 2014). Two studies reported beneficial effects on subjective memory questionnaires (Aben 2014; Westerberg 2007), but neither of these reported any significant effects on memory abilities. One study reported beneficial effects on memory ability but not functional abilities (Zucchella 2014). One study reported beneficial effects on functional abilities but did not assess memory abilities (Chen 2006). One study reported significant improvement in memory in the intervention group but not the control group, but did not report a direct comparison (Lin 2014). Two studies reported no significant effects of intervention (Doornhein 1998; Prokopenko 2013).

\section{Excluded studies}

On the basis of the exclusion criteria specified for this review, we formally excluded 32 studies on the following criteria.

Six did not meet the criteria for stroke. One study had only one participant with a stroke (Ownsworth 1999), one did not include any participants with stroke in a mixed brain injury sample (Thoene 1995), and four had mixed diagnosis groups where separate data for those with stroke could not be obtained (de Joode 2013; de Luca 2014; Lundqvist 2010; McDonald 2011).

Eight studies were not RCTs. Two studies had no control group (Klonoff 2007; Sohlberg 2007), two studies used alternate allocation (Fish 2008; Thickpenny-Davis 2007), two studies allocated based on performance (Hildebrandt 2006; Tailby 2003), one study did not allocate all participants randomly (Miller 2014), and one study used a matched pairs design (Fong 2009).

Thirteen studies did not investigate memory difficulties. Four studies covered executive functioning (Bushnick 2010; Chen 2011; Skidmore 2015, Man 2006), and four studies focused on attention (Barker-Collo 2009; Blanchet 2016; Chen 2015; Schupp 2002). Four studies evaluated cognitive orientation to daily occupational performance (CO-OP; McEwan 2014; McEwen 2015; Polatajko 2012; Wolf 2015), and one motor function (Liu 2009).

Four studies did not provide cognitive rehabilitation (Brainin 2015; Markle-Reid 2011; Rasmussen 2016; Yu 2009), and one compared methods of delivery of cognitive rehabilitation (Gamito 2014).

We excluded four studies from the previous version of this review (Evans 2000; Gasparrini 1979; Imes 1984; Wilson 2001), and these were not included in the results of the search for this update.

\section{Risk of bias in included studies}

We used the data extraction tool described above to assess the quality of the studies considered for inclusion. We paid particular attention to the randomisation, treatment allocation concealment and blinding procedures, and the flow of participants through the trial. See Figure 2 and Figure 3. 
Figure 2. Risk of bias summary: review authors' judgements about each risk of bias item for each included study.

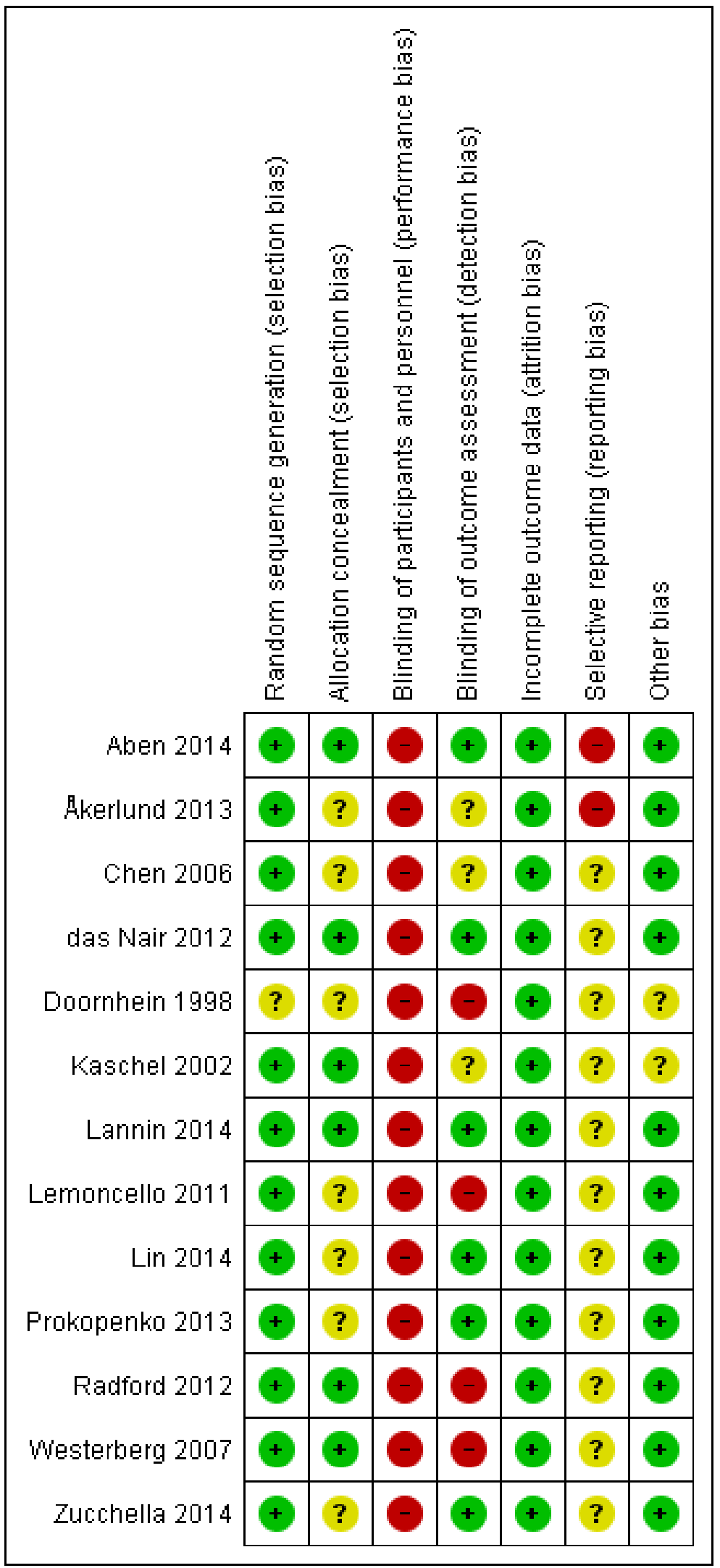


Figure 3. Risk of bias graph: review authors' judgements about each risk of bias item presented as percentages across all included studies.

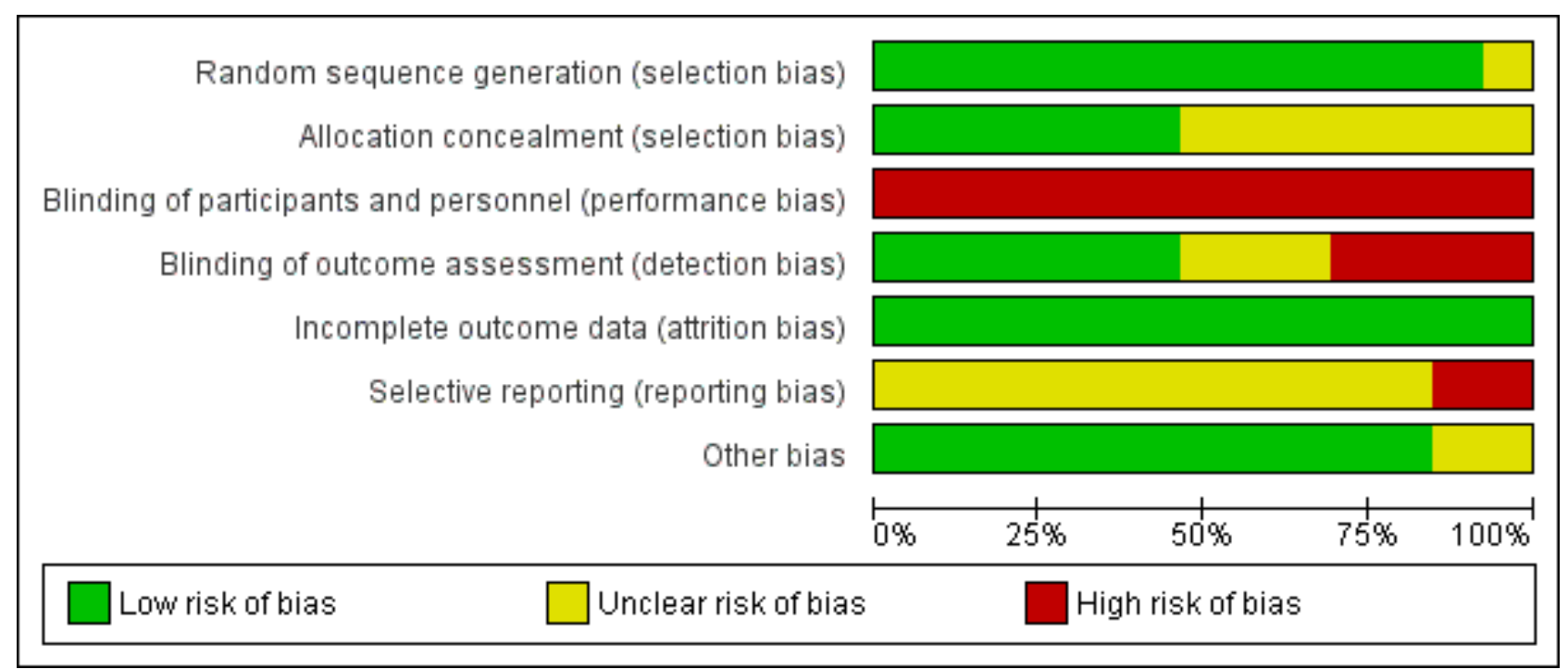

\section{Allocation}

We judged 12 studies to have adequate random sequence generation. We judged one study as being unclear as the study authors reported that participants were assigned at random with no further detail provided (Doornhein 1998).

We judged six studies to have adequate allocation concealment with randomisation into groups using a computerised system (Radford 2012), a sealed envelope system (Lannin 2014; Westerberg 2007), or having a separate staff member who was not further involved in the study to complete allocation (Aben 2014; das Nair 2012; Kaschel 2002).

\section{Blinding}

In all studies the participants and those delivering the intervention were aware of the allocation, suggesting a high risk of performance bias.

Six studies had observer-blinded assessment of outcomes (Aben 2014; das Nair 2012; Lannin 2014; Lin 2014; Prokopenko 2013; Zucchella 2014). We considered four studies to have high risk of bias because those delivering the intervention also conducted the outcome assessments (Doornhein 1998; Lemoncello 2011; Radford 2012; Westerberg 2007). Three studies were unclear in their description of the methods used (Åkerlund 2013; Chen 2006; Kaschel 2002).

\section{Incomplete outcome data}

We deemed incomplete outcome data to be a low risk in 11 studies. In four studies all participants completed the outcome assessments (Doornhein 1998; Lannin 2014; Lin 2014; Prokopenko 2013); in seven studies the attrition rates provided were comparable between groups (Aben 2014; das Nair 2012; Kaschel 2002; Lemoncello 2011; Radford 2012; Westerberg 2007; Zucchella 2014). This information was not clear for two studies (Åkerlund 2013; Chen 2006). No studies had more than $30 \%$ attrition.

\section{Selective reporting}

We deemed selective reporting to be a high risk of bias in two studies (Aben 2014; Åkerlund 2013). Aben 2014 did not report the EQ-5D Utility score, only the visual analogue scale (VAS) score. Åkerlund 2013 only reported on some memory outcomes, whereas there were other outcomes that were also assessed at follow-up, and data were only reported for 'good adherers' to the intervention.

\section{Other potential sources of bias}

We did not identify any other sources of bias.

\section{Effects of interventions}

See: Summary of findings for the main comparison

For the meta-synthesis, we only included data from 11 of the 13 included studies, based on the data that were available. We summarised the outcomes under the domains of subjective memory, objective memory, functional abilities, mood, and quality of life. When pooling the data, we used a random-effects model because these were studies performed on a heterogeneous group of participants, with the intervention (being a complex intervention) being slightly different between studies (e.g. number of sessions). This would allow us to generalise our findings to most memory rehabilitation interventions offered for people who have had a stroke.

\section{Outcome 1: Subjective memory measures}

Subjective measures of memory were used in seven studies (Aben 2014; Doornhein 1998; das Nair 2012; Kaschel 2002; Lannin 2014; Radford 2012; Westerberg 2007), of which three included longterm follow-up (Aben 2014; das Nair 2012; Kaschel 2002). The various subjective memory measures used were: Metamemory in Adulthood Questionnaire, Everyday Memory Questionnaire, Memory Questionnaire, Memory Assessments Clinics rating scale, Memory Functioning Questionnaire (frequency of forgetting carer), Comprehensive Assessment of Prospective Memory self, and the Cognitive Failures Questionnaire. There was a significant effect 
of treatment on subjective reports of memory in the short term (standardised mean difference (SMD) $0.36,95 \%$ confidence interval (CI) 0.08 to $0.64, P=0.01$; Analysis 1.1 ), but not the long term (SMD $0.31,95 \% \mathrm{Cl}-0.02$ to $0.64, \mathrm{P}=0.06$; Analysis 1.2 ). We observed no statistical heterogeneity in the short- or longer-term analyses ( $\mathrm{Tau}^{2}$ $=0.00 ; \mathrm{Chi}^{2}=5.69, \mathrm{df}=6(\mathrm{P}=0.46) ; \mathrm{I}^{2}=0 \%$ and $\mathrm{Tau}^{2}=0.00 ; \mathrm{Chi}^{2}=$ $\left.0.73, d f=2(P=0.69) ; I^{2}=0 \%\right)$.

\section{Outcome 2: Objective memory measures}

Ten studies included data on objective measures of memory immediately after treatment (Aben 2014; Åkerlund 2013; das Nair 2012; Doornhein 1998; Kaschel 2002; Lannin 2014; Lin 2014; Radford 2012; Westerberg 2007; Zucchella 2014), and four of these studies examined long-term effects of treatment (Aben 2014; Åkerlund 2013; das Nair 2012; Kaschel 2002). Several objective memory measures were used, including comprehensive batteries (Rivermead Behavioural Memory Test, Wechsler Memory Scale) and verbal memory sub-tests (Rivermead Behavioural Memory Test story recall, 15 words test, Rey Auditory Verbal Learning Test delayed, Claeson-Dahl delayed). There were no significant differences found between intervention and control groups on either immediate or long-term follow-up on either memory test batteries (SMD $0.25,95 \% \mathrm{Cl}-0.36$ to $0.86, \mathrm{P}=0.43$ and SMD -0.17 , $95 \% \mathrm{Cl}-0.74$ to $0.41, \mathrm{P}=0.57$, respectively; Analysis 1.3; Analysis 1.4). The $1^{2}$ statistic was $42 \%$ for objective memory assessed by a comprehensive battery immediately after intervention. On the verbal learning task, there was no significant difference between groups immediately after treatment (SMD $0.21,95 \% \mathrm{Cl}-0.03$ to $0.46, P=0.08$ ). Data from only one study were available in relation to long-term verbal learning outcome and this was therefore not included in the meta-analysis (Aben 2014).

\section{Outcome 3: Functional abilities (activities of daily living: ADL)}

Three studies included measures of participants' function in terms of ADL immediately after treatment (Chen 2006; das Nair 2012; Zucchella 2014), and one study in the long term (das Nair 2012). The Functional Independence Measure, Extended Activities of Daily Living scale and an unspecified independence measure were used as the outcome measures of ADL. There was no significant effect of treatment on functional ability immediately after treatment (SMD $1.17,95 \% \mathrm{Cl}-0.35$ to $2.68, \mathrm{P}=0.13$; Analysis 1.5 ). The $\mathrm{I}^{2}$ statistic suggested significant statistical heterogeneity at $93 \%$. Data from only one study were available in relation to long-term functional outcome and this was therefore not included in the meta-analysis.

\section{Outcome 4: Mood}

Three studies included measures of participants' mood immediately after treatment and at long-term follow-up (Aben 2014; Åkerlund 2013; das Nair 2012). Mood was measured on the General Health Questionnaire, Hospital Anxiety and Depression Scale (depression sub-scale) and the Centre for Epidemiological Studies Depression scale. No effect of treatment was found on mood either immediately (SMD $-0.07,95 \% \mathrm{Cl}-0.35$ to $0.21, \mathrm{P}=0.63$; Analysis 1.6), or on long-term follow-up (SMD - $0.17,95 \% \mathrm{Cl}-0.54$ to $0.19, \mathrm{P}=0.35$; Analysis 1.7 ). There was no statistical heterogeneity at immediate or long-term follow-up $\left(\mathrm{Tau}^{2}=0.00 ; \mathrm{Chi}^{2}=0.66, \mathrm{df}=\right.$ $2(\mathrm{P}=0.72) ; \mathrm{I}^{2}=0 \%$ and $\mathrm{Tau}^{2}=0.02 ; \mathrm{Chi}^{2}=2.40, \mathrm{df}=2(\mathrm{P}=0.30) ; \mathrm{I}^{2}$ $=17 \%)$.

Cognitive rehabilitation for memory deficits after stroke (Review)

Copyright (c) 2016 The Cochrane Collaboration. Published by John Wiley \& Sons, Ltd.

\section{Outcome 5: Quality of life}

Only one study included measures of participants' quality of life (assessed on the EQ-5D) immediately after treatment and at long-term follow-up (Aben 2014). Therefore, we did not enter this into the meta-analysis. There were no statistically significant differences in the mean quality of life measures (immediate outcome) between the intervention and control groups on the Utility score (intervention: $m=0.76$; standard deviation (SD) 0.26 ; control: $m=0.76 ; S D ~ 0.25 ; P=1.00 ; d=0$ ), or the visual analogue scale (VAS) score (intervention: $\mathrm{m}=67.89$; SD 16.61; control: $\mathrm{m}=$ 70.23; SD 15.67; $P=0.39 ; d=0.15$ ); or in the long term on the Utility score (intervention: $\mathrm{m}=0.76$; $\mathrm{SD} 0.26$; control: $\mathrm{m}=0.78$; SD 0.22; $\mathrm{P}$ $=0.63 ; \mathrm{d}=0.08$ ), or the VAS score (intervention: $\mathrm{m}=68.38 ; \mathrm{SD} 17.94$; control: $\mathrm{m}=71.51$; $\mathrm{SD} 13.61 ; \mathrm{P}=0.25 ; \mathrm{d}=0.19$ ).

\section{DISCUSSION}

\section{Summary of main results}

Overall, the results suggested a beneficial effect of memory rehabilitation on subjective reports of memory problems in daily life immediately after treatment. However, no statistically significant effects of treatment were observed on these outcomes at longer-term follow-up. Similarly, no statistically significant differences were observed between groups on objective memory abilities immediately after intervention or long-term as assessed by comprehensive memory batteries, or immediately as assessed on verbal learning tasks. No statistically significant differences were observed on measures of mood or functional abilities, either immediately after the intervention or on long-term follow-up. We could not assess the impact of memory rehabilitation on quality of life as only one study had assessed this outcome.

Therefore, it appears that memory rehabilitation has a positive effect on subjective reports of memory problems in people who have had a stroke. This, however, was not substantiated by the findings from the objective tests of memory (either as a comprehensive test battery or as a verbal learning task). This discrepancy might suggest that people 'feel' that they have improved, with no actual change to their memory function, because they have learnt to cope with their memory problems. Often, subjective reports of memory are associated with mood (Lamb 2013; van Rijsbergen 2014), but this was not evident from our review. Another interpretation is that the subjective and objective measures of memory assess two different aspects of memory. The significant effect of memory rehabilitation on subjective memory measures was strongly influenced by results from one study that had a large sample size (Aben 2014). These results will remain tentative until there are more large studies.

There was a lack of consistency in the outcome domains assessed. While many studies included measures of subjective memory problems, mood, and functional abilities, they rarely used the same measure. Several objective memory measures were used, and often the primary outcome was not clearly specified by the trialists.

Indeed, many studies suffered from poor quality of reporting, particularly failing to state the procedures for randomisation, allocation concealment, blinding, and reasons for loss to followup. Most trialists did not comply with the CONSORT guidelines in reporting their trial (Moher 2001). The obvious result of such failings was the lack of clarity in discerning the methods of the 
study. Another major concern was the degree of clinical and methodological heterogeneity that trials in memory rehabilitation possess. Without trials explicitly elucidating methodological procedures, heterogeneity cannot be adequately addressed. Furthermore, although statistical heterogeneity was not evident in most of the analyses, on two outcomes it was in the low to moderate range, and on one outcome it was high. We were unable to conduct a thorough inspection of the cause of this heterogeneity because of the small sample size and small number of studies. However, we suspect that it may have been caused because many trials used multiple tests of objective memory function (with comprehensive batteries having several different sub-tests, each measuring a different component of memory). In addition, in all trials both participants and therapists were aware of the group to which they were allocated. This is difficult to avoid in trials of cognitive rehabilitation, but may lead to some bias.

The results of this review suggest that there is some evidence to support the effectiveness of memory rehabilitation for subjective memory impairments immediately after treatment, but these benefits are not maintained at long-term follow-up. Overall, there was insufficient evidence to support or refute the effectiveness of cognitive rehabilitation for memory ability, mood, independence in activities of daily living, or quality of life.

\section{Overall completeness and applicability of evidence}

There are limitations to this review. Many of the studies identified included samples with mixed diagnoses, and although several study authors provided separate data for those with stroke, the sample sizes were small. A sensitivity analysis could have been conducted to compare the stroke-only studies with those with stroke patients as part of a mixed diagnosis group, but given that most trials had small samples further fractionating may have led to further reduction in power, which we felt would lead to inconclusive findings. Mixed diagnoses studies are beneficial in determining the potential for the generalisability of training programmes across diagnostic groups and reflect usual clinical practice in many centres, but there are likely to be differential effects of the training based on diagnosis and even severity (Cicerone 2000). This is an area that requires further investigation.

\section{Quality of the evidence}

These findings are limited due to the small number of studies included for each outcome and the small sample sizes. The evidence was limited due to poor quality of reporting in many studies and lack of consistency in the choice of outcome measures. Furthermore, as seen from the GRADE quality ratings, we rated most studies as being of moderate quality. Downgrading was typically due to serious study limitations, where we had assessed studies as having two or more areas with a high risk of bias. Other reasons for downgrading were wide confidence intervals, small sample sizes, mixed diagnosis groups, and inconsistency (large $\mathrm{I}^{2}$ values).

\section{Potential biases in the review process}

Two authors (RdN, NBL) conducted one of the trials included in the review (das Nair 2012). To mitigate bias, study selection and data extraction were undertaken by the two review authors not involved in any of the included trials.

\section{Agreements and disagreements with other studies or reviews}

Our findings are similar to two previous reviews (Cumming 2013; Gillespie 2015), which highlighted the paucity of evidence for the effectiveness of cognitive rehabilitation after stroke and they are consistent with the previous Cochrane review (das Nair 2007), in that there was insufficient evidence to support or refute the effectiveness of memory rehabilitation on most outcomes. However, unlike the previous Cochrane review, this review found evidence to suggest that there was a beneficial effect of cognitive rehabilitation for memory on subjective measures of memory in the short term.

\section{AUTHORS' CONCLUSIONS}

\section{Implications for practice}

Given that a large number of individuals complain of memory problems following a stroke, and considering that some centres are offering a variety of interventions to address these problems, questioning the effectiveness of these treatment programmes is pertinent. The studies examined in this review reflected the diversity of intervention strategies employed in memory rehabilitation, and variation in outcome measures used to evaluate their effectiveness. In this review, we found some evidence to suggest that memory rehabilitation was more effective than no rehabilitation or control. However, our results indicate that any benefits of memory rehabilitation were limited to improvements in subjective reports of memory function in the short term and they are inconclusive for long-term follow-up.

\section{Implications for research}

The evidence base for the effectiveness of cognitive rehabilitation for memory problems following stroke, from the literature surveyed, appears weak. Few randomised controlled trials (RCTs) have been reported, and many had methodological flaws inherent in the study design. There was an increased risk of random errors due to sampling errors and small sample sizes, an over-reliance and misinterpretation of significance tests (without mention of confidence intervals), problems related to poor (or absent) reporting of randomisation procedures, poor (or absent) blinding, differences in the nature of the outcomes measured, and overall poor quality of reporting of trials. The results of this review suggest that there is an urgent need for further well-conceptualised, executed, and reported RCTs of memory rehabilitation for people who have had a stroke, which take into consideration some of the issues raised in this review.

\section{ACKNOWLEDGEMENTS}

We thank Jennifer Drury at the Greenfield Medical Library (University of Nottingham) for her valuable assistance in reviewing and suggesting changes to the electronic search strategy used in this review. We also thank Hazel Fraser at the Cochrane Stroke Group for her continued support and specialist guidance. A special thanks to our peer reviewers and our 'consumer reviewers' Julie Gildie and Odie Geiger for their valuable suggestions. 


\section{R E F E R E N C E S}

\section{References to studies included in this review}

\section{Aben 2014 \{published and unpublished data\}}

Aben L. Metamemory intervention in chronic stroke patients: long-term effects on social participation and quality of life. http://www.trialregister.nl/trialreg/admin/rctview.asp?TC=1656 2008.

Aben L, Heijenbrok-Kal M, Ponds R, van Busschbach J, Ribbers $\mathrm{G}$. Long term effects of a memory self-efficacy training program for stroke patients in the chronic stage: a randomized controlled trial. Brain Injury 2012;26(4-5):414-5.

* Aben L, Heijenbrok-Kal MH, Ponds RWHM, Busschbach JV, Ribbers GM. Long-lasting effects of a new memory self-efficacy training for stroke patients: a randomized controlled trial. Neurorehabilitation and Neural Repair 2014;28(3):199-206.

Aben L, Heijenbrok-Kal MH, van Loon EM, Groet E, Ponds RW, Busschbach JJ, et al. Training memory self-efficacy in the chronic stage after stroke: a randomized controlled trial. Neurorehabilitation and Neural Repair 2013;27(2):110-7. [PUBMED: 22895620]

Heijenbrok-Kal MH. Email communication 2016.

Åkerlund 2013 \{published and unpublished data\} Björkdahl A. Email communication 2016.

* Åkerlund E, Esbjörnsson E, Sunnerhagen KS, Björkdahl A Can computerized working memory training improve impaired working memory, cognition and psychological health?. Brain Injury 2013;27(13-4):1649-57.

\section{Chen 2006 \{published data only\}}

Chen S. Email communication 2016.

* Chen S, Jiang Q, Liu P, Huang D, Ding J. Effect of the cognitive rehabilitation on the functional independence of hemiplegic patients with stroke. Chinese Journal of Clinical Rehabilitation 2006;10(18):14-6.

\section{das Nair 2012 \{published and unpublished data\}}

O'Brien MC, das Nair R, Lincoln NB. A comparison of the content of memory rehabilitation groups for patients with neurological disabilities. Neuropsychological Rehabilitation 2013;23(3):321-32.

das Nair R, Lincoln N, Kontou E, Vella K, O'Brien MC. A comparison of the effectiveness of two types of memory rehabilitation strategies following brain damage: a single blind, randomised control trial. Proceedings of the Oliver Zangwill 10th Anniversary Conference. 16-17 November 2006. Cambridge, UK. 2006.

* das Nair R, Lincoln NB. Evaluation of rehabilitation of memory in neurological disabilities (ReMiND): a randomized controlled trial. Clinical Rehabilitation 2012;26(10):894-903.
Doornhein 1998 \{published data only\}

Doornhein K, deHaan EHF. Cognitive training for memory deficits in stroke patients. Neuropsychological Rehabilitation 1998;8(4):393-400.

\section{Kaschel 2002 \{published data only\}}

Kaschel R, Della Sala S, Cantagallo A, Fahlbock A, Laaksonen R, Kazen M. Imagery mnemonics for the rehabilitation of memory: a randomised group controlled trial. Neuropsychological Rehabilitation 2002;12(2):127-53.

Lannin 2014 \{published and unpublished data\}

Carr B, Allaous J, Lannin N, MacKenzie B, Falcon A, Tate R, et al. Efficacy of using handheld computers plus occupational therapy training to compensate for memory and planning difficulties after brain injury: a randomised control trial. Neurorehabilitation and Neural Repair 2012;26(6):687.

Lannin N. Email communication 2016

* Lannin N, Carr B, Allaous J, Mackenzie B, Falcon A, Tate R. A randomized controlled trial of the effectiveness of handheld computers for improving everyday memory functioning in patients with memory impairments after acquired brain injury. Clinical Rehabilitation 2014;28(5):470-81.

Lannin NA, Schmidt J, Carr B, Allaous J, Falcon A, Tate R. Occupational therapy training to use handheld personal digital assistant (PDA) devices to address memory and planning difficulties after acquired brain injury: a randomised controlled trial. Stroke 2014;45(12):296.

Lemoncello 2011 \{published and unpublished data\} Lemoncello R. Email communication 2016.

Lemoncello R, Sohlberg MM, Fickas S, Prideaux J. A randomised controlled crossover trial evaluating Television Assisted Prompting (TAP) for adults with acquired brain injury. Neuropsychological Rehabilitation 2011;21(6):825-46.

\section{Lin 2014 \{published data only\}}

Lin ZC, Tao J, Gao YL, Yin DZ, Chen AZ, Chen LD. Analysis of central mechanism of cognitive training on cognitive impairment after stroke: resting-state functional magnetic resonance imaging study. Journal of International Medical Research 2014;42(3):659-68.

\section{Prokopenko 2013 \{published data only\}}

Mozheyko EY. Email communication 2016.

* Prokopenko SV, Mozheyko EY, Petrova MM, Koryagina TD, Kaskaeva DS, Chernykh TV, et al. Correction of post-stroke cognitive impairments using computer programs. Journal of the Neurological Sciences 2013;325(1):148-53.

Radford 2012 \{published and unpublished data\}

Miller L. Email communication 2016.

* Radford K, Lah S, Thayer Z, Say MJ, Miller LA. Improving memory in outpatients with neurological disorders using a 
group-based training program. Journal of the International Neuropsychological Society 2012;18(04):738-48.

\section{Westerberg 2007 \{published data only\}}

Westerberg $\mathrm{H}$, Jacobaeus $\mathrm{H}$, Hirvikoski T, Clevberger $\mathrm{P}$, Ostenson ML, Bartfai A, et al. Computerised training of working memory - a new method for cognitive rehabilitation after stroke. Proceedings of the Karolinska Stroke Update Meeting. 15-16 November 2004. Stockholm, Sweden. 2004.

* Westerberg H, Jacobaeus H, Hirvikoski T, Clevberger P, Östensson ML, Bartfai A, et al. Computerized working memory training after stroke - a pilot study. Brain Injury 2007;21(1):21-9.

\section{Zucchella 2014 \{published and unpublished data\}}

Bartolo M. Email communication 2016.

* Zucchella C, Capone A, Codella V, Vecchione C, Buccino G, Sandrini $G$, et al. Assessing and restoring cognitive functions early after stroke. Functional Neurology 2014;29(4):255.

\section{References to studies excluded from this review}

Barker-Collo 2009 \{published data only\}

Barker-Collo SL, Feigin VL, Lawes CMM, Parag V, Senior H, Rodgers A. Reducing attention deficits after stroke using attention process training: a randomized controlled trial. Stroke 2009;40(10):3293-8.

\section{Blanchet 2016 \{published data only\}}

* Blanchet S. Impact of combined aerobic and cognitive training on cognitive functioning in individuals with vascular cognitive impairment: a pilot study [Abstract]. Proceedings of the 8th World Stroke Congress. Brasilia, Brazil, 10-13 October 2012.

Blanchet S, Richards CL, Leblond J, Olivier C, Maltais DB. Cardiorespiratory fitness and cognitive functioning following short-term interventions in chronic stroke survivors with cognitive impairment: a pilot study. International Journal of Rehabilitation Research 2016;39(2):153-9.

Brainin 2015 \{published data only\}

Brainin M. Email communication 2016.

* Brainin M, Matz K, Nemec M, Teuschl Y, Dachenhausen A, Asenbaum-Nan $S$, et al. Prevention of poststroke cognitive decline: ASPIS - a multicenter, randomized, observer-blind, parallel group clinical trial to evaluate multiple lifestyle interventions - study design and baseline characteristics. International Journal of Stroke 2015;10(4):627-35.

Matz K, Teuschl Y, Firlinger B, Dachenhausen A, Keindl M, Seyfang $L$, et al. Multidomain lifestyle interventions for the prevention of cognitive decline after ischemic stroke randomized trial. Stroke 2015;46(10):2874-80.

\section{Bushnick 2010 \{published data only\}}

Bushnick T, Englander J, Oggins J, Levinson R, Halper D. A randomized clinical trial of a cognitive orthotic with executive planning capability in individuals with cognitive dysfunction. Brain Injury 2010;24(3):392-3.

\section{Chen 2011 \{published data only\}}

Chen AJ, Novakovic-Agopian T, Nycum TJ, Song S, Turner GR, Hills NK, et al. Training of goal-directed attention regulation enhances control over neural processing for individuals with brain injury. Brain 2011;134(5):1541-54.

Chen 2015 \{published data only\}

Chen CX, Mao RH, Li SX, Zhao YN, Zhang M. Effect of visual training on cognitive function in stroke patients. International Journal of Nursing Sciences 2015;2(4):329-33.

de Joode 2013 \{published and unpublished data\}

* De Joode EA, Van Heugten CM, Verhey FRJ, Van Boxtel MPJ. Effectiveness of an electronic cognitive aid in patients with acquired brain injury: a multicentre randomised parallel-group study. Neuropsychological Rehabilitation 2013;23(1):133-56.

de Joode EA. Email communication 2016.

de Luca 2014 \{published data only (unpublished sought but not used)\}

Calabrò RS. Email communication 2016.

* De Luca R, Calabrò RS, Gervasi G, De Salvo S, Bonanno L, Corallo $F$, et al. Is computer-assisted training effective in improving rehabilitative outcomes after brain injury? A casecontrol hospital-based study. Disability and Health Journal 2014;7(3):356-60.

\section{Evans 2000 \{published data only\}}

Evans JJ, Wilson BA, Schuri U, Andrade J, Baddeley A, Bruna O, et al. A comparison of 'errorless' and 'trial-and-error' learning methods for teaching individuals with acquired memory deficits. Neuropsychological Rehabilitation 2000;10(1):67-101.

\section{Fish 2008 \{published data only\}}

Fish J, Emslie H, Evans JJ, Manly T, Wilson BA. Further investigations into the NeuroPage system for memory and planning disorders. Proceedings of the 34th International Neuropsychological Society Annual Meeting: From Plasticity to Rehabilitation, 26-29 July. Zurich, Switzerland. 2006:17.

* Fish J, Manly T, Emslie H, Evans JJ, Wilson BA. Compensatory strategies for acquired disorders of memory and planning: differential effects of a paging system for patients with brain injury of traumatic versus cerebrovascular aetiology. Journal of Neurology, Neurosurgery and Psychiatry 2008;79(8):930-5.

\section{Fong 2009 \{published data only\}}

Fong KNK, Howie DR. Effects of an explicit problem-solving skills training program using a metacomponential approach for outpatients with acquired brain injury. American Journal of Occupational Therapy 2009;63(5):525-34.

\section{Gamito 2014 \{published data only\}}

Gamito P, Oliveira J, Santos N, Pacheco J, Morais D, Saraiva T, et al. Virtual exercises to promote cognitive recovery in stroke patients: the comparison between head mounted displays versus screen exposure methods. International Journal of Disability and Human Development 2014;13(3):337-42. 
Gasparrini 1979 \{published data only\}

Gasparrini B. Personal communication 2007.

* Gasparrini B, Satz P. A treatment for memory problems in left hemisphere CVA patients. Journal of Clinical Neuropsychology 1979;1(2):137-50.

\section{Hildebrandt 2006 \{published data only\}}

Hildebrandt H, Bussmann-Mork B, Schwendemann G. Group therapy for memory impaired patients: a partial remediation is possible. Journal of Neurology 2006;253:512-9.

\section{Imes 1984 \{published data only\}}

Imes C. Interventions with stroke patients: EMG biofeedback, group activities, cognitive retraining. Cognitive Rehabilitation 1984;2(5):4-17.

\section{Klonoff 2007 \{published data only\}}

Klonoff PS, Talley MC, Dawson LK, Myles SM, Watt LM, Gehrels JA, et al. The relationship of cognitive retraining to neurological patients' work and school status. Brain Injury 2007;21(11):1097-107.

\section{Liu 2009 \{published data only\}}

Liu KPY. Use of mental imagery to improve task generalisation after a stroke. Hong Kong Medical Journal/Xianggang yi xue za zhi 2009;15(3 Suppl 4):37-41.

\section{Lundqvist 2010 \{published data only\}}

Lundqvist A. Email communication 2016.

* Lundqvist A, Grundström K, Samuelsson K, Rönnberg J. Computerized training of working memory in a group of patients suffering from acquired brain injury. Brain Injury 2010;24(10):1173-83.

\section{Man 2006 \{published data only\}}

Man DWK, Soong WYL, Tam SF, Hui-Chan CWY. A randomized clinical trial study on the effectiveness of a tele-analogy-based problem-solving programme for people with acquired brain injury (ABI). NeuroRehabilitation 2006;21(3):205-17.

\section{Markle-Reid 2011 \{published data only\}}

Markle-Reid M, Orridge C, Weir R, Browne G, Gafni A, Lewis M, et al. Interprofessional stroke rehabilitation for stroke survivors using home care. Canadian Journal of Neurological Sciences 2011;38(02):317-34.

McDonald 2011 \{published data only (unpublished sought but not used)\}

Haslam C. Email communication 2016.

* McDonald A, Haslam C, Yates P, Gurr B, Leeder G, Sayers A. Google Calendar: a new memory aid to compensate for prospective memory deficits following acquired brain injury. Neuropsychological Rehabilitation 2011;21(6):784-807.

\section{McEwan 2014 \{published data only\}}

McEwen SE, Wolf T, Baum C, Polatajko H. Combined taskspecific and cognitive strategy training in subacute stroke: a phase II randomized controlled trial. Stroke 2014;45(Suppl 1):ATP110.

McEwen 2015 \{published data only\}

McEwen S, Polatajko H, Baum C, Rios J, Cirone D, Doherty M, et al. Combined cognitive-strategy and task-specific training improve transfer to untrained activities in subacute stroke: an exploratory randomized controlled trial. Neurorehabilitation and Neural Repair 2015;29(6):526-36.

Miller 2014 \{published data only\}

Miller LA, Radford K. Testing the effectiveness of groupbased memory rehabilitation in chronic stroke patients. Neuropsychological Rehabilitation 2014;24(5):721-37.

\section{Ownsworth 1999 \{published data only\}}

Ownsworth TL, McFarland K. Memory remediation in long-term acquired brain injury: two approaches in diary training. Brain Injury 1999;13(8):605-26.

\section{Polatajko 2012 \{published data only\}}

Polatajko HJ, McEwen SE, Ryan JD, Baum CM. Pilot randomized controlled trial investigating cognitive strategy use to improve goal performance after stroke. American Journal of Occupational Therapy 2012;66(1):104-9.

\section{Rasmussen 2016 \{published data only\}}

Rasmussen RS, Overgaard K, Østergaard A, Kjær P, Skerris A, Skou $C$, et al. Post-stroke rehabilitation at home reduced disability and improved quality of life: a randomized controlled trial. Cerebrovascular Diseases 2013;35 Suppl 3:94-5.

* Rasmussen RS, Østergaard A, Kjær P, Skerris A, Skou C, Christoffersen J, et al. Stroke rehabilitation at home before and after discharge reduced disability and improved quality of life: a randomised controlled trial. Clinical Rehabilitation 2016;30(3):225-36

\section{Schupp 2002 \{published data only\}}

Schupp W, Rohring S, Kulke H, Peetz H. Home-based neuropsychological training using tele therapy - practicability and first results. [Abstract]. Proceedings of the 3rd World Congress in Neurological Rehabilitation. 2-6 April 2002. Venice, Italy, 2002.

\section{Skidmore 2015 \{published data only\}}

Skidmore ER, Dawson DR, Butters MA, Grattan ES, Juengst SB, Whyte $E M$, et al. Strategy training shows promise for addressing disability in the first 6 months after stroke. Neurorehabilitation and Neural Repair 2015;29(7):668-76.

\section{Sohlberg 2007 \{published data only\}}

Sohlberg MM, Fickas S, Hung P-F, Fortier A. A comparison of four prompt modes for route finding for community travellers with severe cognitive impairments. Brain Injury 2007;21(5):531-8.

\section{Tailby 2003 \{published data only\}}

Tailby R, Haslam C. An investigation of errorless learning in memory-impaired patients: improving the technique and clarifying theory. Neuropsychologia 2003;41(9):1230-40. 
Thickpenny-Davis 2007 \{published data only\}

Thickpenny-Davis KL, Barker-Collo SL. Evaluation of a structured group format memory rehabilitation program for adults following brain injury. Journal of Head Trauma Rehabilitation 2007;22(5):303-13.

Thoene 1995 \{published data only\}

Thoene Al, Glisky EL. Learning of name-face associations in memory impaired patients: a comparison of different training procedures. Journal of the International Neuropsychological Society 1995;1(1):29-38.

Wilson 2001 \{published data only\}

Emslie HC. Personal communication 2006.

* Wilson BA, Emslie HC, Evans JJ. Reducing everyday memory and planning problems by means of a paging system: a randomised control crossover study. Journal of Neurology Neurosurgery and Psychiatry 2001;70:477-82.

Wolf 2015 \{unpublished data only\}

Wolf TJ. Cognitive Oriented Strategy Training Augmented Rehabilitation (COSTAR) treatment approach for stroke. https:// clinicaltrials.gov/show/NCT01910454.

\section{Yu 2009 \{published data only\}}

Yu J, Hu Y, Wu Y, Chen W, Zhu Y, Cui X, et al. The effects of community-based rehabilitation on stroke patients in China: a single blind, randomized controlled multicentre trial. Clinical Rehabilitation 2009;23(5):408-17.

\section{References to studies awaiting assessment}

\section{Bezdenezhnykh 2014 \{published data only\}}

Bezdenezhnykh A, Prokopenko S, Mozheyko E, Koryagina T, Chernukh T, Shvetsova I, et al. Computer cognitive training for patients with cognitive impairments in acute ischemic stroke. International Journal of Stroke 2014;9:218.

\section{Bezdenezhnykh 2015 \{published data only\}}

Bezdenezhnykh A, Prokopenko S, Mozheiko E, Petrova M, Grippa E, Lipatnikova S, et al. Neuropsychological computer training versus entertaining computer games in patients with post-stroke cognitive impairments: randomized clinical study. International Journal of Stroke 2015;10 Suppl S2:412.

Matz 2007 \{published data only\}

Matz K, Brainin M, Teuschl Y, Eckhardt R, Herbst A, Dachenhausen A. Prevention of post-stroke cognitive decline - a randomized pilot trial testing cognitive training in patients with first lacunar stroke. International Journal of Stroke 2008;23 Suppl 1:400.

* Matz K, Teuschl Y, Eckhardt R, Herbst A, Dachenhausen A, Brainin M. Cognitive training in patients with first lacunar stroke - a randomized pilot trial for the prevention of post-stroke cognitive decline. Cerebrovascular Diseases 2007;23 Suppl 2:42.

\section{Prokopenko 2011 \{published data only\}}

Prokopenko SV, Mozhe ko E, Levin OS, Koriagina TD, Chernykh TV, Berezovskaia MA. Cognitive disorders and its correction in the acute period of ischemic stroke. Zhurnal nevrologii i psikhiatrii imeni SS Korsakova/Ministerstvo zdravookhraneniia i meditsinskoi promyshlennosti Rossiiskoi Federatsii, Vserossiiskoe obshchestvo nevrologov [i] Vserossiiskoe obshchestvo psikhiatrov 2011;112(8 Pt 2):35-9.

\section{References to ongoing studies}

ISRCTN45171788 \{unpublished data only\}

Frommelt P. Email communication 2016.

* Frommelt P. Neuropsychological rehabilitation: modular cognitive retraining versus compensatory skills training. http:// www.isrctn.com/ISRCTN45171788.

\section{ISRCTN59754564 \{unpublished data only\}}

Manly T, Peers P. Progressive home-based working memory and attention training following stroke, implications for spatial bias: a preliminary study. http://www.isrctn.com/ISRCTN59754564.

NCT01674790 \{published data only\}

Mackay-Lyons M. Combined effects of aerobic exercise and cognitive training on cognition after stroke. ClinicalTrials.gov 2012.

NCT02384057 \{unpublished data only\}

Shin JH. Cognitive rehabilitation for participants with stroke or brain injury using C8 sciences. https://clinicaltrials.gov/show/ NCT02384057.

\section{NCT02482688 \{unpublished data only\}}

Humphreys GW, Barutchu A. A new rehabilitation treatment following stroke. https://clinicaltrials.gov/ct2/show/ NCT02482688.

Sahakian 2016 \{unpublished data only\}

Sahakian B. Investigation into the efficacy of cognitive training on cognition in adults with brain injury. https:// www.ukctg.nihr.ac.uk/trials/trial-details/trial-details? trialld=32055. [IRAS ID 159857]

Yang 2014 \{published data only\} Yang S. Email communication 2016.

* Yang S, Ye H, Huang J, Tao J, Jiang C, Lin Z, et al. The synergistic effect of acupuncture and computer-based cognitive training on post-stroke cognitive dysfunction: a study protocol for a randomized controlled trial of $2 \times 2$ factorial design. $B M C$ Complementary and Alternative Medicine 2014;14(1):290.

\section{Additional references}

\section{Baddeley 1994}

Baddeley A, Emslie H, Nimmo-Smith I. The Doors and People Test: A Test of Visual and Verbal Recall and Recognition. Bury St Edmunds: Thames Valley Test Company, 1994.

\section{Beck 1990}

Beck AT, Steer RA. Beck Anxiety Inventory (BAI) Manual. Oxford: Pearson, 1990. 


\section{Beck 2003}

Beck AT, Steer R, Brown G. Beck Depression Inventory-Fast Screen for Medical Patients. San Antonio: Psychological Corporation, 2003.

\section{Broadbent 1982}

Broadbent DE, Cooper PF, FitzGerald P, Parkes KR. The Cognitive Failures Questionnaire (CFQ) and its correlates. British Journal of Clinical Psychology 1982;21:1-16.

\section{Cicerone 2000}

Cicerone KD, Dahlberg C, Kalmar K, Langenbahn DM, Malec JF, Bergquist TF, et al. Evidence-based cognitive rehabilitation: recommendations for clinical practice. Archives of Physical Medicine and Rehabilitation 2000;81:1596-615.

\section{Cicerone 2005}

Cicerone KD, Dahlberg C, Malec JF, Langenbahn DM, Felicetti T, Kneipp S, et al. Evidence-based cognitive rehabilitation: updated review of the literature from 1998 through 2002. Archives of Physical Medicine and Rehabilitation 2005;86:1681-92.

\section{Cicerone 2011}

Cicerone KD, Langenbahn DM, Braden C, Malec JF, Kalmar K, Fraas M, et al. Evidence-based cognitive rehabilitation: updated review of the literature from 2003 through 2008. Archives of Physical Medicine and Rehabilitation 2011;92:519-30.

\section{Coughlan 1988}

Coughlan A, Storey P. The Wimbledon Self-Report Scale: emotional and mood appraisal. Clinical Rehabilitation 1988;2(3):207-13.

\section{Crook 1992}

Crook TH, Feher EP, Larrabee GJ. Assessment of memory complaint in age-associated memory impairment: the MAC-Q. International Psychogeriatrics 1992;4(02):165-76.

\section{Cumming 2013}

Cumming TB, Marshall RS, Lazar RM. Stroke, cognitive deficits, and rehabilitation: still an incomplete picture. International Journal of Stroke 2013;8(1):38-45.

\section{Davis 1995}

Davis AM, Cockburn AM, Wade DT, Smith PT. A subjective memory assessment questionnaire for use with elderly people after stroke. Clinical Rehabilitation 1995;9(3):238-44.

\section{Duncan 1999}

Duncan PW, Wallace D, Lai SM, Johnson D, Embretson S, Laster LJ. The stroke impact scale version 2.0 evaluation of reliability, validity, and sensitivity to change. Stroke 1999;30(10):2131-40.

\section{Gillespie 2015}

Gillespie DC, Bowen A, Chung CS, Cockburn J, Knapp P, Pollock A. Rehabilitation for post-stroke cognitive impairment: an overview of recommendations arising from systematic reviews of current evidence. Clinical Rehabilitation 2015;29(2):120-8.

\section{Goldberg 1988}

Goldberg DP, Williams PA. User's Guide to the GHQ. Windsor: NFER Nelson, 1988.

\section{GRADEpro [Computer program]}

GRADE Working Group, McMaster University. GRADEpro GDT. Version accessed May 2015. Hamilton (ON): GRADE Working Group, McMaster University, 2014.

\section{Hall 1997}

Hall KM. The Functional Assessment Measure (FAM). Journal of Rehabilitation Outcomes Measurement 1997;1(3):63-5.

\section{Hamilton 1987}

Hamilton BB, Granger CV, Sherwin FS, Zielezny M, Tashman JS. A uniform national data system for medical rehabilitation. In: Fuhrer JM editor(s). Rehabilitation Outcomes: Analysis and Measurement. Baltimore: Brookes, 1987:137-47.

\section{Higgins 2011}

Higgins JPT, Green S (editors). Cochrane Handbook for Systematic Reviews of Interventions Version 5.1.0 [updated March 2011]. The Cochrane Collaboration, 2011. Available from www.cochrane-handbook.org.

\section{Lamb 2013}

Lamb F, Anderson J, Saling M, Dewey H. Predictors of subjective cognitive complaint in postacute older adult stroke patients. Archives of Physical Medicine and Rehabilitation 2013;94(9):1747-52.

\section{Lincoln 2012}

Lincoln NB, Kneebone II, Macniven JAB, Morris RC. Psychological Management of Stroke. Hoboken: John Wiley \& Sons, 2012.

\section{Mahoney 1965}

Mahoney FI. Functional evaluation: the Barthel Index. Maryland State Medical Journal 1965;14:61-5.

\section{Middleton 2014}

Middleton LE, Lam B, Fahmi H, Black SE, Mcllroy WE, Stuss T, et al. Frequency of domain-specific cognitive impairment in sub-acute and chronic stroke. Neurorehabilitation 2014;34(2):305-12.

\section{Moher 2001}

Moher D, Schulz KF, Altman DG. The CONSORT statement: revised recommendation for improving the quality of reports of parallel-group randomised trials. Lancet 2001;357:1191-4.

\section{Moher 2010}

Moher D, Hopewell S, Schulz KF, Montori V, Gøtzsche PC, Devereaux PJ, et al. CONSORT 2010 explanation and elaboration: updated guidelines for reporting parallel group randomised trials. Journal of Clinical Epidemiology 2010;63(8):e1-e37.

\section{Nouri 1987}

Nouri FM, Lincoln NB. An extended activities of daily living scale for stroke patients. Clinical Rehabilitation 1987;1(4):301-5. 


\section{RevMan 2014 [Computer program]}

The Nordic Cochrane Centre, The Cochrane Collaboration. Review Manager (RevMan). Version 5.3. Copenhagen: The Nordic Cochrane Centre, The Cochrane Collaboration, 2014.

\section{Robertson 2001}

Robertson IH, Wilson A. Neuropsychological rehabilitation. In: Fawcett JW, Rosser AE, Dunnett SB editor(s). Brain Damage, Brain Repair. Oxford: Oxford University Press, 2001.

\section{Schaapsmeerders 2013}

Schaapsmeerders P, Maaijwee NA, van Dijk EJ, RuttenJacobs LC, Arntz RM, Schoonderwaldt HC, et al. Long-term cognitive impairment after first-ever ischemic stroke in young adults. Stroke 2013;44(6):1621-8.

\section{Snaphaan 2007}

Snaphaan L, de Leeuw FE. Poststroke memory function in nondemented patients a systematic review on frequency and neuroimaging correlates. Stroke 2007;38(1):198-203.

\section{Sunderland 1983}

Sunderland A, Harris JE, Baddeley AD. Do laboratory tests predict everyday memory? A neuropsychological study. Journal of Verbal Learning and Verbal Behavior 1983;22(3):341-57.

\section{van Rijsbergen 2014}

van Rijsbergen MWA, Mark RE, de Kort PLM, Sitskoorn MM. Subjective cognitive complaints after stroke: a systematic review. Journal of Stroke and Cerebrovascular Diseases 2014;23(3):408-20.

\section{Ware 2001}

Ware JE, Kosinski M. SF-36 Physical \& Mental Health Summary Scales: A Manual for Users of Version 1. Quality Metric, 2001.

\section{Wechsler 1997}

Wechsler D. Wechsler Memory Scale - Third edition (WMSIII). San Antonio: Harcourt Assessment, 1997.

\section{CHARACTERISTICS OF STUDIES}

\section{Characteristics of included studies [author-defined order]}

\section{WHOQOL 1993}

WHOQoL Group. Study protocol for the World Health Organization project to develop a Quality of Life assessment instrument (WHOQOL). Quality of Life Research 1993;2(2):153-9.

\section{Williams 1999}

Williams LS, Weinberger M, Harris LE, Clark DO, Biller J. Development of a stroke-specific quality of life scale. Stroke 1999;30(7):1362-9.

\section{Wilson 1985}

Wilson BA, Cockburn J, Baddeley A. The Rivermead Behavioural Memory Test. Bury St. Edmunds: Thames Valley Test Company, 1985.

\section{Wilson 2005}

Wilson BA, Shiel A, Foley J, Emslie H, Groot Y, Hawkins K, et al. Cambridge Test of Prospective Memory (CAMPROMPT). San Antonio: Pearson Assessment, 2005.

\section{Zigmond 1983}

Zigmond AS, Snaith RP. The Hospital Anxiety and Depression Scale. Acta Psychiatrica Scandinavica 1983;67(6):361-70.

\section{References to other published versions of this review}

\section{das Nair 2007}

das Nair R, Lincoln N. Cognitive rehabilitation for memory deficits following stroke. Cochrane Database of Systematic Reviews 2007, Issue 3. [DOI: 10.1002/14651858.CD002293.pub2]

\section{Majid 2000}

Majid MJ, Lincoln NB, Weyman N. Cognitive rehabilitation for memory deficits following stroke. Cochrane Database of Systematic Reviews 2000, Issue 3. [DOI: 10.1002/14651858.CD002293]

* Indicates the major publication for the study

Aben 2014

Methods Multi-site RCT

Participants block randomised (10 per site) by randomisation programme to intervention group (I) or control group (C; attention control)

Outcomes assessed at 4 points: 3 weeks prior to intervention (T0), 10 days after last intervention session (T1), 6 months post baseline (T2) and 12 months post baseline (T3)

The Netherlands
Community
Memory impairment assessed using subjective interviews to identify memory complaints
Method of stroke diagnosis not stated, but study recruited from 2 rehabilitation centres


Aben 2014 (Continued)

$$
\text { At randomisation } \mathrm{n}=153
$$

$\mathrm{I}: \mathrm{n}=77$

Mean age: 58.3 (10.36), 33/44 (female/male)

Mean time (months) since onset 52.41 (39.38)

$42 \mathrm{LH}, 35 \mathrm{RH} ; 54$ ischaemic, 23 not stated

C: $n=76$

Mean age 57.86 (9.00), 36/40 (female/male)

Mean time (months) since onset 55.34 (35.08)

$45 \mathrm{LH}, 31 \mathrm{RH}$; 50 ischaemic, 26 not stated

Lost to follow-up: at T1 $\mathrm{n}=10(5 \mathrm{I}, 5 \mathrm{C}$; sample $\mathrm{n}=72 \mathrm{I}, 71 \mathrm{C})$ with ITT analysis, at T2 $\mathrm{n}=1(1 \mathrm{I}, 1 \mathrm{C}$ participants previously lost returned with measures; sample $n=71$ I, 72 C), T3 $n=4$ (4 I, 0 C, sample $n=67 \mathrm{I}, 72$ C)

I: $9 \times 1$-hour sessions/twice weekly (9 hours total). Groups of 4 to 6 . Memory Self Efficacy training programme covering: 1) theoretical introduction on memory and stroke, 2) training on internal and external memory strategies to improve compensation, 3) psycho-education on effect of mood, anxiety and memory-related worries on memory complaints. Training booklet provided plus half-hour homework per session

C: $9 \times 1$-hour sessions/twice weekly (9 hours total). Groups of 4 to 6 . Peer support groups, no therapeutic intervention. Education on causes and consequences of stroke; sharing of problems. Hand-outs provided, but no homework assigned

Objective memory measure: RBMT story recall delayed

Mood measure: CES-D

Quality of life measure: EQ-5D Utility

Other outcomes assessed:

Health-related quality of life (WHOQoL-Bref; EQ-5D - VAS), Memory (AVLT), Social Support List, problem experience (Impact on Participation and Autonomy)

Exclusion criteria: progressive neurological disorder (e.g. dementia or MS), insufficient knowledge and comprehension of Dutch, alcohol/drug abuse, subdural haematoma or subarachnoid haemorrhage

Adequate matching: demographics and baseline characteristics non-significant on most measures Method of diagnosing stroke: not stated, but recruited from 2 rehabilitation centres

Coping, personality traits, aphasia and executive functioning measures were taken at baseline only

Statistical tests used: independent $t$-tests for continuous variables and $x^{2}$ tests for categorical variables using baseline data for MSE and z-scores for AVLT and RBMT

Short-term follow-up data also presented in Aben 2013 paper, which used an ITT analysis on T1 results 
Aben 2014 (Continued)

Risk of bias

\begin{tabular}{|c|c|c|}
\hline Bias & Authors' judgement & Support for judgement \\
\hline $\begin{array}{l}\text { Random sequence genera- } \\
\text { tion (selection bias) }\end{array}$ & Low risk & $\begin{array}{l}\text { Randomisation conducted by someone independent to the trial, using a ran- } \\
\text { domisation program }\end{array}$ \\
\hline $\begin{array}{l}\text { Allocation concealment } \\
\text { (selection bias) }\end{array}$ & Low risk & $\begin{array}{l}\text { "Allocation of the group to either the experimental or control condition was } \\
\text { performed by an independent investigator who was not involved in the study" }\end{array}$ \\
\hline $\begin{array}{l}\text { Blinding of participants } \\
\text { and personnel (perfor- } \\
\text { mance bias) } \\
\text { All outcomes }\end{array}$ & High risk & $\begin{array}{l}\text { "Patients were not informed on the type of intervention they had been allocat- } \\
\text { ed to". Those delivering intervention were aware }\end{array}$ \\
\hline $\begin{array}{l}\text { Blinding of outcome as- } \\
\text { sessment (detection bias) } \\
\text { All outcomes }\end{array}$ & Low risk & $\begin{array}{l}\text { "All patients were assessed [...] by trained research psychologists who were } \\
\text { blinded to group allocation. The data were entered [...] by the blinded re- } \\
\text { search psychologists." }\end{array}$ \\
\hline $\begin{array}{l}\text { Incomplete outcome data } \\
\text { (attrition bias) } \\
\text { All outcomes }\end{array}$ & Low risk & Missing outcome data explained and equal in both groups \\
\hline $\begin{array}{l}\text { Selective reporting (re- } \\
\text { porting bias) }\end{array}$ & High risk & $\begin{array}{l}\text { No protocol available to cross-check. However, } 2 \text { additional published pa- } \\
\text { pers show same outcome measures with equal participants in each. From the } \\
\text { EQ-5D only the VAS score was reported, but not the Utility score }\end{array}$ \\
\hline Other bias & Low risk & \\
\hline
\end{tabular}

Åkerlund 2013

Methods

RCT between March 2008 and December 2010

Single site

Participants randomised by lot to an intervention group (I) or a waiting-list control group (C)

Outcomes assessed at 3 time points: T0 baseline (pre-randomisation), T1 6 weeks post-baseline (1 week following end of intervention sessions) and T2 18 weeks post baseline (13 weeks following end of intervention sessions)

\section{Participants}

\section{Sweden}

Community (out-patients)

Mixed diagnoses group with $n=29$ stroke participants (whole group $n=47$ )

Method of diagnosis of stroke not specified, but participants recruited through a department of rehabilitation

Memory problems identified through performance below normal range $(6 \pm 1)$ on WAIS-III Digit span and/or Span board

Undergoing T0, T1 and T2 assessments $(n=29)$ :

$\mathrm{I}: \mathrm{n}=15$

Mean age: 45.93 (11.27), 9/6 (female/male) 
Åkerlund 2013 (Continued)

Mean time (months) since onset: 7.44 (2.59)

$5 \mathrm{LH}, 10 \mathrm{RH}$

C: $n=14$

Mean age: 52.86 (7.48), 8/6 (female/male)

Mean time (months) since onset: 6.40 (3.21)

$7 \mathrm{LH}, 6 \mathrm{RH}$

Lost to follow-up: 3 ( $n=32$ at randomisation)

Interventions

Both groups received standard rehabilitation

I: trained 30 to 45 -minute session, 5 days/week for 5 weeks with a computerised WM training program, Cogmed QM (a battery of visuospatial and verbal auditory WM tasks). All parts of the battery trained at each session, over 90 trials each day. All Cogmed tasks involved: (1) maintenance of multiple stimuli at the same time, (2) short delays during which representation of stimuli should be held in WM, (3) unique sequencing of stimuli order in each trial, (4) difficulty level adapting as individual performance

Program provides continuous feedback and reinforcement

Additional personal and individual feedback once a week, by a specially trained coach

C: completed baseline and follow-up assessments only. Cogmed was offered, and followed up, after study completion

Objective memory measure: RBMT Profile Score
Mood measure: Hospital Anxiety and Depression Scale: HADS-D
Other outcomes assessed: WM and information processing (Span board and Digit span sub-tests of
WAIS-III NI), working memory sub-scale (aggregated from combined scaled-scored results of Digit span,
Arithmetic and Letter-Number Sequences of WAIS-III NI), cognitive function (Barrow Neurological Insti-
tute Screen for Higher Cerebral Functions; BNIS), executive function (Dysexecutive Questionnaire; DEX),
psychological health (anxiety, HADS-A)

Notes

Inclusion criteria: patients below normal range $(6 \pm 1)$ with a performance of $\leq 5$ digits forwards and/or $\leq 4$ digits reversed in the WAIS-III Digit span and/or $\leq 5$ blocks forwards and/or $\leq 4$ blocks reversed in the WAIS-III NI Span board

Exclusion criteria: aphasia/non-Swedish speaking, participation in study contraindicated due to medical reasons (according to physician's health assessment, i.e. pronounced fatigue, pain or depression)

Adequate matching at baseline, only a small age difference between groups

Statistical tests used: Mann-Whitney U-test, independent samples, for ordinal data and $\mathrm{Chi}^{2}$ test for nominal data for between-group differences. Wilcoxon signed-rank test for within-group differences. Spearman's Rank correlation for associations between variables

RBMT data provided by authors as unpublished data

\section{Risk of bias}

Bias Authors' judgement Support for judgement

Random sequence genera- Low risk tion (selection bias)
"After a baseline assessment the patients were randomised by lot into either the intervention group or the control group."

Allocation concealment Unclear risk
(selection bias)

No indication of who conducted allocation - however, baseline assessments were conducted before randomisation 
Åkerlund 2013 (Continued)

Blinding of participants High risk Participants and personnel knew of allocation and personnel (performance bias)

All outcomes

\begin{tabular}{lll}
\hline $\begin{array}{l}\text { Blinding of outcome as- } \\
\text { sessment (detection bias) } \\
\text { All outcomes }\end{array}$ & Unclear risk & Not stated whether outcome assessors were blinded \\
\hline $\begin{array}{l}\text { Incomplete outcome data } \\
\begin{array}{l}\text { (attrition bias) } \\
\text { All outcomes }\end{array}\end{array}$ & Low risk & $\begin{array}{l}\text { 3 randomised but not followed up. Reasons for attrition not specified for } \\
\text { stroke sample }\end{array}$ \\
\hline $\begin{array}{l}\text { Selective reporting (re- } \\
\text { porting bias) }\end{array}$ & High risk & $\begin{array}{l}\text { No published protocol available, however additional data provided by authors } \\
\text { includes RBMT and Fatigue Impact Scale (FIS) }\end{array}$ \\
\hline \begin{tabular}{l} 
Other bias \\
\hline
\end{tabular} & Low risk & \\
\hline
\end{tabular}

Chen 2006

Rethods between August 2003 and April 2005
Inpatient (rehabilitation and neurology)
Single site
Participants randomised using a random number generator to either the intervention group (I) or a TAU
control group (C)

Outcomes assessed at 2 time points: T0 baseline and T1 post-treatment

\begin{tabular}{|c|c|}
\hline \multirow[t]{9}{*}{ Participants } & China \\
\hline & Method of determining memory problems, stroke diagnosis and time since stroke onset not stated \\
\hline & At randomisation $(n=60)$ : \\
\hline & $\mathrm{I}: \mathrm{n}=30$ \\
\hline & Mean age: 62.12 (6.98), 14/16 (female/male) \\
\hline & $14 \mathrm{LH}, 16 \mathrm{RH}$; haemorrhage 13, infarction 17 \\
\hline & $C: n=30$ \\
\hline & Mean age: 63.60 (7.43), 12/18 (female/male) \\
\hline & $12 \mathrm{LH}, 18 \mathrm{RH}$; haemorrhage 15 , infarction 15 \\
\hline \multirow[t]{2}{*}{ Interventions } & $\begin{array}{l}\text { I: TAU plus cognitive retraining according to impairments (attention/concentration, memory, coping } \\
\text { strategies for apraxia and memory) }\end{array}$ \\
\hline & C: TAU - physiotherapy, occupational therapy \\
\hline \multirow[t]{2}{*}{ Outcomes } & Functional independence measure: scale name not stated \\
\hline & $\begin{array}{l}\text { Other outcomes assessed: cognitive (Loewenstein occupational therapy cognitive assessment; LOTCA), } \\
\text { motor (Fugl Meyer motor assessment; FMS) }\end{array}$ \\
\hline
\end{tabular}


Chen 2006 (Continued)

Notes

Inclusion criteria: met national infarction and haemorrhage guidelines 1995, CT and MRI scan results, first time illness, aged 45 to 70 years, stable illness, one-sided paralysis, secondary school education or above

Exclusion criteria: serious cardiac problems, serious speech impairment

Original paper published in Chinese and translated by a staff member of the lead author's department

\section{Risk of bias}

\begin{tabular}{|c|c|c|}
\hline Bias & Authors' judgement & Support for judgement \\
\hline $\begin{array}{l}\text { Random sequence genera- } \\
\text { tion (selection bias) }\end{array}$ & Low risk & "Random number generator" \\
\hline $\begin{array}{l}\text { Allocation concealment } \\
\text { (selection bias) }\end{array}$ & Unclear risk & Unsure who conducted the allocation \\
\hline $\begin{array}{l}\text { Blinding of participants } \\
\text { and personnel (perfor- } \\
\text { mance bias) } \\
\text { All outcomes }\end{array}$ & High risk & Participants and therapists knew about allocation \\
\hline $\begin{array}{l}\text { Blinding of outcome as- } \\
\text { sessment (detection bias) } \\
\text { All outcomes }\end{array}$ & Unclear risk & Unknown whether outcome assessor was blinded \\
\hline $\begin{array}{l}\text { Incomplete outcome data } \\
\text { (attrition bias) } \\
\text { All outcomes }\end{array}$ & Low risk & No details of attrition are given \\
\hline $\begin{array}{l}\text { Selective reporting (re- } \\
\text { porting bias) }\end{array}$ & Unclear risk & $\begin{array}{l}\text { All measures discussed are reported in results. No published protocol to sup- } \\
\text { port a judgement }\end{array}$ \\
\hline Other bias & Low risk & \\
\hline
\end{tabular}

das Nair 2012

$\begin{array}{ll}\text { Methods } & \text { Single-site RCT } \\ \text { Block randomisation (4 participants) via computer-generated random number sequence generator } \\ \text { Group intervention } \\ \text { Participants randomised to } 1 \text { of } 2 \text { intervention groups (Compensation A, Restoration B) or a self-help } \\ \text { control group (Self-help C) }\end{array}$

Outcomes assessed at 3 points: at pre-randomisation (T0), 5 months post-randomisation (T1) and 7 months post-randomisation (T3)

UK
Community
Mixed diagnoses group with $\mathrm{n}=17$ stroke patients $(\mathrm{n}=72$ whole sample)
Method of diagnosis of stroke not specified


das Nair 2012 (Continued)

Memory impairment determined by an overall profile score $>1$ on the RBMT. Stroke diagnosis verified by hospital or GP records

A: (Compensation) $n=4$

Mean age: 50.3 (3.30), 3/1 (female/male)

Mean time (months) since onset: 73.25 (98.42)

B: (Restitution) $n=2$

Mean age: 43.0 (8.49), 0/2 (female/male)

Mean time (months) since onset: 15.50 (0.71)

$\mathrm{C}: \mathrm{n}=11$

Mean age: 54.8 (10.36), 3/8 (female/male)

Mean time (months) since onset: 32.30 (22.99)

Interventions

Manual-based programmes (ensuring consistency of delivery of sessions across time and groups).

Comparable format and duration of all 3 programmes

2 individual and 10 weekly group sessions. Sessions lasted approximately 1.5 hours, with 10 to 15 minute break. Homework assigned to translate what was learned in sessions to everyday life and practise use of memory aids and relaxation strategies

$A$ and B: use of internal memory aids and errorless learning techniques

A: use of external memory aids

B: exercises to practise encoding and retrieval (including attention retraining exercises, e.g. letter and number cancellation tasks)

C: no memory strategies taught; relaxation techniques and ways in which they could cope with their condition

Objective measure: RBMT - Extended Version

Functional ability measure: Nottingham Extended Activities of Daily Living Scale (EADL)

Mood measure: General Health Questionnaire-12 (GHQ)

Other outcomes assessed: use of memory aids (Internal and External Memory Aids Questionnaires), Emotional state (Wimbledon Self Report Scale), Psychological adjustment (Mental Adjustment to Brain Damage scale)

Inclusion criteria: over the age of 18 , reported memory problems, diagnosed at least 1 month prior to recruitment, no previous diagnosis of brain damage or other severe disability

Exclusion criteria: did not speak English, lived more than 50 miles from Nottingham or Derby Patients were not recruited if they had: uncorrected visual or hearing impairments which prevented them from completing the assessments, no demonstrable memory deficit (defined as overall profile score $>1$ on RBMT- Extended version)

Adequate matching at baseline - no significant differences at baseline, though larger number of stroke patients in control group

Pre-morbid IQ (National Adult Reading Test), language ability (Sheffield Screening Test for Acquired Language Disorders), memory (WAIS-III spatial and digit span, Doors and People), and executive abilities (Trail Making Task, Stroop) were measured at baseline 
ITT analysis used with LOCF: sensitivity analysis, area under the curve and Mann-Whitney U-tests

\section{Risk of bias}

\begin{tabular}{|c|c|c|}
\hline Bias & Authors' judgement & Support for judgement \\
\hline $\begin{array}{l}\text { Random sequence genera- } \\
\text { tion (selection bias) }\end{array}$ & Low risk & Computerised random number generation by independent researcher \\
\hline $\begin{array}{l}\text { Allocation concealment } \\
\text { (selection bias) }\end{array}$ & Low risk & $\begin{array}{l}\text { Conducted by independent researcher and allocation was not known by inter- } \\
\text { vention provider after randomisation }\end{array}$ \\
\hline $\begin{array}{l}\text { Blinding of participants } \\
\text { and personnel (perfor- } \\
\text { mance bias) } \\
\text { All outcomes }\end{array}$ & High risk & Participants and therapists aware of allocation \\
\hline $\begin{array}{l}\text { Blinding of outcome as- } \\
\text { sessment (detection bias) } \\
\text { All outcomes }\end{array}$ & Low risk & $\begin{array}{l}\text { Outcome assessors were blind to the random allocation and the intervention } \\
\text { participants received. Participants were requested not to disclose any infor- } \\
\text { mation about intervention at follow-up }\end{array}$ \\
\hline $\begin{array}{l}\text { Incomplete outcome data } \\
\text { (attrition bias) } \\
\text { All outcomes }\end{array}$ & Low risk & $\begin{array}{l}\text { List-wise deletion utilised and baseline data were imputed for missing fol- } \\
\text { low-up data }\end{array}$ \\
\hline $\begin{array}{l}\text { Selective reporting (re- } \\
\text { porting bias) }\end{array}$ & Unclear risk & $\begin{array}{l}\text { All data discussed were analysed and results disclosed, however protocol not } \\
\text { published }\end{array}$ \\
\hline Other bias & Low risk & \\
\hline
\end{tabular}

Doornhein 1998

\begin{tabular}{ll}
\hline Methods & RCT \\
Single centre \\
Participants assigned at random to control group (C) or intervention group (I) \\
Outcome assessment done by person who carried out training at end of training \\
No long-term follow-up \\
\hline The Netherlands \\
In-patient (rehabilitation centre) \\
Memory impairment assessed on Dutch version of Rey auditory learning test \\
Method of diagnosing stroke not stated, but all participants recruited from a rehabilitation centre \\
Time since stroke: 3 to 5 months \\
At randomisation ( $n=12$ ) \\
I: $n=6 ;$ mean age 51.3 years \\
C: $n=6 ;$ mean age 51.7 years \\
I: memory strategy training 2 sessions per week for 4 weeks; subjective memory problems assessed; \\
mnemonic strategies taught were 'association' and 'organisation'. Homework books used \\
C: 'drill and practice' exercises, pay more attention, spend more time repeating material
\end{tabular}


Doornhein 1998 (Continued)

Outcomes Subjective memory measure: Memory Questionnaire

Objective memory measure: 15 Words Test

Other outcomes assessed: target memory tasks (Name-Face Paired Associated Memory Test, Stylus Maze Test), control memory tasks (Oxford Recurring Faces Test)

Notes

Patients with severe aphasia, apraxia, or agnosia were excluded

Experimental and control groups comparable on important demographic and illness characteristics Number and flow of participants, by intervention group, throughout trial not mentioned Statistics: 2 way-ANOVA, post-hoc Tukey test, ITT analysis not stated, power not stated

\section{Risk of bias}

\begin{tabular}{|c|c|c|}
\hline Bias & Authors' judgement & Support for judgement \\
\hline $\begin{array}{l}\text { Random sequence genera- } \\
\text { tion (selection bias) }\end{array}$ & Unclear risk & $\begin{array}{l}\text { "Assigned at random". No indication of how the random sequence was gener- } \\
\text { ated }\end{array}$ \\
\hline $\begin{array}{l}\text { Allocation concealment } \\
\text { (selection bias) }\end{array}$ & Unclear risk & No information \\
\hline $\begin{array}{l}\text { Blinding of participants } \\
\text { and personnel (perfor- } \\
\text { mance bias) } \\
\text { All outcomes }\end{array}$ & High risk & $\begin{array}{l}\text { Both personnel and participants knew allocation, but unclear what effect this } \\
\text { may have had on outcome }\end{array}$ \\
\hline $\begin{array}{l}\text { Blinding of outcome as- } \\
\text { sessment (detection bias) } \\
\text { All outcomes }\end{array}$ & High risk & $\begin{array}{l}\text { "testing was not 'blind' and that the evaluation was done by the same person } \\
\text { who carried out the training sessions." }\end{array}$ \\
\hline $\begin{array}{l}\text { Incomplete outcome data } \\
\text { (attrition bias) } \\
\text { All outcomes }\end{array}$ & Low risk & No attrition reported \\
\hline $\begin{array}{l}\text { Selective reporting (re- } \\
\text { porting bias) }\end{array}$ & Unclear risk & $\begin{array}{l}\text { All data discussed were analysed and results disclosed, however protocol not } \\
\text { published }\end{array}$ \\
\hline Other bias & Unclear risk & $\begin{array}{l}\text { Number and flow of participants, by intervention group, throughout trial not } \\
\text { mentioned } \\
\text { Statistics: ITTanalysis not stated, power not stated }\end{array}$ \\
\hline
\end{tabular}

Kaschel 2002

\begin{tabular}{ll}
\hline Methods & $\begin{array}{l}\text { RCT. A-B-A designed trial consisting of: a 4-week no training baseline (A), } 10 \text { weeks of training (B), and a } \\
\text { 3-month no training follow-up (A) } \\
\text { Multi-centre (7 sites) } \\
\text { Participants assigned at random to pragmatic (control) group (C) or imagery (intervention) group (I) } \\
\text { Outcomes assessed at } 4 \text { time points: pre-baseline, baseline, post-intervention, follow-up at } 3 \text { months }\end{array}$ \\
\hline Participants & Europe \\
In-patient and out-patient \\
Mixed diagnoses group with $\mathrm{n}=7$ stroke patients ( $\mathrm{n}=21$ total sample) \\
Stroke diagnosed through CT or MRI scan
\end{tabular}


Kaschel 2002 (Continued)

Memory deficits identified by score of 15 or less on RBMT

At randomisation ( $n=7$, overall mean age: 46.3 years)

$\mathrm{I}: \mathrm{n}=4$

Mean age: 51 years

$1 \mathrm{LH}, 2 \mathrm{RH}, 1$ bilateral

$\mathrm{C}: \mathrm{n}=3$

Mean age: 41.7 years

$1 \mathrm{LH}, 1$ bilateral, 1 brain stem

Lost to follow-up: I n = 1

Interventions

Both groups received 10 weeks of training, comprising of 30 individual sessions (70 to 90 minutes)

I: imagery training. Patients received 2 training periods: (1) learning the skill of generating images rapidly given verbal information - steps included motivation for imagery training, rapid generation of images of objects and generation and retrieval of images of simple actions; (2) transfer to target problems in everyday life - steps included identification of the problem, identification of the manner in which imagery could help in this situation, simulation of using imagery in this situation (within sessions), transfer of imagery to these kinds of situations (outside sessions)

C: pragmatic training. Each participant received individualised treatment including: taught a variety of internal and external strategies, elements of attention training and planning procedures and practical guidelines to encode and retrieve information, according to usual care in their centre

Subjective memory measure: Memory Assessment Clinics rating scale (self)
Objective memory measure: RBMT Profile score
$\begin{aligned} & \text { Other outcomes assessed: (1) Wechsler Memory Scale (total score), RBMT immediate and delayed sto- } \\ & \text { ry recall, 'Appointments' Everyday Memory Test, Memory Assessment Clinics (family) rating scales, d2 } \\ & \text { subtest }\end{aligned}$

Notes

Inclusion criteria: either in- or out-patients, referred for the rehabilitation of memory problems, age between 20 and 60 years, brain damage documented by CT or MRI scan, at least 6 months following onset, score equal to or less than 15 on the immediate/delayed story recall test from the RBMT

Exclusion criteria: patients with severe memory problems (RBMT scores of 12 points or less), aphasia, neglect, hemianopia, apraxia, agnosia, psychiatric history, substance misuse, affective disorder, or those who cannot generate visual imagery

Participating centres had to make sure they could follow up the participants without any break (except holidays) for 7 months, and that they could fulfil the number of training session requirements

\section{Risk of bias}

\begin{tabular}{lll}
\hline Bias & Authors' judgement & Support for judgement \\
\hline $\begin{array}{l}\text { Random sequence genera- } \\
\text { tion (selection bias) }\end{array}$ & Low risk & $\begin{array}{l}\text { "They were randomly allocated to one or another of the two experimental } \\
\text { groups consecutively as the statistician received their data." Method of ran- } \\
\text { dom sequence generation not specified }\end{array}$ \\
\hline $\begin{array}{l}\text { Allocation concealment } \\
\text { (selection bias) }\end{array}$ & Low risk & Conducted by statistician \\
\hline $\begin{array}{l}\text { Blinding of participants } \\
\text { and personnel (perfor- } \\
\text { mance bias) }\end{array}$ & High risk & Participants and therapists aware of allocation \\
\hline
\end{tabular}


Kaschel 2002 (Continued)

All outcomes

\begin{tabular}{lll}
$\begin{array}{l}\text { Blinding of outcome as- } \\
\text { sessment (detection bias) } \\
\text { All outcomes }\end{array}$ & Unclear risk & Not stated whether outcome assessor was blind to allocation \\
\hline $\begin{array}{l}\text { Incomplete outcome data } \\
\text { (attrition bias) } \\
\text { All outcomes }\end{array}$ & Low risk & 1 lost to follow-up \\
\hline $\begin{array}{l}\text { Selective reporting (re- } \\
\text { porting bias) }\end{array}$ & Unclear risk & No protocol available to support a judgement \\
\hline $\begin{array}{l}\text { Other bias } \\
\text { Unclear risk }\end{array}$ & $\begin{array}{l}\text { "We did not want to invest a lot of hours with patients who would cease to par- } \\
\text { ticipate after a few weeks or whose discharge to other wards was planned." } \\
\text { Selection for the study seems highly biased towards participants who were } \\
\text { less likely to withdraw }\end{array}$
\end{tabular}

Lannin 2014

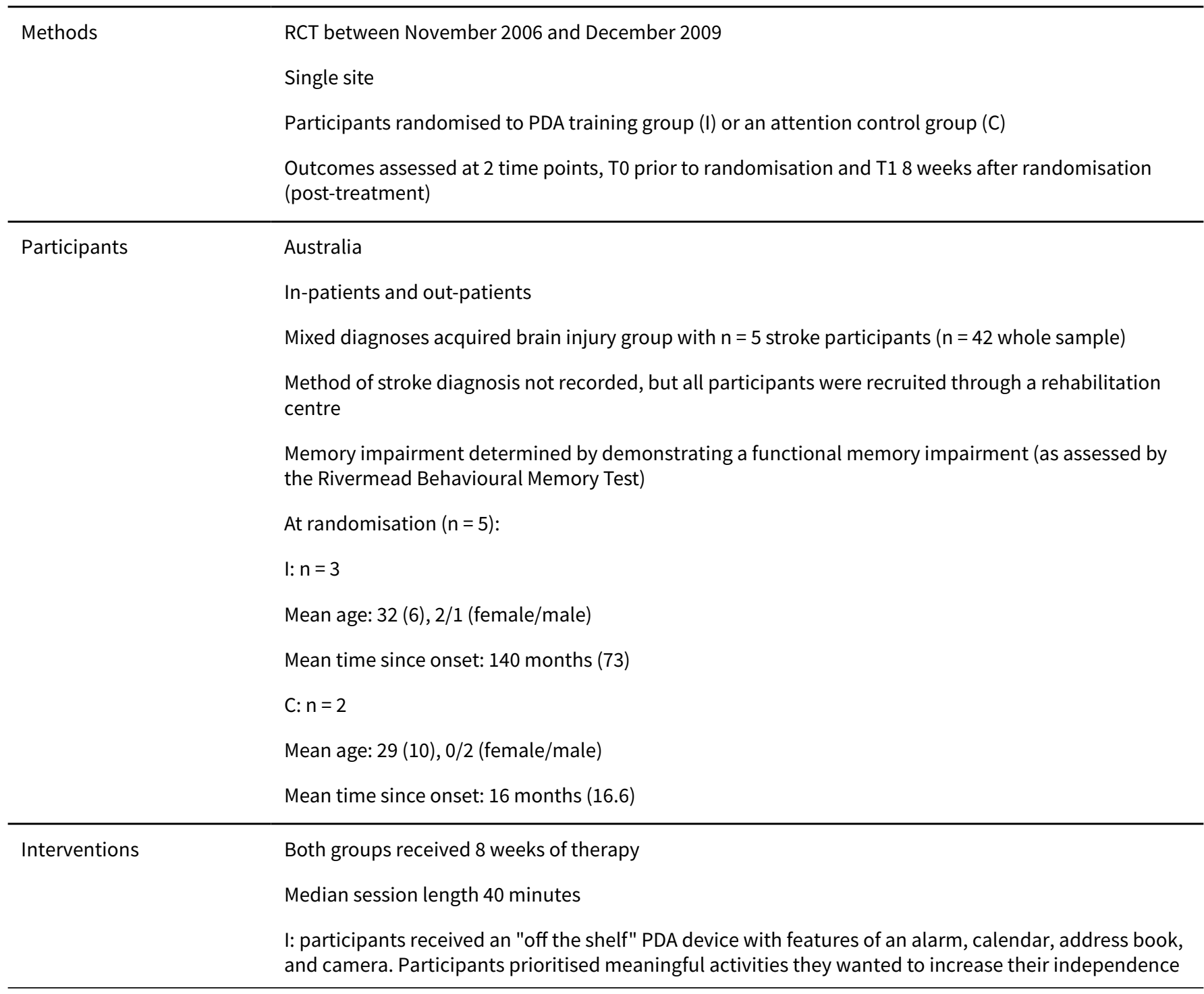


Lannin 2014 (Continued)

in or memory of. They received support/training in its use, which consisted of 5 training modules covering selection of an appropriate device, awareness of deficit(s), application skills, and organisational strategies. In addition, training incorporated generalisation of strategies outside the therapy and errorless learning. $m=7$ hours $( \pm 2)$ therapy time over an average 8 sessions

C: participants received 'standard rehabilitation' including the same prioritisation of meaningful activities as I group, and use of non-electronic memory aids (paper diaries, lists, cueing strategies, mnemonics). Individual and group sessions focused on strategies to promote independence. Participants asked not to use electronic devices including alarms. Following the trial participants were given the opportunity to train with the PDA. $m=8$ hours $( \pm 4)$ over an average 9 sessions

Outcomes

Subjective memory measure: Memory Functioning Questionnaire - frequency of forgetting (carer; MFQ)

Objective memory measure: RBMT Profile score

Additional outcomes assessed: improvement in functional memory goal performance (Goal Attainment Scale), MFQ - severity of forgetting (carer), Memory Compensation Questionnaire (MCQ), Wechsler Test of Adult Reading (WTAR), Controlled Oral Word Association Test (COWAT), Delis-Kaplan Executive Function System Color Word (DKEFS CW), Behavioural Assessment of the Dysexecutive Syndrome (BADS), Full Scale Intelligence Quotient (FSIQ)

Notes

Inclusion criteria: aged $\geq 17$ years, diagnosis of acquired brain injury, functional memory impairment (on RBMT), emerged from post-traumatic amnesia, sufficient hand function to use PDA

Exclusion criteria not stated

MFQ forgetting (carer) scale was used in meta-analysis as this was the only subjective memory data received by the authors for the stroke sub-sample

Stroke group had a difference in time since stroke onset but unlikely to have affected outcomes

Statistical tests used: t-tests

\section{Risk of bias}

\begin{tabular}{lll}
\hline Bias & Authors' judgement & Support for judgement \\
\hline $\begin{array}{l}\text { Random sequence genera- } \\
\text { tion (selection bias) }\end{array}$ & Low risk & $\begin{array}{l}\text { "Simple randomisation methodology", "Computer generated and stored off- } \\
\text { site" }\end{array}$ \\
\hline $\begin{array}{l}\text { Randomisation used a computerised simple randomisation strategy } \\
\text { (selection bias) }\end{array}$ & Low risk & $\begin{array}{l}\text { "Concealed in opaque, consecutively numbered envelopes by a person not } \\
\text { otherwise involved in the study", "a secretary [...] opened these envelopes and } \\
\text { read aloud the group allocation" }\end{array}$ \\
\hline
\end{tabular}

Blinding of participants High risk Participants and therapists aware of group allocation
and personnel (perfor-
mance bias)

\begin{tabular}{|c|c|c|}
\hline $\begin{array}{l}\text { Blinding of outcome as- } \\
\text { sessment (detection bias) } \\
\text { All outcomes }\end{array}$ & Low risk & $\begin{array}{l}\text { "Assessors were blind to group allocation", "asked before each assessment not } \\
\text { to inform the assessors about their group or interventions received" }\end{array}$ \\
\hline $\begin{array}{l}\text { Incomplete outcome data } \\
\text { (attrition bias) } \\
\text { All outcomes }\end{array}$ & Low risk & No attrition \\
\hline
\end{tabular}

\begin{tabular}{|c|c|c|}
\hline $\begin{array}{l}\text { Selective reporting (re- } \\
\text { porting bias) }\end{array}$ & Unclear risk & $\begin{array}{l}\text { No protocol published; do not appear to be any methodological differences } \\
\text { from earlier conference proceedings available online }\end{array}$ \\
\hline
\end{tabular}


Lannin 2014 (Continued)

Other bias

Low risk

Lemoncello 2011

\begin{tabular}{|c|c|}
\hline \multirow[t]{5}{*}{ Methods } & $\mathrm{RCT}$ \\
\hline & Cross-over design \\
\hline & $\begin{array}{l}\text { Participants assigned at random (coin flip) to } 1 \text { of } 2 \text { intervention presentation order groups (A: TAP or B: } \\
\text { TYP) }\end{array}$ \\
\hline & $\begin{array}{l}\text { Outcomes assessed at } 5 \text { time points: pre-randomisation (T0), at } 2 \text { weeks (post-first condition, T1), at } 4 \\
\text { weeks (post-first cross-over, T2), at } 6 \text { weeks (post-second cross-over), at } 8 \text { weeks (post-third cross-over, } \\
\text { T3) and at } 10 \text { weeks (post-final cross-over, T4) }\end{array}$ \\
\hline & Only T1 data used \\
\hline \multirow[t]{12}{*}{ Participants } & USA \\
\hline & Community \\
\hline & Mixed diagnoses group, with stroke $n=4$ ( $n=23$ whole sample) \\
\hline & All participants $>12$ months since last stroke \\
\hline & $\begin{array}{l}\text { Memory impairment determined through self, carer or therapist reported cognitive challenges and a } \\
\text { cognitive assessment battery (PASAT, CVLT-II). Method of diagnosing stroke not stated, participants re- } \\
\text { cruited from acquired brain injury (ABI) groups and referrals from speech-language pathologists and } \\
\text { ABI specialists. }\end{array}$ \\
\hline & At T1 assessment $(n=4)$ : \\
\hline & A: TAP $n=3$ \\
\hline & Mean age: $A: 60$ (12.17) \\
\hline & 3 men \\
\hline & B: TYP $n=1$ \\
\hline & Mean age $62(9.98)$ \\
\hline & 1 woman \\
\hline
\end{tabular}

Interventions

Both groups completed 6 tasks; 2 self-selected preferred, 2 self-selected not-preferred, 2 researcher allocated

Participants completed 1 condition for 2 weeks, and then alternated to the other condition. This repeated 2 additional times $(2 \times 2$ week on TAP, $2 \times 2$ week on TAP)

A: TAP

Television assisted prompting (set top box) that provided reminders at prespecified times for activities personalised to each participant. No prompting by carers/family. Prompts varied in frequency but displayed until participant acknowledged or up to 1 hour

B: TYP

Participants carried out tasks using typical memory methods/strategies. Provided with a list of prospective memory tasks. Carers/family encouraged to remind/motivate 
Lemoncello 2011 (Continued)

Additional outcomes assessed: task completion rates (tracking logs and journal entries) and satisfaction with intervention (qualitative interview)

\section{Notes}

Inclusion criteria: documented diagnosis of $\mathrm{ABI}>12$ months prior, 18+ years old, reported cognitive challenges limiting completion of home tasks (by patients, carer or therapist), functional vision and hearing to access information on a television

Attention (PASAT), Memory (CVLT-2, EMQ) and Executive Functions (BADS) measures were only taken at baseline

Statistical tests used: Hierarchical Linear Model (mixed model)

\section{Risk of bias}

\begin{tabular}{lll}
\hline Bias & Authors' judgement & Support for judgement \\
\hline $\begin{array}{l}\text { Random sequence genera- } \\
\text { tion (selection bias) }\end{array}$ & Low risk & "Participants were randomly assigned to group by the flip of a coin" \\
\hline $\begin{array}{l}\text { Allocation concealment } \\
\text { (selection bias) }\end{array}$ & Unclear risk & Does not state who completed randomisation \\
\hline $\begin{array}{l}\text { Blinding of participants } \\
\begin{array}{l}\text { and personnel (perfor- } \\
\text { mance bias) }\end{array}\end{array}$ & High risk & Participants and therapists aware of group allocation \\
All outcomes & \\
\hline
\end{tabular}

\section{Blinding of outcome as- High risk} sessment (detection bias) All outcomes
Not blinded - researchers also advised of condition switches. "made every effort not to influence participants' report of task completion"

\begin{tabular}{|c|c|c|}
\hline $\begin{array}{l}\text { Incomplete outcome data } \\
\text { (attrition bias) }\end{array}$ & Low risk & $\begin{array}{l}\text { Reasons for loss to follow-up explained for whole (ABI) group, but no details } \\
\text { for those with stroke }\end{array}$ \\
\hline
\end{tabular}

\begin{tabular}{|c|c|c|}
\hline $\begin{array}{l}\text { Selective reporting (re- } \\
\text { porting bias) }\end{array}$ & Unclear risk & Gives all outcome measures described in procedure. No published protocol \\
\hline Other bias & Low risk & \\
\hline
\end{tabular}

Lin 2014

$\begin{array}{ll}\text { Methods } & \text { RCT between July } 2011 \text { and November } 2012 \\ & \text { Single site } \\ & \text { Participants assigned at random to an intervention group (I) or control group (C) } \\ \text { Outcomes assessed at } 2 \text { time points: T0 baseline (at randomisation) and T1 } 10 \text { weeks post-randomisa- } \\ \text { tion (post-intervention) }\end{array}$


Lin 2014 (Continued)

$$
\begin{aligned}
& \text { At randomisation }(n=34) \text { : } \\
& \text { I: } n=16
\end{aligned}
$$

Mean age: 62.4 (6.0), 6/10 (female/male)

Mean time (months) since onset: 7.48 (0.79)

$6 \mathrm{LH}, 10 \mathrm{RH}$

$\mathrm{C}: \mathrm{n}=18$

Mean age: 63.2 (5.7), 8/10 (female/male)

Mean time (months) since onset: 7.50 (0.61)

$9 \mathrm{LH}, 9 \mathrm{RH}$

Interventions

I: 60 hours of training ( 6 x 1-hour sessions per week for 10 weeks). Computer-assisted executive function and memory training using RehaCom. Training performed by 2 trained psychologists

C: received no cognitive training (TAU)

\begin{tabular}{ll}
\hline Outcomes & Objective memory measure: WMS (Memory Quotient total score) \\
& $\begin{array}{l}\text { Additional outcomes assessed: WMS subtest scores (information, orientation, mental control, logical } \\
\text { memory, digits forwards/backwards, visual reproduction, associated learning), TMT-A and TMT-B, fMRI } \\
\text { data (functional connectivity) }\end{array}$
\end{tabular}

Notes

Inclusion criteria: confirmed diagnosis of first stroke, deficits in memory and executive function $(\mathrm{z} \leq 1.5$ in WMS Memory Quotient and Trail Making Test), right handed, education $\geq 8$ years, 6 to 10 months (180 to 300 days) post-stroke, 45 to 70 years, normal hearing and vision

Exclusion criteria: mental retardation, history of Alzheimer's or mental illness (e.g. schizophrenia) prior to stroke, vital organ failure, concomitant antidepressant, psychoactive drug or steroid therapy During fMRI scans participants were excluded if they moved their head $>1.5 \mathrm{~mm}$ in any direction or with $>1.5$ ' rotation

Study focused on fMRI data

Adequate matching at baseline, with no significant differences between clinical and demographic characteristics or baseline neuropsychological test data

Statistical tests used: paired t-tests and $\mathrm{Chi}^{2}$ tests

\section{Risk of bias}

\begin{tabular}{lll}
\hline Bias & Authors' judgement & Support for judgement \\
\hline $\begin{array}{l}\text { Random sequence genera- } \\
\text { tion (selection bias) }\end{array}$ & Low risk & "Random number table" \\
\hline $\begin{array}{l}\text { Allocation concealment } \\
\text { (selection bias) }\end{array}$ & Unclear risk & $\begin{array}{l}\text { Random number table not described to have been concealed from study per- } \\
\text { sonnel }\end{array}$ \\
\hline $\begin{array}{l}\text { Blinding of participants } \\
\text { and personnel (perfor- } \\
\text { mance bias) }\end{array}$ & High risk & Participants or personnel knew allocation \\
All outcomes & & \\
\hline
\end{tabular}

$\begin{array}{ll}\begin{array}{l}\text { Blinding of outcome as- } \\ \text { sessment (detection bias) }\end{array} \quad \text { Low risk } & \begin{array}{l}\text { "Assessments were performed by two trained psychologists who were blinded } \\ \text { to group assignment" }\end{array}\end{array}$


Lin 2014 (Continued)

All outcomes

$\begin{array}{ll}\begin{array}{l}\text { Incomplete outcome data } \\ \text { (attrition bias) }\end{array} & \text { Low risk }\end{array}$

All outcomes

domised

\begin{tabular}{lll}
\hline $\begin{array}{l}\text { Selective reporting (re- } \\
\text { porting bias) }\end{array}$ & Unclear risk & $\begin{array}{l}\text { No indication of selective reporting, but no published protocol to determine } \\
\text { this }\end{array}$ \\
\hline Other bias & Low risk & \\
\hline
\end{tabular}

\section{Prokopenko 2013}

\begin{tabular}{|c|c|}
\hline \multirow[t]{4}{*}{ Methods } & $\mathrm{RCT}$ \\
\hline & Single site \\
\hline & $\begin{array}{l}\text { Participants assigned at random via "method of letters" (sealed envelopes) to either an intervention } \\
\text { group (I) or a TAU control group (C) }\end{array}$ \\
\hline & $\begin{array}{l}\text { Outcomes assessed at } 2 \text { time points: T0 baseline (pre-training on day of inclusion) and T1 } 14 \text { to } 16 \text { days } \\
\text { after T0 (post training) }\end{array}$ \\
\hline \multirow[t]{10}{*}{ Participants } & Russia \\
\hline & In-patient rehabilitation centre \\
\hline & Method of diagnosing memory impairment not stated \\
\hline & Stroke diagnosed with NIHSS and routine MRI \\
\hline & Recruited 2 weeks post-stroke \\
\hline & At randomisation $(n=43)$ \\
\hline & $\mathrm{I}: \mathrm{n}=24$ \\
\hline & Median age: 61 (57;69), 11/13 (female/male) \\
\hline & $C: n=19$ \\
\hline & Median age: 66 (61;69), 9/10 (female/male) \\
\hline \multirow[t]{2}{*}{ Interventions } & $\begin{array}{l}\text { I: up to } 15 \text { hours total ( } 25 \text { to } 30 \text { minutes/day for } 2 \text { weeks) use of computer programs. (1) Training of at- } \\
\text { tention using computerised Schulte's tables - provision of on screen feedback (performance speed). } \\
\text { (2) Training of visual and spatial gnosis with computer-based "figure-background test" - feedback and } \\
\text { gradual decreasing intensity of background noise. (3) Training of visual and spatial memory - remem- } \\
\text { bering the positioning of images with gradually increasing number of distractors. (4) Also "remember- } \\
\text { ing a sequence of symbols", "arranging the clock hands" and "the serial count" }\end{array}$ \\
\hline & C: received only standard treatment at the rehabilitation centre (TAU) \\
\hline
\end{tabular}

\section{Outcomes}

\section{Objective memory measure: MoCA}

Functional ability measure: IADL scale

Mood measure: HADS

Quality of life measure: SS-QoL 
Additional outcomes assessed: dementia severity (MMSE), cognitive disorders (FAB), executive functions (Clock drawing test), attention deficit (Schulte's tables), satisfaction with the results of treatment (CGIS and PGIS scales)

Notes

Inclusion criteria: cognitive impairments (ranging from mild cognitive impairments to mild dementia) after a hemisphere stroke, no significant speech pathology, no epilepsy, in the acute and early restorative period of stroke

Exclusion criteria: did not give informed consent, experienced severe cognitive deficits (MMSE < 20), medically unstable, not fluent in Russian, had another condition that could impact results (e.g. aphasia)

Adequate baseline matching of groups, no significant differences on demographic characteristics or neuropsychological tests (based on median data)

Statistical tests used: Mann-Whitney $\mathrm{U}$ test for between group differences, Wilcoxon Matched Pairs test for within subject differences

The study is not included in quantitative analysis as only median results were available, despite contacting authors for mean and SD data

\section{Risk of bias}

Bias Authors' judgement Support for judgement

Random sequence genera- Low risk tion (selection bias)

"Method of letters" (sealed envelopes), "Patients, who were suitable for inclusion criteria, asked to choose one of two identical envelopes, each of envelopes contained a note with number of group inside."

Method of generating random sequence not specified

\begin{tabular}{lll}
\hline $\begin{array}{l}\text { Allocation concealment } \\
\text { (selection bias) }\end{array}$ & Unclear risk & $\begin{array}{l}\text { "Patients, [...], asked to choose one of two identical envelopes" } \\
\text { However, not clear how this resulted in unequal group sizes }\end{array}$ \\
\hline $\begin{array}{l}\text { Blinding of participants } \\
\text { and personnel (perfor- } \\
\text { mance bias) }\end{array}$ & High risk & $\begin{array}{l}\text { Both participants and intervention provider knew which group they were allo- } \\
\text { cated to - effects of this on outcomes unclear }\end{array}$ \\
All outcomes &
\end{tabular}

\begin{tabular}{|c|c|c|}
\hline $\begin{array}{l}\text { Blinding of outcome as- } \\
\text { sessment (detection bias) } \\
\text { All outcomes }\end{array}$ & Low risk & $\begin{array}{l}\text { "Assessments were repeated [...] by a trained assessor blind to randomisa- } \\
\text { tion" }\end{array}$ \\
\hline $\begin{array}{l}\text { Incomplete outcome data } \\
\text { (attrition bias) } \\
\text { All outcomes }\end{array}$ & Low risk & No attrition \\
\hline $\begin{array}{l}\text { Selective reporting (re- } \\
\text { porting bias) }\end{array}$ & Unclear risk & $\begin{array}{l}\text { Data presented in medians and confidence intervals } \\
\text { Measures are given in results but not described (SS-QoL) }\end{array}$ \\
\hline Other bias & Low risk & \\
\hline
\end{tabular}

Radford 2012

$\begin{array}{ll}\text { Methods } & \text { RCT } \\ & \text { Single site }\end{array}$


Participants assigned using a computerised procedure ("Minim") stratified by sex, age, estimated fullscale IQ, aetiology, baseline memory (RAVLT Delayed Recall score)

Wait-list cross-over trial with participants allocated to an early training group (I) or a late training group (C)

Outcomes assessed at 3 time points: T0 baseline, post-randomisation, T1 1 month post early training group's final session (12 weeks after T0) and T2 1 month post late training group's final session (24 weeks after T0)

T1 data used only

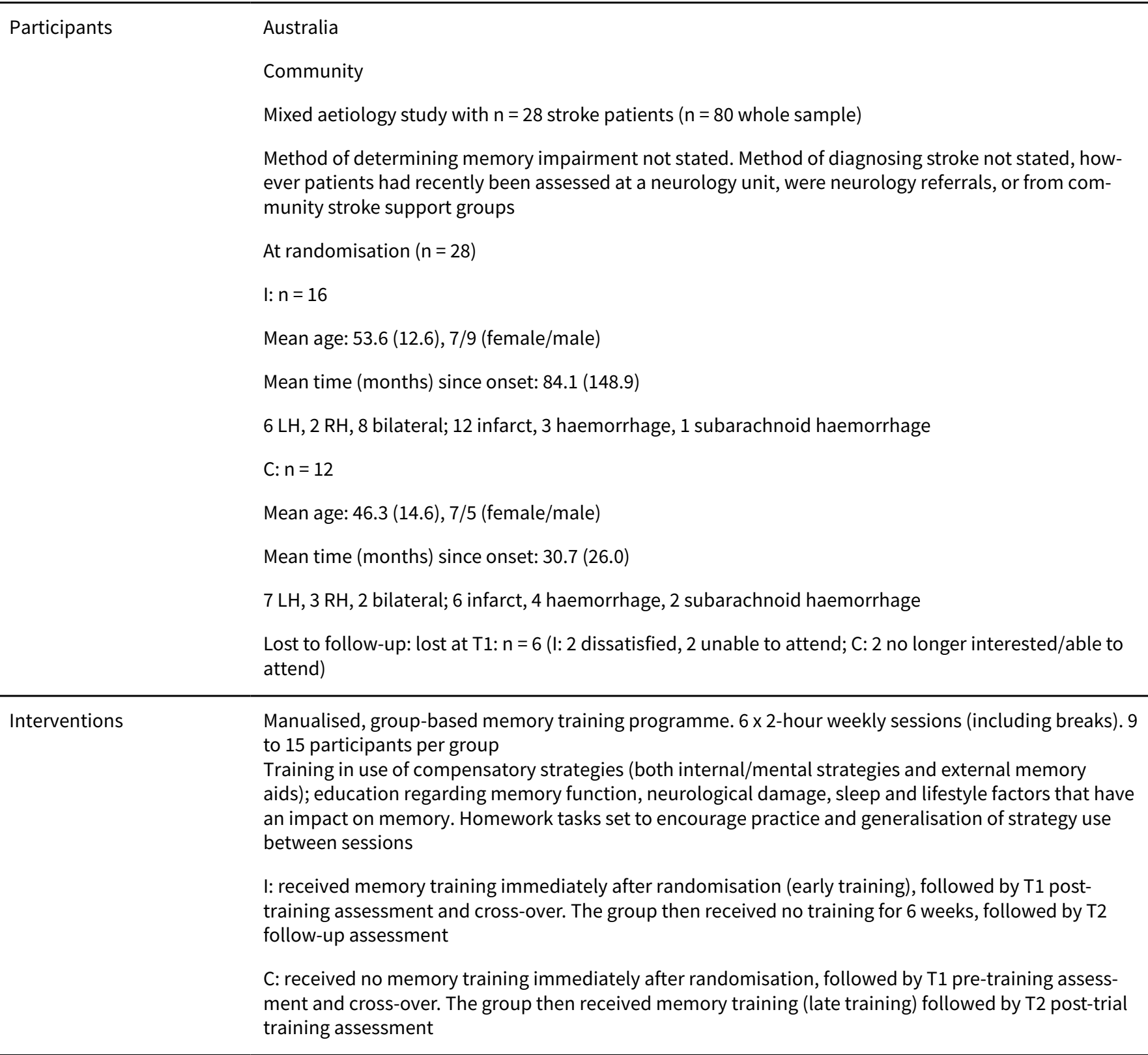

Outcomes

Subjective memory measure: Comprehensive Assessment of Prospective Memory (CAPM-Self)

Objective memory measure: RAVLT Delayed Recall

Additional outcomes assessed: CAPM-Other (report of a relative or friend), estimate of self-awareness of memory function (absolute discrepancy between scores from the CAPM-self and CAPM-other), RAVLT 
Total Learning score, prospective memory function (Royal Prince Alfred Prospective Memory Test; RPAProMem), self-reported memory strategy use (number and type of strategies used)

Notes

Only pre-cross-over data included in this analysis (T1)

Inclusion criteria: memory complaints, English as language of choice, proximity to the hospital, age between 18 and 70 , estimated Full Scale IQ $\geq 80$

Exclusion criteria: history of psychiatric (other than a mood) disorder, progressive lesions

Compliance: participants had to attend at least 4 of 6 training sessions to be retained in the study

Mood was measured at baseline only on the Depression Anxiety Stress Scale (DASS-21) - short form

Adequacy of matching at baseline unclear as stroke sub-sample data at baseline are not presented.

Likely to be well matched due to stratification of randomisation procedure

Statistical tests used: one-way ANOVA and $\mathrm{Chi}^{2}$ tests on baseline data, repeated measures $(3 \times 2)$ ANO-

VA, reliable change indices, Wilcoxon signed-rank tests for pre-post training changes

\section{Risk of bias}

\begin{tabular}{lll}
\hline Bias & Authors' judgement & Support for judgement \\
\hline $\begin{array}{l}\text { Random sequence genera- } \\
\text { tion (selection bias) }\end{array}$ & Low risk & $\begin{array}{l}\text { Stratified randomisation procedure using software program which allowed } \\
\text { predetermined variables relevant for group matching to be entered into a } \\
\text { database for each participant. Allocations generated by factoring in previous } \\
\text { allocations and balancing predetermined variables across groups }\end{array}$ \\
\hline
\end{tabular}

Allocation concealment Low risk Centralised randomisation using a computerised system

(selection bias)

Blinding of participants High risk $\quad$ Therapists and participants aware of group allocation
and personnel (perfor-
mance bias)

\begin{tabular}{|c|c|c|}
\hline $\begin{array}{l}\text { Blinding of outcome as- } \\
\text { sessment (detection bias) } \\
\text { All outcomes }\end{array}$ & High risk & $\begin{array}{l}\text { Lack of blinding to treatment allocation for assessment. Same clinicians were } \\
\text { involved in conduct of training groups and outcome assessment }\end{array}$ \\
\hline $\begin{array}{l}\text { Incomplete outcome data } \\
\text { (attrition bias) } \\
\text { All outcomes }\end{array}$ & Low risk & $\begin{array}{l}\text { Reasons for attrition in stroke group not specified in published data, but au- } \\
\text { thors did provide additional information }\end{array}$ \\
\hline $\begin{array}{l}\text { Selective reporting (re- } \\
\text { porting bias) }\end{array}$ & Unclear risk & No published protocol available to enable a judgement \\
\hline Other bias & Low risk & \\
\hline
\end{tabular}

Westerberg 2007

$\begin{array}{ll}\text { Methods } & \text { RCT (pilot study) } \\ \text { Single site } & \\ \text { Participants assigned to conditions using sealed, pre-addressed envelopes (prepared by persons unre- } \\ \text { lated to study) opened after the initial assessment }\end{array}$


Westerberg 2007 (Continued)

Allocation to either a treatment group (I) or a passive control group (C)

Outcomes assessed at 2 points: T0 pre-treatment (baseline) and T1 after 5 weeks post-baseline

\begin{tabular}{|c|c|}
\hline \multirow[t]{14}{*}{ Participants } & Sweden \\
\hline & Community \\
\hline & Method of diagnosing memory difficulties not stated \\
\hline & Stroke diagnosed through PET, MRI or CT scan \\
\hline & At randomisation $n=21$, at $T 1 n=19$ : \\
\hline & $\mathrm{I}: \mathrm{n}=9$ \\
\hline & Mean age: 55 (8), 1/8 (female/male) \\
\hline & Mean time (months) since onset: 19.3 (6.2) \\
\hline & $4 \mathrm{LH}, 2 \mathrm{RH}, 8$ bilateral; 6 haemorrhages, 3 infarctions \\
\hline & C: $n=9$ \\
\hline & Mean age: 53.6 (8), $5 / 4$ (female/male) \\
\hline & Mean time (months) since onset: 20.8 (6.2) \\
\hline & $3 \mathrm{LH}, 4 \mathrm{RH} ; 2$ haemorrhages, 7 infarctions \\
\hline & $\begin{array}{l}\text { Lost to follow-up: } \mathrm{n}=3 \text { (l: } 1 \text { computer problems, } 1 \text { depression and changed medication; C: } 1 \text { epilepsy } \\
\text { debut) }\end{array}$ \\
\hline \multirow[t]{2}{*}{ Interventions } & $\begin{array}{l}\text { I: computerized training on battery of visuospatial and auditory WM tasks } 90 \text { trials ( } 40 \text { minutes) x } 5 \text { days } \\
\text { per week for } 5 \text { weeks. Participants given a CD with training software (RoboMemo, Cogmed Cognitive } \\
\text { Medical Systems, Sweden) and asked to complete } 5 \text { weeks of WM training at home on a PC. All training } \\
\text { tasks involved: (1) maintenance of multiple stimuli at same time; (2) short delays during which the rep- } \\
\text { resentation of stimuli should be held in WM; (3) unique sequencing of stimuli order in each trail; (4) the } \\
\text { difficulty level adapting as a function of individual performance } \\
\text { Participants reported daily results via the Internet to a server at the hospital }\end{array}$ \\
\hline & C: no training provided. Did not receive telephone calls during the 5 weeks between test and retest \\
\hline
\end{tabular}

Outcomes Subjective memory measure: Cognitive Failures Questionnaire (CFQ) - modified

Objective memory measure: Claeson-Dahl word list - delayed recall

Additional outcomes assessed: neuropsychological test battery including digit span (WAIS-R; auditory WM), span board (WAIS-R NI; visuospatial WM), PASAT version A (WM and attention control), Ruff 2 and7 - serial cancellation test (WM and attention control), Claeson-Dahl word list recall test (learning and declarative memory), Stroop test (interference control), Raven's progressive matrices - modified (non-verbal reasoning and problem-solving ability)

Notes Inclusion criteria: suffering stroke between 12 and 36 months ago, stroke documented by PET, MR or CT, ages 30 to 65 , having daily access to a PC with Internet connection at home, self-reported deficits in attention

Exclusion criteria: IQ < 70 (based on age-normalised results from WAIS-R), motor or perceptual handicap that would prevent use of computer program, changing medication during study period, fulfilling criteria for major depressive disorder diagnosis (DSM-IV), known history of abuse of alcohol or illicit drugs

Compliance: criterion for sufficient compliance was defined before the study as more than 20 days of training $(\mathrm{m}=23$ training days (SD 2.2)) 
Westerberg 2007 (Continued)

Adequate matching at baseline as there does not appear to be any significant differences between groups. Only a slight greater proportion of men in control group (but small sample size so difficult to determine if this may have had an effect)

Statistical tests used: ANCOVA with baseline score as a covariate and effect sizes

\section{Risk of bias}

\begin{tabular}{|c|c|c|}
\hline Bias & Authors' judgement & Support for judgement \\
\hline $\begin{array}{l}\text { Random sequence genera- } \\
\text { tion (selection bias) }\end{array}$ & Low risk & $\begin{array}{l}\text { Use of sealed, pre-addressed envelopes, however method regarding prepara- } \\
\text { tion sealed envelopes was not specified }\end{array}$ \\
\hline $\begin{array}{l}\text { Allocation concealment } \\
\text { (selection bias) }\end{array}$ & Low risk & $\begin{array}{l}\text { Allocation was not known by intervention provider until envelopes were } \\
\text { opened (after baseline assessment) }\end{array}$ \\
\hline $\begin{array}{l}\text { Blinding of participants } \\
\text { and personnel (perfor- } \\
\text { mance bias) } \\
\text { All outcomes }\end{array}$ & High risk & Participants and therapists aware of allocation \\
\hline $\begin{array}{l}\text { Blinding of outcome as- } \\
\text { sessment (detection bias) } \\
\text { All outcomes }\end{array}$ & High risk & Post-randomisation, test administrators were no longer blind to allocation \\
\hline $\begin{array}{l}\text { Incomplete outcome data } \\
\text { (attrition bias) } \\
\text { All outcomes }\end{array}$ & Low risk & 3 lost to follow-up \\
\hline $\begin{array}{l}\text { Selective reporting (re- } \\
\text { porting bias) }\end{array}$ & Unclear risk & No published protocol available to enable a judgement \\
\hline Other bias & Low risk & \\
\hline
\end{tabular}

\section{Zucchella 2014}

\begin{tabular}{|c|c|}
\hline \multirow[t]{4}{*}{ Methods } & RCT between 1 June 2010 and 31 December 2012 \\
\hline & Single site \\
\hline & Participants assigned to either an intervention group (I) or an attention control group (C) \\
\hline & $\begin{array}{l}\text { Outcomes assessed at } 2 \text { time points: T0 baseline, within } 2 \text { weeks of admission to a neurorehabilitation } \\
\text { unit, and T1 at } 4 \text { weeks, directly after intervention }\end{array}$ \\
\hline \multirow[t]{7}{*}{ Participants } & Italy \\
\hline & In-patient rehabilitation unit \\
\hline & $\begin{array}{l}\text { Method of diagnosing memory problems from scores below population norms on } 3+\text { neuropsychologi- } \\
\text { cal tests }\end{array}$ \\
\hline & Stroke diagnosis confirmed through neuroimaging (CT or MRI) \\
\hline & Mean time (months) since onset for all participants was less than 4 weeks \\
\hline & At randomisation $n=92$, demographic details provided at $T 1 n=87$ : \\
\hline & $\mathrm{I}: \mathrm{n}=42$ \\
\hline
\end{tabular}


$12 \mathrm{LH}, 18 \mathrm{RH}, 1$ bilateral; 8 brain stem, 3 cerebellum, 31 ischaemic, 11 haemorrhagic

C: $n=45$

Mean age: 69.4 (11), 22/23 (female/male)

14 LH, 27 RH, 1 bilateral; 3 brain stem, 34 ischaemic, 11 haemorrhagic

Lost to follow-up: $\mathrm{n}=5$ (I: 3 (1 poor compliance, 2 worsening of clinical condition); C. 2 (poor clinical condition so no T1 follow-up))

Interventions

I: 16 hours ( 1 hour $x$ 4/week for 4 weeks). 45 minutes therapist-guided computer exercises using 2 software programs ("una palestra per la menta", "Training di riabilitazione cognitiva") on time orientation, spatial orientation, visual attention, logical reasoning, memory, executive function. Exercises increased in difficulty when $70 \%$ correct. Given metacognitive strategies to improve awareness and self-regulation. 15 minutes to discuss problems, how to transfer strategies to everyday, and imagination to improve memory

C: 16 hours with a psychologist discussing general topics, news and their recent activities

Outcomes
Functional ability measure: Functional Independence Measure
Additional outcomes assessed: MMSE, digit span, Corsi's test, RAVLT immediate recall, logical memory
(WMS), Progressive Matrices 47 (PM47), Frontal Assessment Battery (FAB), TMT-A/B, Attentive matrices,
phonological and semantic fluency, Rey-Osterrieth Complex Figure copy

Notes Inclusion criteria: first ever ischaemic/haemorrhagic stroke (confirmed by neuroimaging), acute event within 4 weeks, 45 to 80 years, MMSE $>10$, below population norm on $3+$ neuropsychological tests

Exclusion criteria: progressing stroke, neglect, aphasia, additional neurological/psychological disorder, HDRS score $>7$, premorbid IQ $<70$ /pre-existing dementia, visual deficits, motor impairment

Groups were adequately matched at baseline: no significant differences on socio-demographic, clinical, and functional aspects, or on neuropsychological tests

Statistical tests used: all data were presented as medians and upper/lower quartiles, and data were not normally distributed. Mann-Whitney $\mathrm{U}$ test and the $\mathrm{Chi}^{2}$ test for demographic and baseline data. Wilcoxon signed-rank tests for within group analysis. Mann-Whitney $U$ tests for between-group outcome analysis

Authors were contacted for means and SDs of measures

\section{Risk of bias}

\begin{tabular}{lll}
\hline Bias & Authors' judgement & Support for judgement \\
\hline $\begin{array}{l}\text { Random sequence genera- } \\
\text { tion (selection bias) }\end{array}$ & Low risk & "Randomly assigned [...] by means of a computer random number generator" \\
\hline $\begin{array}{l}\text { Allocation concealment } \\
\text { (selection bias) }\end{array}$ & Unclear risk & Not described \\
\hline $\begin{array}{l}\text { Blinding of participants } \\
\begin{array}{l}\text { and personnel (perfor- } \\
\text { mance bias) }\end{array}\end{array}$ & High risk & Participants and therapist aware of group allocation \\
\begin{tabular}{l} 
All outcomes \\
\hline
\end{tabular} & \\
\hline
\end{tabular}


Zucchella 2014 (Continued)

Blinding of outcome as- Low risk_ "Assessments done by a psychologist blind to the patients' randomisation and sessment (detection bias) not involved in their care"

All outcomes

\begin{tabular}{|c|c|c|}
\hline $\begin{array}{l}\text { Incomplete outcome data } \\
\text { (attrition bias) }\end{array}$ & Low risk & $\begin{array}{l}\text { Similar numbers of attrition for both arms with similar reasons "worsening of } \\
\text { clinical condition" }\end{array}$ \\
\hline
\end{tabular}

All outcomes clinical condition"

Selective reporting (re- Unclear risk $\quad$ No published protocol
porting bias)

Other bias Low risk

ABI: acquired brain injury; (R)AVLT: Rey Auditory Verbal Learning Test; C: control; CBT: cognitive behavioural therapy; CES-D: Center for Epidemiological Studies Depression Scale; CGIS: Clinical Global Impressions - Severity; CT: computerised tomography; DSM-IV: Diagnostic and Statistical Manual of Mental Disorders, 4th Edition; EMQ: Everyday Memory Questionnaire; EQ-5D: EuroQol five dimensions; fMRI: functional magnetic resonance imaging; GP: general practitioner; HADS: Hospital Anxiety and Depression Scale; HDRS: Hamilton Depression Rating Scale; I: intervention; IADL: Instrumental Activities of Daily Living; ITT: intention-to-treat; LH: left hemisphere; LOCF: last observation carried forward; MMSE: Mini-Mental State Examination; MSE: Memory Self Efficacy; MoCa: Montreal Cognitive Assessment; MRI: magnetic resonance imaging; MS: multiple sclerosis; NIHSS: National Institute of Health Stroke Scale; PASAT: Paced Auditory Serial Addition Test; PDA: personal digital assistant; PET: positron emission tomography; PGIS: Patient Global Impressions - Severity; RBMT: Rivermead Behavioural Memory Test; RCT: randomised controlled trial; RH: right hemisphere; SD: standard deviation; SS-QoL: Stroke Specific Quality of Life Scale; TAU: treatment as usual; TMT: Trail Making Test; VAS: visual analogue scale; WAIS: Wechsler Adult Intelligence Scale; WM: working memory; WMS: Wechsler Memory Scale

\section{Characteristics of excluded studies [ordered by study ID]}

\begin{tabular}{|c|c|}
\hline Study & Reason for exclusion \\
\hline Barker-Collo 2009 & Not memory - rehabilitation focused on attention difficulties \\
\hline Blanchet 2016 & Not memory - rehabilitation focused on aerobic exercises and attention training \\
\hline Brainin 2015 & $\begin{array}{l}\text { Not cognitive rehabilitation - intervention specifies "Intensive control and motivation for better } \\
\text { compliance with medication, regular blood pressure measurements, diet changes and physical ac- } \\
\text { tivity", no cognitive component to intervention }\end{array}$ \\
\hline Bushnick 2010 & Not memory - rehabilitation focused on executive functioning \\
\hline Chen 2011 & Not memory - rehabilitation focused on attention and executive control \\
\hline Chen 2015 & Not memory - rehabilitation focused on attention \\
\hline de Joode 2013 & $\begin{array}{l}\text { Not stroke - mixed aetiology study with no separate data available for those with stroke. Could not } \\
\text { obtain separate stroke data - none provided in published study or via authors }\end{array}$ \\
\hline de Luca 2014 & $\begin{array}{l}\text { Not stroke - mixed aetiology study and could not obtain separate stroke data - none provided in } \\
\text { published study or via authors }\end{array}$ \\
\hline Evans 2000 & Not cognitive rehabilitation (2007 review) \\
\hline Fish 2008 & Not RCT - study used same randomisation procedure as Wilson 2001 \\
\hline Fong 2009 & Not RCT - matched pairs design, not randomly allocated \\
\hline
\end{tabular}




\begin{tabular}{|c|c|}
\hline Study & Reason for exclusion \\
\hline Gamito 2014 & $\begin{array}{l}\text { Not cognitive rehabilitation - both intervention groups received the same rehabilitation through } \\
\text { different method (either on screen or through a headset) }\end{array}$ \\
\hline Gasparrini 1979 & $\begin{array}{l}\text { Not RCT ( } 2007 \text { review) - alternate allocation, not random, poor concealment, allocation, treatment, } \\
\text { and outcomes all completed by same person }\end{array}$ \\
\hline Hildebrandt 2006 & Not RCT - no indication of method of randomisation, allocated according to age and scores on tests \\
\hline Imes 1984 & Review paper (2007 review) \\
\hline Klonoff 2007 & Not RCT - no allocation to groups \\
\hline Liu 2009 & Not memory - focus on mental imagery for motor function \\
\hline Lundqvist 2010 & $\begin{array}{l}\text { Not stroke - mixed aetiology group and could not obtain separate stroke data - none provided in } \\
\text { published study or via authors }\end{array}$ \\
\hline Man 2006 & Not memory - skill training focused on problem solving \\
\hline Markle-Reid 2011 & $\begin{array}{l}\text { Not cognitive rehabilitation - the "specialised, evidence-based rehabilitation strategy" did not in- } \\
\text { volve cognitive rehabilitation }\end{array}$ \\
\hline McDonald 2011 & $\begin{array}{l}\text { Not stroke - mixed aetiology study and could not obtain separate stroke data - none provided in } \\
\text { published study or via authors }\end{array}$ \\
\hline McEwan 2014 & Not memory - CO-OP training does not cover aspects of memory \\
\hline McEwen 2015 & Not memory - study used same CO-OP training as previous excluded McEwan 2014 study \\
\hline Miller 2014 & $\begin{array}{l}\text { Not RCT - pseudo-random allocation with final } 16 \text { enrolled participants allocated on demographic } \\
\text { variables }\end{array}$ \\
\hline Ownsworth 1999 & Not stroke - mixed aetiology study and data not available for the 1 stroke patient \\
\hline Polatajko 2012 & Not memory - study used CO-OP training \\
\hline Rasmussen 2016 & $\begin{array}{l}\text { Not cognitive rehabilitation - home-based rehabilitation did not involve any cognitive rehabilita- } \\
\text { tion }\end{array}$ \\
\hline Schupp 2002 & $\begin{array}{l}\text { Not memory - rehabilitation focused on attention. Only able to find study poster in conference pro- } \\
\text { ceedings }\end{array}$ \\
\hline Skidmore 2015 & Not memory - intervention targets executive functioning \\
\hline Sohlberg 2007 & Not RCT - no randomisation, all participants received the same intervention \\
\hline Tailby 2003 & $\begin{array}{l}\text { Not RCT - no randomisation. "Participants were divided into three groups, with eight in each, on } \\
\text { the basis of their performance on the Verbal Memory Index (VMI) on the Wechsler Memory Scale-III" }\end{array}$ \\
\hline Thickpenny-Davis 2007 & Not RCT - non-random allocation, every second participant allocated to wait-list control \\
\hline Thoene 1995 & Not stroke - no stroke participants in brain injury sample \\
\hline Wilson 2001 & Not RCT (2007 review) - alternate allocation of blocks to treatment or waiting list \\
\hline
\end{tabular}




\begin{tabular}{ll}
\hline Study & Reason for exclusion \\
\hline Wolf 2015 & Not memory - study used CO-OP training \\
\hline Yu 2009 & Not cognitive rehabilitation - community-based rehabilitation \\
\hline
\end{tabular}

CO-OP: Cognitive Orientation to daily Occupational Performance; RCT: randomised controlled trial

Characteristics of studies awaiting assessment [ordered by study ID]

Bezdenezhnykh 2014

RCT
Single site
Participants assigned to either an intervention (I) or TAU control group (C)
Outcomes assessed at 3 time points: T0 baseline (10 to 12 days post-stroke), T1 post-intervention
(18 to 20 days after randomisation) and T2 6 to 8 months post-intervention

\begin{tabular}{ll}
\hline Participants & Age range: 45 to 65 years \\
\hline Interventions & $\begin{array}{l}\text { I: TAU plus } 10 \text { to } 14 \text { daily training sessions with neuropsychological computer program for } 40 \text { min- } \\
\text { utes per day for } 2 \text { weeks }\end{array}$ \\
C: TAU with no special cognitive correction
\end{tabular}

\begin{tabular}{ll}
\hline Outcomes & Objective memory measure: FAB \\
& $\begin{array}{l}\text { Additional outcomes assessed: MMSE, CDT, speech tests (cognitive, neurological, affective, and } \\
\text { functional states assessed) }\end{array}$ \\
\hline Notes & $\begin{array}{l}\text { Authors have not yet been contacted to obtain published results outside of this conference ab- } \\
\text { stract }\end{array}$ \\
\hline
\end{tabular}

$\begin{array}{ll}\text { Methods } & \text { RCT } \\ & \text { Single site } \\ & \text { Participants were allocated to } 1 \text { of } 3 \text { groups: an intervention (I), an active control (C1), or a TAU con- } \\ \text { trol (C2) } & \text { Outcomes assessed at } 2 \text { time points: T0 baseline (before training) and T1 post training }\end{array}$

\section{Participants}

55 participants with post-stroke (acute) vascular cognitive impairments

Age range: 37 to 67 years

Interventions

I: 10 daily (40 minute) sessions with neuropsychological computer programs

$\mathrm{C} 1$ : entertaining games keeping the identical regimen

C2: TAU 
Bezdenezhnykh 2015 (Continued)

$\begin{array}{ll}\text { Outcomes } & \text { Objective memory measure: FAB } \\ & \text { Functional ability measure: IADL } \\ & \text { Additional outcomes assessed: MMSE, MoCA, CDT, Shulte's test }\end{array}$

Notes

Authors have not yet been contacted to obtain published results outside of this conference abstract

Matz 2007

\begin{tabular}{ll}
\hline Methods & RCT \\
& Single site \\
& Participants assigned to either treatment group (I) or treatment as usual control group (C) \\
& Outcomes assessed at 2 time points: T0 baseline and T1 after 3 months of rehabilitation \\
\hline Participants & 32 participants with lacunar stroke \\
\hline Interventions & I: regular cognitive training sessions for 3 months guided by neuropsychologist \\
& C: standard care without cognitive training \\
\hline Outcomes & Objective memory measure: memory test from neuropsychological test battery \\
Other outcomes assessed: neuropsychological test battery (speed of cognitive processing, execu- \\
tive functions, attention, visuo-spatial function), lipid values (total cholesterol, HDL-cholesterol, \\
LDL-cholesterol, triglycerides), 24-hour blood pressure recording, brain imaging with MRT
\end{tabular}

Notes Authors have not yet been contacted to obtain published results outside of this conference ab-
stract

\section{Prokopenko 2011}

\begin{tabular}{ll} 
Methods & $\begin{array}{l}\text { Single site } \\
\text { Participants allocated to either an intervention group (I) or a TAU control group (C) }\end{array}$ \\
\hline Participants & 100 post-stroke (acute) participants with mild cognitive impairment to mild dementia \\
\hline Interventions & I: TAU with computer programs 20 to 30 minutes per day 5 x per week over 14 days \\
C: TAU
\end{tabular}

Outcomes Objective memory measures: FAB

Additional outcomes assessed: MMSE, CDT, Shulte's tables, and a letter correction test

Notes $\begin{aligned} & \text { Authors have not yet been contacted to obtain published results outside of this conference ab- } \\ & \text { stract }\end{aligned}$
Not stated whether allocation was randomised


CDT: Clock Drawing Test; FAB: Frontal Assessment Battery; HDL: high-density lipoprotein; IADL: Instrumental Activities of Daily Living; LDL: low-density lipoprotein; MMSE: Mini-Mental State Examination; MoCA: Montreal Cognitive Assessment; MRT: magnetic resonance tomography; RCT: randomised controlled trial; TAU: treatment as usual

Characteristics of ongoing studies [ordered by study ID]

\section{ISRCTN45171788}

\begin{tabular}{ll}
\hline Trial name or title & $\begin{array}{l}\text { Neuropsychological rehabilitation: modular cognitive retraining versus compensatory skills train- } \\
\text { ing }\end{array}$ \\
\hline Methods & RCT \\
\hline Participants & Severe head trauma and stroke patients at a neuropsychological inpatient centre \\
\hline Interventions & $\begin{array}{l}\text { Compensatory skills training (memory skills) versus retraining basic cognitive impairments control } \\
\text { (problem solving) }\end{array}$ \\
\hline Outcomes & Noeks of intervention \\
\hline Starting date & 1 April 2002 \\
\hline Contact information & Dr Peter Frommelt, Asklepios Klinik Schaufling, p.frommelt@asklepios.com \\
\hline Notes & Overall trial status reported as completed, no study results available (authors contacted) \\
\hline
\end{tabular}

\section{ISRCTN59754564}

\begin{tabular}{ll}
\hline Trial name or title & Investigating the effects of cognitive training on attention \\
\hline Methods & RCT \\
& Outcomes assessed at T1, 4 weeks post baseline and T2, 3 months post baseline \\
\hline Participants & Stroke patients. Planned sample size $n=100$ \\
\hline Interventions & $\begin{array}{l}\text { 2 intervention conditions: home-based online working memory training or a similar training pro- } \\
\text { gramme focused on attention skills. 20 minutes/day, } 5 \text { times/week over } 4 \text { weeks (20 sessions total) }\end{array}$ \\
\hline Outcomes & 1 control condition: waiting list control group \\
\hline Starting date & A range of cognitive tasks and questionnaires about everyday function \\
\hline Contact information & November 2014 \\
\hline Notes & Dr Polly Peers, MRC Cognition and Brain Sciences Unit, polly.peers@mrc-cbu.cam.ac.uk \\
\hline
\end{tabular}

\section{NCT01674790}

Trial name or title

Combined effects of aerobic exercise and cognitive training on cognition after stroke 
NCT01674790 (Continued)

Methods RCT

Factorial assignment

Outcomes assessed at baseline, T0 and at 10 weeks T1

\begin{tabular}{ll}
\hline Outcomes & $\begin{array}{l}\text { Subjective memory measure: Cognitive Failures Questionnaire } \\
\text { Objective memory measure: Sternberg digit memory task }\end{array}$ \\
$\begin{array}{l}\text { Additional outcomes assessed: Flanker Test, Raven's matrices test, peak oxygen consumption, Fa- } \\
\text { tigue Severity Scale, Montreal Cognitive Assessment, Expression of BDNF and IGF-1 in peripheral } \\
\text { blood samples }\end{array}$ \\
\hline Starting date & September 2012 \\
\hline Contact information & Marilyn MacKay-Lyons, 9024942632, m.mackay-lyons@dal.ca \\
\hline Notes & Still recruiting participants \\
\hline
\end{tabular}

\section{NCT02384057}

\begin{tabular}{ll}
\hline Trial name or title & Cognitive rehabilitation with C8 Sciences \\
\hline Methods & RCT, single-blind \\
& Outcomes assessed at T0 baseline, T1, 34 days from baseline and T2, 64 days from baseline \\
\hline Participants & Stroke and brain injury patients. Estimated enrolment $\mathrm{n}=64$ \\
\hline Interventions & $\begin{array}{l}\text { Intervention: } \mathrm{C} 8 \text { sciences cognitive rehabilitation with } \mathrm{C} 8 \text { sciences, computerised cognitive training } \\
\text { program (1000 minutes })\end{array}$ \\
& Control: conventional cognitive rehabilitation \\
\hline
\end{tabular}

\section{Outcomes}

Subjective memory measure: subjective memory complaint questionnaire

Objective memory measure: CANTAB

Functional abilities measure: Korean Instrumental Activities of Daily Living (K-IADL)

Mood measure: Beck Depression Index

QoL measure: Stroke Impact Scale 
NCT02384057 (Continued)

Additional outcomes assessed: mood (Geriatric Depression Scale), cognitive abilities (Korean MMSE; K-MMSE), activities of daily living (Korean Activities of Daily Living; K-ADL), clinical dementia rating scale (CDR), Stroke Impact Scale, NIH toolbox, autobiographical memory, Trail Making Test (TMT-A/B and TMT Black and White)

\begin{tabular}{ll}
\hline Starting date & December 2014 \\
\hline Contact information & Joon-Ho Shin, MS, National Rehabilitation Center, Seoul, Korea, asfreelyas@gmail.com \\
\hline Notes & Study is currently recruiting participants \\
\hline
\end{tabular}

\section{NCT02482688}

Trial name or title A randomised controlled study of early versus late, and unisensory versus multisensory rehabilitation for stroke patients with perceptual and cognitive impairments

Methods RCT, single-blind

Outcomes assessed at T1, 1 month post randomisation and T2, 6 month post randomisation

\begin{tabular}{|c|c|}
\hline Participants & Stroke patients, estimated enrolment $n=80$ \\
\hline \multirow[t]{4}{*}{ Interventions } & 2 intervention conditions: \\
\hline & $\begin{array}{l}\text { Multisensory Acute (multisensory intervention delivered within } 2 \text { months post-stroke) and Multi- } \\
\text { sensory Chronic (multisensory intervention delivered } 6 \text { months post-stroke) }\end{array}$ \\
\hline & 2 control conditions (active comparators): \\
\hline & $\begin{array}{l}\text { Unisensory Acute (unisensory intervention delivered within } 2 \text { months post-stroke) and Unisensory } \\
\text { Chronic (unisensory intervention delivered } 6 \text { months post-stroke) }\end{array}$ \\
\hline \multirow[t]{3}{*}{ Outcomes } & Functional abilities measure: Nottingham Extended ADL (EADL) \\
\hline & Quality of life measures: unspecified quality of life measure \\
\hline & $\begin{array}{l}\text { Additional outcomes assessed: Birmingham Cognitive Screen (BCoS), Oxford Cognitive Screen } \\
\text { (OCS), functional outcome (Stroke Impact Scale - SIS), fMRI data }\end{array}$ \\
\hline Starting date & April 2015 \\
\hline Contact information & Ayla Barutchu PhD, University of Oxford, ayla.barutchu@psy.ox.ac.uk \\
\hline Notes & Study is currently recruiting participants \\
\hline
\end{tabular}

Sahakian 2016

\begin{tabular}{ll}
\hline Trial name or title & Investigation into the efficacy of cognitive training on cognition in adults with brain injury \\
\hline Methods & Insufficient information \\
\hline Participants & Adults with brain injury (traumatic injury, stroke or brain tumour), estimated enrolment $n=50$ \\
\hline Interventions & 12 hours of cognitive training on a Neurogame \\
\hline
\end{tabular}


Sahakian 2016 (Continued)

Outcomes Cognitive function, brain injury-related symptomatology, health, mood, impulsivity, and well-being

\begin{tabular}{ll}
\hline Starting date & December 2014 \\
\hline Contact information & Prof Barbara Sahakian, bjs-sec@medschl.cam.ac.uk \\
\hline Notes & Not stated whether the trial is randomised, still recruiting \\
\hline
\end{tabular}

\section{Yang 2014}

Trial name or title

The synergistic effect of acupuncture and computer-based cognitive training on post-stroke cognitive dysfunction: a study protocol for a randomised controlled trial of $2 \times 2$ factorial design

Methods RCT, $2 \times 2$ factorial design

Outcomes assessed at T1, 4 weeks post baseline, T2, 8 weeks, and T3, 12 weeks

\begin{tabular}{ll}
\hline Participants & Stroke patients, estimated enrolment $\mathrm{n}=240$ \\
\hline Interventions & 3 intervention groups: \\
& $\begin{array}{l}\text { RehaCom, acupuncture, or combination RehaCom and acupuncture. 12-week intervention, } 30 \text { min- } \\
\text { utes/day } 5 \text { days/week } \\
1 \text { control group: treatment as usual }\end{array}$ \\
\hline
\end{tabular}

Outcomes $\quad$ Functional abilities measure: FIM

Additional outcomes assessed: Montreal Cognitive Assessment (MoCa), MMSE, fMRI data

\begin{tabular}{ll}
\hline Starting date & January 2012 \\
\hline Contact information & Lidian Chen, Fujan University of Traditional Chinese Medicine, lidianchen87@163.com \\
\hline Notes & Study has finished recruiting participants, no response from author for request for findings \\
\hline
\end{tabular}

CANTAB: Cambridge Neuropsychological Test Automated Battery; EADL: extended activities of daily living; FIM: Functional Independence Measure; fMRI: functional magnetic resonance imaging; GHQ: General Health Questionnaire; NIH: National Institutes of Health; RBMT-E: Rivermead Behavioural Memory Test - extended version; MMSE: Mini-Mental State Examination; NIHSS: National Institute of Health Stroke Subscale; RCT: randomised controlled trial

\section{DATA AND ANALYSES}

\section{Comparison 1. Memory training versus no memory training}

\begin{tabular}{|c|c|c|c|c|}
\hline Outcome or subgroup title & No. of studies & $\begin{array}{l}\text { No. of partici- } \\
\text { pants }\end{array}$ & Statistical method & Effect size \\
\hline $\begin{array}{l}1 \text { Subjective memory mea- } \\
\text { sures (immediate outcome) }\end{array}$ & 7 & & $\begin{array}{l}\text { Std. Mean Difference (IV, Random, } \\
95 \% \mathrm{CI} \text { ) }\end{array}$ & Subtotals only \\
\hline 1.1 Memory questionnaires & 7 & 215 & $\begin{array}{l}\text { Std. Mean Difference (IV, Random, } \\
95 \% \mathrm{Cl} \text { ) }\end{array}$ & $0.36[0.08,0.64]$ \\
\hline
\end{tabular}




\begin{tabular}{|c|c|c|c|c|}
\hline Outcome or subgroup title & No. of studies & $\begin{array}{l}\text { No. of partici- } \\
\text { pants }\end{array}$ & Statistical method & Effect size \\
\hline $\begin{array}{l}2 \text { Subjective memory mea- } \\
\text { sures (long-term outcome) }\end{array}$ & 3 & & $\begin{array}{l}\text { Std. Mean Difference (IV, Random, } \\
95 \% \mathrm{CI} \text { ) }\end{array}$ & Subtotals only \\
\hline 2.1 Memory questionnaires & 3 & 149 & $\begin{array}{l}\text { Std. Mean Difference (IV, Random, } \\
95 \% \mathrm{CI})\end{array}$ & $0.31[-0.02,0.64]$ \\
\hline $\begin{array}{l}3 \text { Objective memory measures } \\
\text { (immediate outcome) }\end{array}$ & 10 & & $\begin{array}{l}\text { Std. Mean Difference (IV, Random, } \\
95 \% \mathrm{CI} \text { ) }\end{array}$ & Subtotals only \\
\hline 3.1 Comprehensive batteries & 5 & 91 & $\begin{array}{l}\text { Std. Mean Difference (IV, Random, } \\
95 \% \mathrm{Cl} \text { ) }\end{array}$ & $0.25[-0.36,0.86]$ \\
\hline 3.2 Verbal memory sub-tests & 5 & 266 & $\begin{array}{l}\text { Std. Mean Difference (IV, Random, } \\
95 \% \mathrm{Cl} \text { ) }\end{array}$ & $0.21[-0.03,0.46]$ \\
\hline $\begin{array}{l}4 \text { Objective memory measures } \\
\text { (long-term outcome) }\end{array}$ & 3 & & $\begin{array}{l}\text { Std. Mean Difference (IV, Random, } \\
95 \% \mathrm{Cl} \text { ) }\end{array}$ & Subtotals only \\
\hline 4.1 Comprehensive batteries & 3 & 49 & $\begin{array}{l}\text { Std. Mean Difference (IV, Random, } \\
95 \% \mathrm{CI} \text { ) }\end{array}$ & $-0.17[-0.74,0.41]$ \\
\hline $\begin{array}{l}5 \text { Functional ability measures } \\
\text { (immediate outcome) }\end{array}$ & 3 & & $\begin{array}{l}\text { Std. Mean Difference (IV, Random, } \\
95 \% \mathrm{CI} \text { ) }\end{array}$ & Subtotals only \\
\hline $\begin{array}{l}5.1 \text { Functional ability mea- } \\
\text { sures }\end{array}$ & 3 & 164 & $\begin{array}{l}\text { Std. Mean Difference (IV, Random, } \\
95 \% \mathrm{Cl} \text { ) }\end{array}$ & $1.17[-0.35,2.68]$ \\
\hline $\begin{array}{l}6 \text { Mood measures (immediate } \\
\text { outcome) }\end{array}$ & 3 & & $\begin{array}{l}\text { Std. Mean Difference (IV, Random, } \\
95 \% \mathrm{Cl})\end{array}$ & Subtotals only \\
\hline 6.1 Mood measures & 3 & 194 & $\begin{array}{l}\text { Std. Mean Difference (IV, Random, } \\
95 \% \mathrm{Cl})\end{array}$ & $-0.07[-0.35,0.21]$ \\
\hline $\begin{array}{l}7 \text { Mood measures (long-term } \\
\text { outcome) }\end{array}$ & 3 & & $\begin{array}{l}\text { Std. Mean Difference (IV, Random, } \\
95 \% \mathrm{Cl} \text { ) }\end{array}$ & Subtotals only \\
\hline 7.1 Mood measures & 3 & 175 & $\begin{array}{l}\text { Std. Mean Difference (IV, Random, } \\
95 \% \mathrm{Cl} \text { ) }\end{array}$ & $-0.17[-0.54,0.19]$ \\
\hline
\end{tabular}

Analysis 1.1. Comparison 1 Memory training versus no memory training, Outcome 1 Subjective memory measures (immediate outcome).

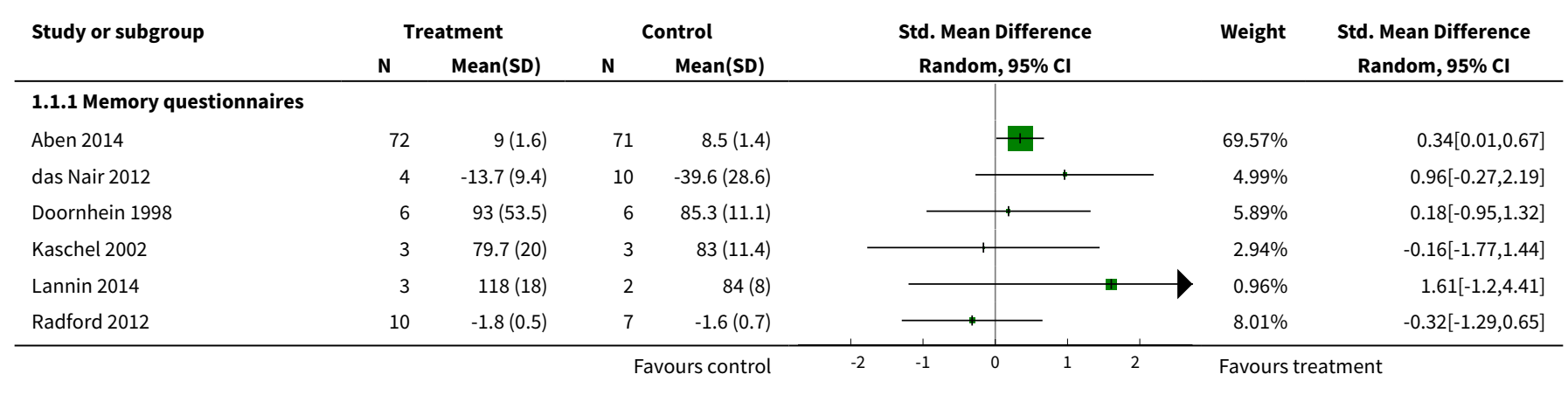




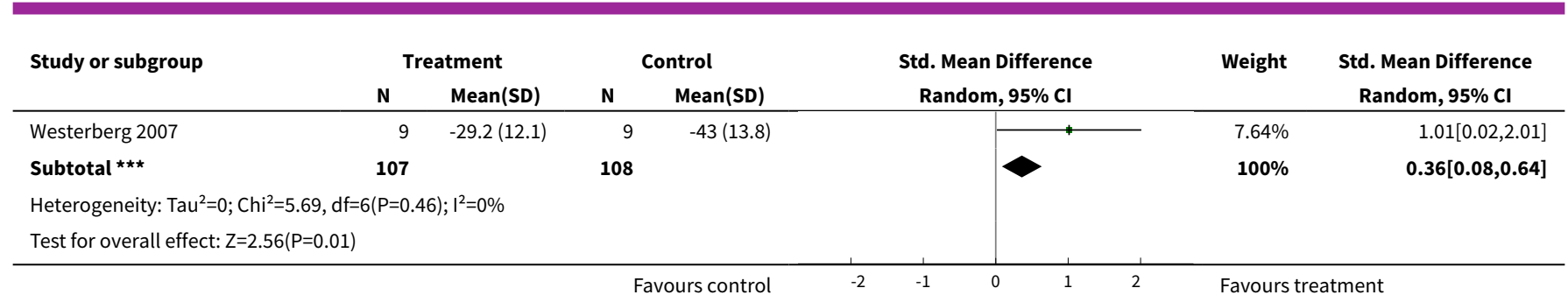

Analysis 1.2. Comparison 1 Memory training versus no memory training, Outcome 2 Subjective memory measures (long-term outcome).

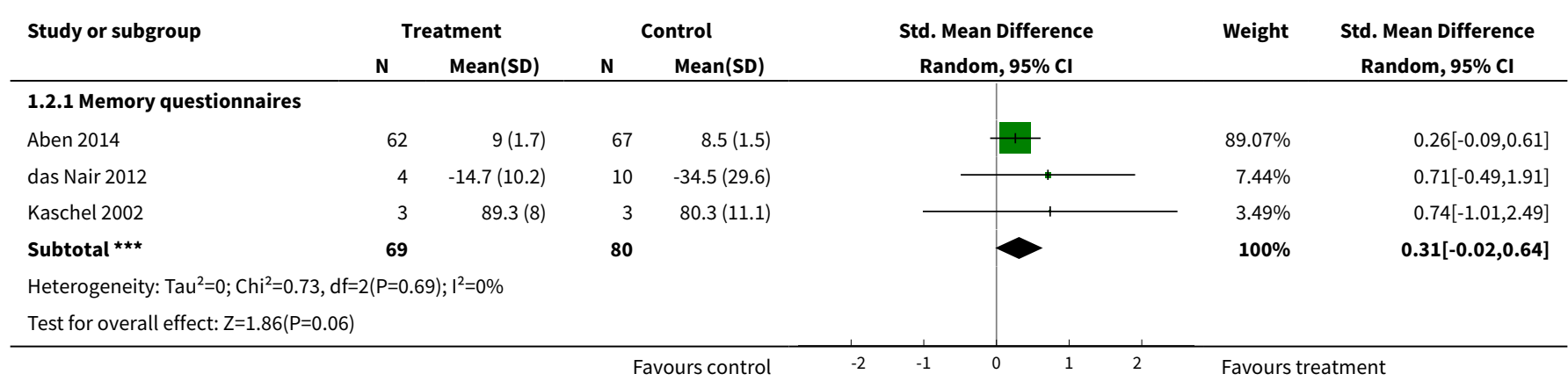

Analysis 1.3. Comparison 1 Memory training versus no memory training, Outcome 3 Objective memory measures (immediate outcome).

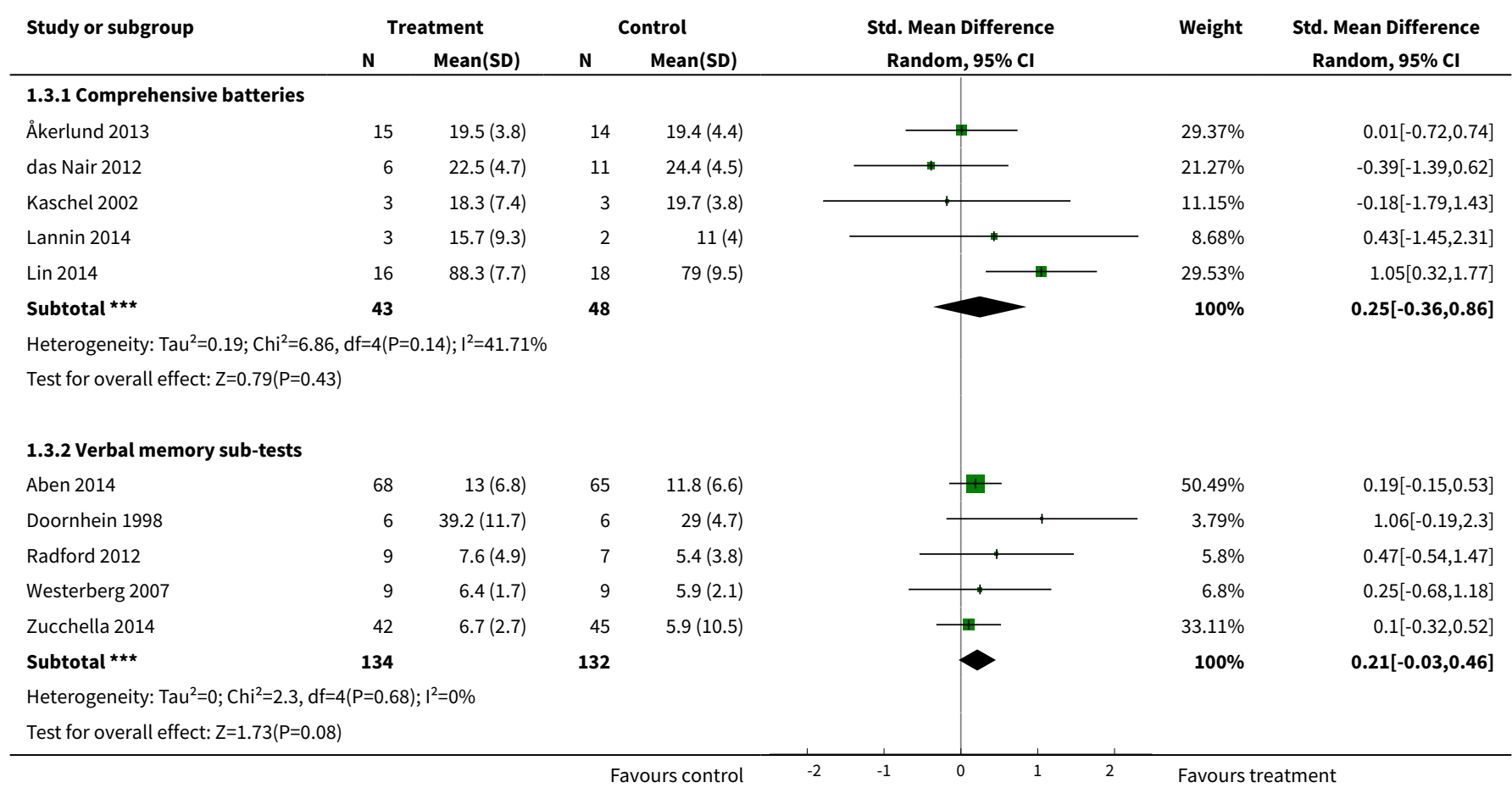


Analysis 1.4. Comparison 1 Memory training versus no memory training, Outcome 4 Objective memory measures (long-term outcome).

\begin{tabular}{|c|c|c|c|c|c|c|c|}
\hline \multirow[t]{2}{*}{ Study or subgroup } & \multicolumn{2}{|c|}{ Treatment } & \multicolumn{2}{|c|}{ Control } & \multirow{2}{*}{$\begin{array}{c}\text { Std. Mean Difference } \\
\text { Random, } 95 \% \mathrm{Cl}\end{array}$} & \multirow[t]{2}{*}{ Weight } & \multirow{2}{*}{$\begin{array}{c}\text { Std. Mean Difference } \\
\text { Random, } 95 \% \mathrm{Cl}\end{array}$} \\
\hline & $\mathbf{N}$ & Mean(SD) & $\mathbf{N}$ & Mean(SD) & & & \\
\hline \multicolumn{8}{|c|}{ 1.4.1 Comprehensive batteries } \\
\hline Åkerlund 2013 & 14 & $19.4(3.7)$ & 12 & $19.6(3.7)$ & & $55.1 \%$ & $-0.06[-0.83,0.71]$ \\
\hline das Nair 2012 & 6 & $24.3(3.9)$ & 11 & $25.9(6.5)$ & 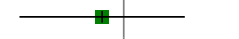 & $32.79 \%$ & $-0.26[-1.26,0.74]$ \\
\hline Kaschel 2002 & 3 & $21.7(1.2)$ & 3 & $22.3(1.5)$ & & $12.11 \%$ & $-0.4[-2.04,1.25]$ \\
\hline Subtotal $* \star \star$ & 23 & & 26 & & & $100 \%$ & $-0.17[-0.74,0.41]$ \\
\hline \multicolumn{3}{|c|}{ Test for overall effect: $Z=0.57(P=0.57)$} & & & & & \\
\hline
\end{tabular}

Analysis 1.5. Comparison 1 Memory training versus no memory training, Outcome 5 Functional ability measures (immediate outcome).

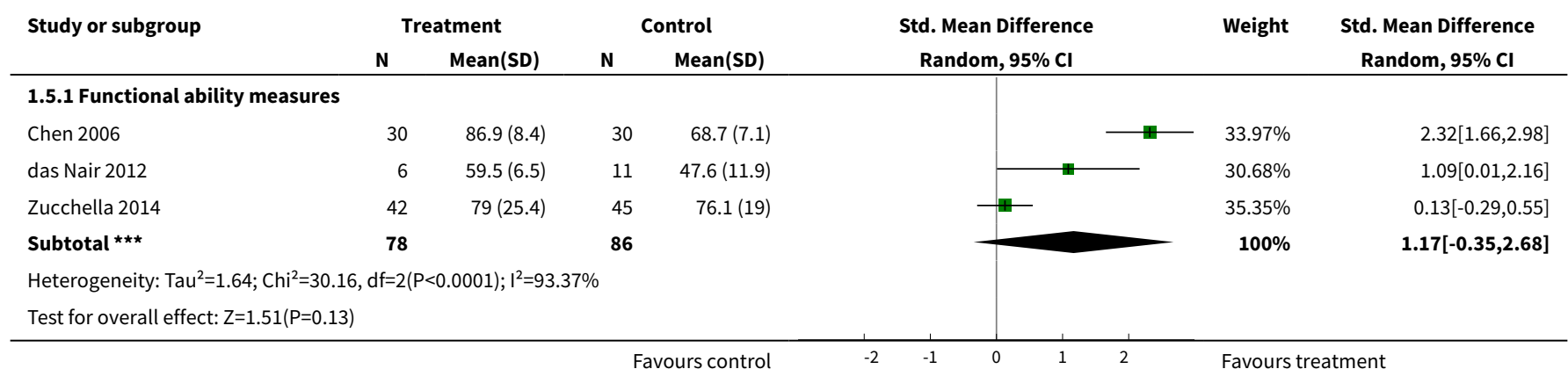

Analysis 1.6. Comparison 1 Memory training versus no memory training, Outcome 6 Mood measures (immediate outcome).

\begin{tabular}{|c|c|c|c|c|c|c|c|}
\hline \multirow[t]{2}{*}{ Study or subgroup } & \multicolumn{2}{|c|}{ Treatment } & \multicolumn{2}{|c|}{ Control } & \multirow{2}{*}{$\begin{array}{c}\text { Std. Mean Difference } \\
\text { Random, } 95 \% \mathrm{Cl}\end{array}$} & \multirow[t]{2}{*}{ Weight } & \multirow{2}{*}{$\begin{array}{c}\text { Std. Mean Difference } \\
\text { Random, } 95 \% \mathrm{Cl}\end{array}$} \\
\hline & $\mathbf{N}$ & $\operatorname{Mean}(S D)$ & $\mathbf{N}$ & $\operatorname{Mean}(S D)$ & & & \\
\hline \multicolumn{8}{|c|}{ 1.6.1 Mood measures } \\
\hline Aben 2014 & 77 & $-12.6(11.4)$ & 71 & $-11.3(8.8)$ & & $76.89 \%$ & $-0.13[-0.45,0.2]$ \\
\hline Åkerlund 2013 & 15 & $-3.8(3.2)$ & 14 & $-4.5(3.5)$ & & $15.02 \%$ & $0.2[-0.53,0.93]$ \\
\hline das Nair 2012 & 6 & $-3.3(3.7)$ & 11 & $-3.3(3.7)$ & & $8.1 \%$ & $-0.02[-1.01,0.98]$ \\
\hline Subtotal $\star \star \star$ & 98 & & 96 & & & $100 \%$ & $-0.07[-0.35,0.21]$ \\
\hline \multicolumn{8}{|c|}{ Test for overall effect: $Z=0.48(P=0.63)$} \\
\hline
\end{tabular}




\section{Analysis 1.7. Comparison 1 Memory training versus no memory} training, Outcome 7 Mood measures (long-term outcome).

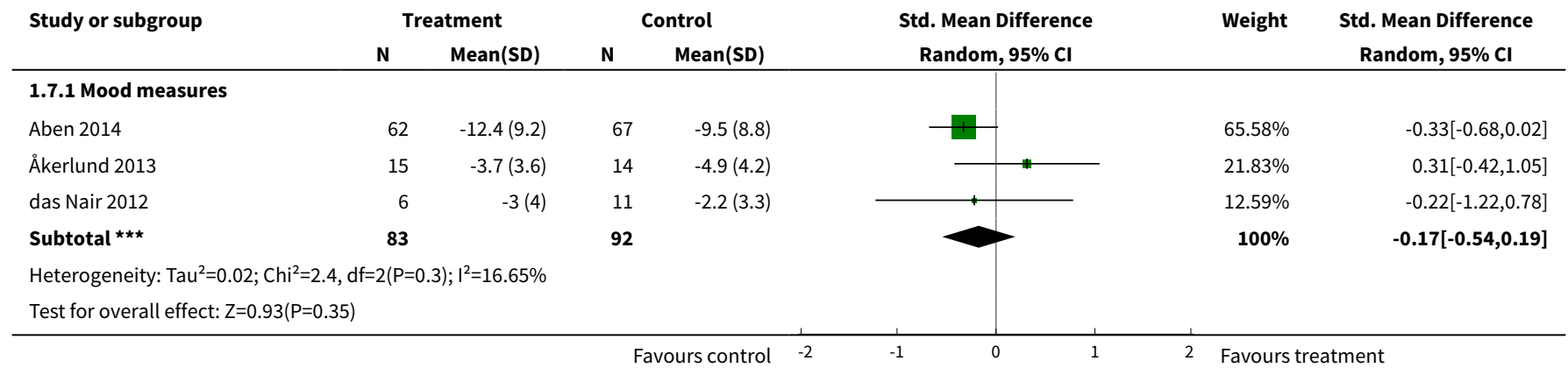

\section{APPENDICES}

\section{Appendix 1. Cochrane Central Register of Controlled Trials (CENTRAL) search strategy}

\#1 MeSH descriptor: [Cerebrovascular Disorders] explode all trees

\#2 (stroke\$ or cerebrovascular\$ or cerebral vascular or CVA\$):ti,ab,kw (Word variations have been searched)

\#3 \#1 or \#2

\#4 MeSH descriptor: [Attention] explode all trees

\#5 MeSH descriptor: [Cognition] explode all trees

\#6 MeSH descriptor: [Memory] explode all trees

\#7 MeSH descriptor: [Cognition Disorders] explode all trees

\#8 MeSH descriptor: [Memory Disorders] explode all trees

\#9 (cognitive or cognition or attention\$ or memory or concentration or distract\$ or alert\$):ti,ab,kw (Word variations have been searched) \#10 \{or \#4-\#9\}

\#11 (training or re-training or retraining or therap\$ or rehabilitation or treatment\$ or therapeutic\$ or computer-assisted therap\$ or computer assisted therap\$):ti,ab,kw (Word variations have been searched)

\#12 MeSH descriptor: [Rehabilitation] explode all trees

\#13 MeSH descriptor: [Therapeutics] explode all trees

\#14 MeSH descriptor: [Cognitive Therapy] explode all trees

\#15 MeSH descriptor: [Computers] explode all trees

\#16 MeSH descriptor: [Therapy, Computer-Assisted] explode all trees

\#17 MeSH descriptor: [Psychological Tests] explode all trees

\#18 (neurorehabilitation or neuropsychological rehabilitation or cognitive rehabilitation or memory rehabilitation or cognitive retraining):ti,ab,kw (Word variations have been searched)

\#19 \{or \#11-\#18\}

\#20 \#10 and \#19

\#21 \#20 and \#3

\#22 adult or aged or "aged, 80 and over" or middle aged

\#23 \#21 and \#22

\section{Appendix 2. MEDLINE (Ovid) search strategy}

The following search strategy was used for MEDLINE (Ovid) and modified for the other databases.

1. exp Cerebrovascular Disorders/

2. (stroke\$ or cerebrovascular\$ or cerebral vascular or CVA\$).tw.

\section{1 or 2}

4. attention/ or exp cognition/ or exp memory/ or exp cognition disorders/ or exp memory disorders/

5. (cognitive or cognition or attention\$ or memory or concentration or distract\$ or alert\$).tw.

6.4 or 5 
7. (training or re-training or retraining or therap\$ or rehabilitation or treatment $\$$ or therapeutic $\$$ or computer-assisted therap\$ or computer assisted therap\$).tw.

8. exp rehabilitation/

9. exp therapeutics/

10. exp cognitive therapy/

11. exp computers/

12. exp therapy, computer-assisted/

13. exp neuropsychological tests/

14. or/7-13

15. 6 and 14

16. (neurorehabilitation or neuropsychological rehabilitation or cognitive rehabilitation or memory rehabilitation or cognitive retraining).tw.

17. 15 or 16

18. 3 and 17

19. Randomized Controlled Trials/

20. random allocation/ or placebos/

21. Controlled Clinical Trials/

22. clinical trials/

23. randomized controlled trial.pt.

24. controlled clinical trial.pt.

25. clinical trial.pt.

26. (random\$ or placebo\$).tw.

27. (controlled adj5 (trial\$ or stud\$)).tw.

28. (clinical\$ adj5 trial\$).tw.

29. or/19-28

30.18 and 29

31. limit 30 to humans

32. adult/ or aged/ or "aged, 80 and over"/ or middle aged/

33. 31 and 32

34. limit 33 to $y r=" 2005-$ Current"

35. remove duplicates from 34

\section{Appendix 3. EMBASE (Ovid) search strategy}

The following search strategy was used for EMBASE (Ovid):

1. exp Cerebrovascular Disorders/

2. (stroke\$ or cerebrovascular\$ or cerebral vascular or CVA\$).tw.

3. 1 or 2

Cognitive rehabilitation for memory deficits after stroke (Review) 
4. attention/ or exp cognition/ or exp memory/ or exp cognition disorders/ or exp memory disorders/

5. (cognitive or cognition or attention $\$$ or memory or concentration or distract $\$$ or alert\$).tw.

\section{4 or 5}

7. (training or re-training or retraining or therap\$ or rehabilitation or treatment $\$$ or therapeutic $\$$ or computer-assisted therap\$ or computer assisted therap\$).tw.

8. exp rehabilitation/

9. exp therapeutics/

10. exp cognitive therapy/

11. exp computers/

12. exp therapy, computer-assisted/

13. exp neuropsychological tests/

14. or/7-13

15. 6 and 14

16. (neurorehabilitation or neuropsychological rehabilitation or cognitive rehabilitation or memory rehabilitation or cognitive retraining).tw.

17. 15 or 16

18. 3 and 17

19. Randomized Controlled Trials/

20. random allocation/ or placebos/

21. Controlled Clinical Trials/

22. clinical trials/

23. randomized controlled trial.pt.

24. controlled clinical trial.pt.

25. clinical trial.pt.

26. (random\$ or placebo\$).tw.

27. (controlled adj5 (trial\$ or stud\$)).tw.

28. (clinical\$ adj5 trial\$).tw.

29. or/19-28

30. 18 and 29

31. limit 30 to humans

32. limit 33 to $y r=" 2005-C u r r e n t "$

33. remove duplicates from 32

34. limit 33 to ("all adult (19 plus years)" or "young adult (19 to 24 years)" or "adult (19 to 44 years)" or "young adult and adult (19-24 and 19-44)" or "middle age (45 to 64 years)" or "middle aged (45 plus years)" or "all aged (65 and over)" or "aged (80 and over)" or "300 adulthood <age 18 yrs and older>" or 320 young adulthood <age 18 to 29 yrs> or 340 thirties <age 30 to 39 yrs> or 360 middle age <age 40 to $64 \mathrm{yrs}>$ or "380 aged <age $65 \mathrm{yrs}$ and older>" or "390 very old <age 85 yrs and older>")

35. limit 34 to adulthood $<18+$ years $>$ 
36. limit 35 to (adult $<18$ to 64 years $>$ or aged $<65+$ years $>$ )

\section{Appendix 4. Trial registries search strategy}

The following search terms were used for trial registries:

Stroke, Cerebrovascular Disorders, Cerebral Vascular Accident (CVA), CVA, Cerebra*, Cerebro*, Memory Disorders, Cognition Disorders, Attention, Cognition, Memory, Cognitive

Cognitive Rehabilitation, Stroke Rehabilitation, Tele-rehabilitation, Rehabilitation, Training, Retraining, Therapy, Therap*, Treatment, Computer, Neuropsychological Testing

Randomised, Control, Randomised Controlled Trials

Adults (18+), Older adults, Young adults, Aged, Middle aged

2005-2016, 2005-current

WHAT'S NEW

\begin{tabular}{lll}
\hline Date & Event & Description \\
\hline 19 May 2016 & $\begin{array}{l}\text { New citation required and conclusions } \\
\text { have changed }\end{array}$ & $\begin{array}{l}\text { The conclusions have changed. The overall conclusions of the } \\
\text { review now show limited evidence to support the benefits from } \\
\text { the intervention on subjective measures of memory in the short } \\
\text { term. There remains insufficient evidence to support or refute } \\
\text { the effectiveness of memory rehabilitation on objective memory } \\
\text { measures, functional abilities, mood, or quality of life. }\end{array}$ \\
\end{tabular}

19 May $2016 \quad$ New search has been performed

New searches have been updated and completed to 19 May 2016. The review now includes 13 trials involving 514 participants. Eleven studies have been added.

Das Nair 2007 and Westerberg 2003 have been moved from 'Ongoing studies' and 'Studies awaiting classification' into 'Included studies'.

In this version of the review we assessed the risk of bias in all new and existing studies, we assessed the quality of the evidence from the included studies using the GRADE approach, and we added a 'Summary of findings' table.

The review team has changed.

\section{H I S T ORY}

Protocol first published: Issue 2, 2000

Review first published: Issue 2, 2000

\begin{tabular}{lll}
\hline Date & Event & Description \\
\hline 4 August 2008 & Amended & Converted to new review format. \\
\hline 19 March 2007 & New search has been performed & $\begin{array}{l}\text { One new trial, Kaschel 2002, has been included in the review } \\
\text { since the previous version. The overall conclusions of the review } \\
\text { have not changed. }\end{array}$ \\
\hline
\end{tabular}




\begin{tabular}{lll}
\hline Date & Event & Description \\
\hline 19 March 2007 & $\begin{array}{l}\text { New citation required but conclusions } \\
\text { have not changed }\end{array}$ & Change to authorship. \\
\hline
\end{tabular}

\section{CONTRIBUTIONS OF AUTHORS}

Roshan das Nair (RdN) developed the search strategies and the template to assess the quality of the studies included, collected the data, and revised the final review.

Nadina Lincoln (NBL) initiated, co-ordinated and designed the format of the review, appraised the studies for review, and revised the final report.

Heather Cogger ( $\mathrm{HC}$ ) and Esme Worthington (EW) conducted the literature searches, extracted the data from studies, appraised the quality of the included studies, and prepared the early drafts of the review.

\section{DECLARATIONS OF INTEREST}

Roshan das Nair: was involved in one of the trials included in this review.

Heather Cogger: none known.

Esme Worthington: none known.

Nadina B Lincoln: was involved in one of the trials included in this review.

\section{SOURCES OF SUPPORT}

\section{Internal sources}

- No sources of support supplied

\section{External sources}

- NIHR Cochrane Review Incentive Scheme 2015, UK.

\section{DIFFERENCES BETWEEN PROTOCOL AND REVIEW}

In the previous review, we considered functional measures (including quality of life) as the primary outcome of interest for memory rehabilitation. However, we believe that while this is still a goal of memory rehabilitation, quality of life is perhaps too distal an outcome, which can be influenced by a variety of factors that may not be related to the intervention. We therefore felt that a subjective rating of problems related to memory in daily life was a more realistic yet meaningful outcome for participants who have had memory rehabilitation. Thus, for this update, we have considered the extent of memory problems in everyday life as the primary outcome. Compared to the previous version, we have expanded the description of outcome measures with greater detail and have updated the methods to include the use of the 'Risk of bias' tool and GRADE methods.

\section{IN DEX TERMS}

\section{Medical Subject Headings (MeSH)}

Attention; Clinical Trials as Topic; Cognition; Memory Disorders [etiology] [ ${ }^{\star}$ rehabilitation]; Perception; Stroke [ ${ }^{*}$ complications]

\section{MeSH check words}

Humans 